ADEMAURO VOLPONI

\title{
OBTENÇÃO E CARACTERIZAÇÃO EXPERIMENTAL DE CAMADAS DE ZEÓLITOS CRISTALINOS COM CADDEIAS Zn-Im-Zn (ZIF) PARA ABSORÇÃO E DETECÇÃO DE $\mathrm{CO}_{2}$
}




\section{ADEMAURO VOLPONI}

\section{OBTENÇÃO E CARACTERIZAÇÃO EXPERIMENTAL DE CAMADAS DE ZEÓLITOS CRISTALINOS COM CADEIAS Zn-Im-Zn (ZIF) PARA ABSORÇÃO E DETECÇÃO DE $\mathrm{CO}_{2}$}

Tese apresentada à Escola Politécnica da Universidade de São Paulo para obtenção do Título de Doutor em Ciências 


\section{ADEMAURO VOLPONI}

\section{OBTENÇÃO E CARACTERIZAÇÃO EXPERIMENTAL DE CAMADAS DE ZEÓLITOS CRISTALINOS COM CADEIAS Zn-Im-Zn (ZIF) PARA ABSORÇÃO E DETECÇÃO DE $\mathrm{CO}_{2}$}

Tese apresentada à Escola Politécnica da Universidade de São Paulo para obtenção do Título de Doutor em Ciências

Área de Concentração:

Microeletrônica

Orientador:

Prof. Dr. Sebastião Gomes dos Santos Filho 
Este exemplar foi revisado e corrigido em relação à versão original, sob responsabilidade única do autor e com a anuência de seu orientador.

São Paulo, de de

Assinatura do autor:

Assinatura do orientador:

VOLPONI, ADEMAURO

OBTENÇÃO E CARACTERIZAÇÃO EXPERIMENTAL DE CAMADAS DE ZEÓLITOS CRISTALINOS COM CADEIAS Zn-Im-Zn (ZIF) PARA ABSORÇÃO E DETECCCÃO DE CO2 / A. VOLPONI -- versão corr. -- São Paulo, 2016. $117 \mathrm{p}$.

Tese (Doutorado) - Escola Politécnica da Universidade de São Paulo. Departamento de Engenharia de Sistemas Eletrônicos.

1.Zeólitos 2.ZIF-8 3.ZIF-90 4.Detecção de CO2 I.Universidade de São Paulo. Escola Politécnica. Departamento de Engenharia de Sistemas Eletrônicos II.t. 


\section{AGRADECIMENTOS}

Em primeiro lugar, a Deus por me permitir participar de mais uma etapa de minha vida, e ao meu orientador, Prof. Dr. Sebastião Gomes dos Santos Filho, todo apoio dado durante esses meses, a paciência e a disponibilidade sempre de que precisei. Agradeço-lhe tudo que me foi ensinado, o carinho, a motivação, a assistência e interesse demonstrados e a ajuda fundamental à execução desse trabalho. O meu muito obrigado!

Aos meus pais, Antônio Volponi e Benedicta Ferreira Volponi, de que tanto gosto, pelo amparo incondicional, pelo incentivo e pelo interesse evidenciados ao longo desta fase de minha vida. À minha mãe, em especial, que sempre acreditou em mim e depositou-me confiança. Queria dizer que estou muito grato e, se não fosse o seu auxílio, a conquista não seria a mesma.

Aos amigos da Fatec Santo André, que me incentivaram e me ajudaram em vários momentos durante esta fase. Por fim queria agradecer à minha esposa, Silvana Aparecida Bergamasco Volponi, a compreensão, a dedicação e o incentivo não só nos momentos bons, mas principalmente nos momentos difíceis. 


\section{RESUMO}

Neste trabalho, foram depositadas sobre lâminas de silício camadas de zeólitos cristalinos, formados por cadeias de átomos de zinco e bases conjugadas do imidazol (ZIF: Zeolitic Imidazolate Framework), com o objetivo de avaliar os processos de adsorção e absorção do $\mathrm{CO}_{2}$ e aplicar essas camadas como pré-concentradores para a detecção de $\mathrm{CO}_{2}$. Para a deposição das camadas ZIF através dos processos Spinning e casting, foi proposta uma solução química alternativa que emprega etanol como solvente em vez de metanol como reportado na literatura, a fim de proporcionar um processo menos tóxico ao ser humano e viabilizar o armazenamento de $\mathrm{CO}_{2}$ para aplicações envolvendo não apenas a sua detecção mas também a sua remoção do ambiente. As camadas ZIF foram depositadas utilizando uma solução obtida a partir da mistura de nitrato de zinco (4,3g) e 2-metilimidazol $(9,7 \mathrm{~g})$ em etanol com diversas diluições com a finalidade de variar o $\mathrm{pH}$ na faixa de 7,2 a 8,2. Como resultado, verificou-se que as camadas obtidas apresentaram estrutura cristalina ZIF-8 ou ZIF-90 apenas na situação de pH próximo de 7 . Além disso, as camadas depositadas através da técnica Spinning apresentaram baixa aderência sobre lâminas de silício e não foi possível depositar camadas com espessuras na faixa de micrômetros. Por outro lado, camadas repetitivas com aproximadamente $7,5 \mu \mathrm{m}$ de espessura foram depositadas nas lâminas de silício através do processo casting em solução de $\mathrm{pH}=7,2(50 \mathrm{ml})$. Após o recozimento dessas camadas na temperatura de $150^{\circ} \mathrm{C}$ por $48 \mathrm{~h}$ em ambiente de nitrogênio ultrapuro, obtiveram-se distribuições repetitivas de nanocristais com tamanhos na faixa de 5 a 400nm e estrutura cristalina tipo ZIF-90. Das medidas de espectroscopia IR nas camadas de ZIF-90, observou-se que a banda localizada em $2337 \mathrm{~cm}^{-1}$ intensifica com o aumento da pressão do $\mathrm{CO}_{2}$ e com o tempo em que a pressão é mantida. Além da banda em $2337 \mathrm{~cm}^{-1}$, foi observada uma segunda banda em $2360 \mathrm{~cm}^{-1}$, indicando dois diferentes tipos de resposta: (i) a banda em $2337 \mathrm{~cm}^{-1}$ foi associada a uma porção substancial de moléculas de $\mathrm{CO}_{2}$ absorvidas dentro da camada junto aos contornos dos nanocristais ou dentro da sua estrutura cristalina, e (ii) a banda em $2360 \mathrm{~cm}^{-1}$ foi atribuída à porção de moléculas de $\mathrm{CO}_{2}$ adsorvidas na superfície. Além disso, se o tempo de exposição da camada de ZIF-90 ao $\mathrm{CO}_{2}$, na pressão atmosférica for de pelo menos 2h, atinge-se sensibilidade de 100ppm ao $\mathrm{CO}_{2}$, considerando a leitura mínima de absorbância como sendo igual a 0,02 para $0,5 \mathrm{l} / \mathrm{min}$ de $\mathrm{CO}_{2}$ fluindo sobre a amostra.

Palavras-chaves: ZIF, zeólitos cristalinos, cadeias Zn-Im-Zn, ZIF-90, ZIF-8, absorção de $\mathrm{CO}_{2}$, detecção de $\mathrm{CO}_{2}$. 


\section{ABSTRACT}

In this work, layers of crystalline zeolites formed by chains of zinc atoms and conjugate bases of the imidazole (ZIF: zeolitic Imidazolate Framework) were deposited to evaluate the desorption and absorption of $\mathrm{CO}_{2}$ and apply these layers as pre-concentrators for $\mathrm{CO}_{2}$ detection. For the deposition of ZIF layers by means of spinning or casting, it was proposed an alternative chemical solution which employs ethanol as solvent instead of methanol, as reported in the literature, to provide a less toxic process to humans and allow one the $\mathrm{CO}_{2}$ storage applications involving not just detection but also its removal from the environment. The ZIF layers were deposited using a solution prepared from a mixture of zinc nitrate (4.3g) and 2-methylimidazole $(9.7 \mathrm{~g})$ with several dilutions in ethanol to vary the $\mathrm{pH}$ in the range of 7.2 to 8.2. As a result, the crystalline structure of the layers was ZIF-8 or ZIF-90 only for pH next to 7. Furthermore, the layers deposited by spinning showed low adhesion to the silicon wafers and it was not possible to deposit layers for thickness in the micrometer range. Moreover, repetitive layers of approximately $7.5 \mu \mathrm{m}$ in thickness were deposited on the silicon wafers by casting for $\mathrm{pH}=7.2(50 \mathrm{ml})$. After annealing these layers at a temperature of $150^{\circ} \mathrm{C}$ for $48 \mathrm{~h}$ in ultra-pure nitrogen, it was obtained repetitive nanocrystals with size distributions in the range of 5 to $400 \mathrm{~nm}$ having a ZIF-90 crystal structure. From infrared (IR) measurements of the ZIF-90 layers, it was observed a band located at $2337 \mathrm{~cm}^{-1}$ that increases with the increase of the $\mathrm{CO}_{2}$ pressure and with the exposure time to this pressure. In addition to the band at $2337 \mathrm{~cm}^{-1}$, it was observed a second band at $2360 \mathrm{~cm}^{-1}$ indicating two different responses: (i) the band at $2337 \mathrm{~cm}^{-1}$ is related to a substantial portion of the $\mathrm{CO}_{2}$ molecules absorbed into the layer along the contours of the nanocrystals or within the crystal structure and (ii) the band at $2360 \mathrm{~cm}^{-1}$ is related to the portion of $\mathrm{CO}_{2}$ molecules adsorbed on the surface. Also, if the ZIF-90 layer is exposed to $\mathrm{CO}_{2}$ at atmospheric pressure for at least $2 \mathrm{~h}$, a 100ppm sensitivity to $\mathrm{CO}_{2}$ is achieved considering the minimum absorbance as being 0.02 when $0.5 \mathrm{l} / \mathrm{min}$ of $\mathrm{CO}_{2}$ is flowing on the sample.

Keywords: ZIF, Crystalline Zeolites, Zn-Im-Zn Chains, ZIF-90, ZIF-8, $\mathrm{CO}_{2}$ Absorption, $\mathrm{CO}_{2}$ Detection. 


\title{
SUMÁRIO
}

\section{Lista de Ilustrações}

\author{
Lista de Tabelas
}

Lista de Siglas e Abreviaturas

1 Introdução

1.1 Gases do efeito estufa e problemas causados pelo $\mathrm{CO}_{2}$ na Atmosfera 16

1.2 Efeito Estufa . . . . . . . . . . . . . . . . . . . 18

1.3 Objetivos e Organização do Trabalho . . . . . . . . . . . . . . . 24

2 Estrutura Cristalina dos Zeólitos $\quad 26$

2.1 Estrutura dos Zeólitos e o tamanho de poros . . . . . . . . . . . . 29

2.2 Composição Química . . . . . . . . . . . . . . . . . . 30

2.3 Troca Iônica . . . . . . . . . . . . . . . . . . . . . . . . . 30

2.4 Interesse Ambiental . . . . . . . . . . . . . . . . . . . . 30

2.5 Catálise . . . . . . . . . . . . . . . . . . . . . . 31

2.6 Unidades de Construção . . . . . . . . . . . . . . . . . . . . . . . 32

2.6.1 Unidades de Construção Secundárias - Secondary Building Units $(\mathrm{SBU}) \ldots \ldots \ldots \ldots . \ldots . \ldots . \ldots . \ldots 33$

2.6.2 Sub-Unidades Estruturais - Strutural SubUnits (SSU) . . . 35 
2.6.3 Representação 2D de redes através das unidades de construção . . . . . . . . . . . . . . . 36

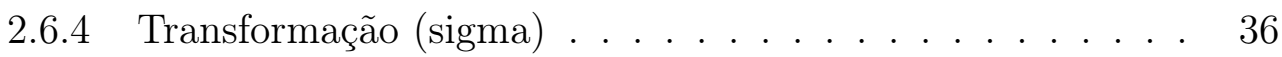

2.6.5 Unidades de Construção Periódicas - Periodic Building Units $(\mathrm{PBU}) \ldots \ldots \ldots \ldots \ldots$

2.6.6 Zeólitos A, X e Y . . . . . . . . . . . . . 38

2.6 .7 Modernita . . . . . . . . . . . . . . . . . . 39

2.6.8 ZSM-5 E ZSM-11 . . . . . . . . . . . . . . . . . . . . 39

2.6.9 Erionita e Ofretita . . . . . . . . . . . . . . . 41

3 Arcabouços cristalinos zeolíticos formados por redes de $\mathrm{Zn}$ e base conjugada imidazol (ZIF: Zeolitic Imidazolate Framework) 43

3.1 ZIF-8 e ZIF-90 . . . . . . . . . . . . . . . . . . . 45

3.1.1 Etapas na Síntese do ZIF-8 e ZIF-90 . . . . . . . . . . 46

3.1.2 Métodos de Síntese do ZIF . . . . . . . . . . . . . . . . 54

3.1.2.1 Método Hidrotérmico . . . . . . . . . . 54

3.1.2.2 Método Solvotérmico . . . . . . . . . . . . . 55

3.2 Membranas de Separação Fabricadas com Estruturas MOF e ZIF 58

3.2.1 SEPARAÇÃO DE GASES . . . . . . . . . . . . . . 62

3.3 Membranas para Separação de Gases Constituídas por Metal Organic Framework (MOF) . . . . . . . . . . . . . . . . 67

4 Técnicas de Análise $\quad 71$

4.1 Espectrometria de Retroespalhamento de Rutherford . . . . . . . 71 
4.2 Espectroscopia Infravermelho com Transformada de Fourier (FTIR). 76

4.3 A espectroscopia de absorção de ultravioleta visível (UV-Vis) . . . 81

\section{PROCEDIMENTOS EXPERIMENTAIS}

5.1 Limpeza de Materiais . . . . . . . . . . . . . . . . . . . . 84

5.1.1 Limpeza dos substratos de silício . . . . . . . . . . . . 84

5.1.2 Limpeza de béqueres e tupperwares . . . . . . . . . . 86

5.2 Deposição das camadas ZIF sobre substratos de silício . . . . . . . 86

5.2.1 Preparação da solução química de deposição . . . . . . . . 87

5.2.2 Técnicas de deposição e tratamentos térmicos empregados 88

5.3 Técnicas de Caracterização Física . . . . . . . . . . . . . . . . . . 88

6 RESULTADOS E DISCUSSÃO 92

6.1 Influência do pH e do processo de deposição . . . . . . . . . . . . 92

6.2 Caracterização de camadas ZIF depositadas por casting . . . . . . 96

6.3 Caracterização dos processos de absorção e adsorção de $\mathrm{CO}_{2}$ pelas camadas ZIF . . . . . . . . . . . . . . . . . . 100

7 CONCLUSÕES E PERSPECTIVAS FUTURAS

Referências 


\section{LISTA DE ILUSTRAÇÕES}

1 Concentração de $\mathrm{CO}_{2}$ na atmosfera entre os anos de 1958 e 2010. . . . . . .

2 Diâmetro (nm) e átomo constituinte de poros característicos de alguns zeólitos

3 Redes tridimensionais 4:2 e sua representação em uma subunidade 2D. Os átomos de oxigênio situam-se nas arestas, entre os dois átomos $\mathrm{T}(\mathrm{Si}, \mathrm{Al})$ de cada vértice . . . . . . . . . . . . . . . . . . . . .

4 Unidades secundárias de construção (SBU's) encontradas em zeólitos e MOF's

5 Zeólitos correlacionados a cavidade- $\beta$ comuns (entre colchetes as vistas segundo os eixos $x y z)$. . . . . . . . . . . . . . . . . . . . . . . . .

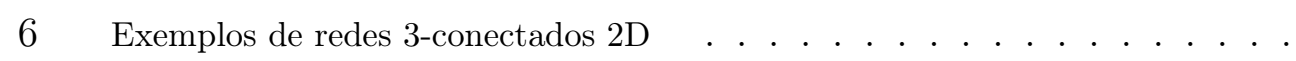

7 Exemplo de transformação sigma para gerar anéis de 6 e 8 átomos T a partir de um anel de 4 átomos $\mathrm{T}(\mathrm{T}=\mathrm{Al}$ ou $\mathrm{Si})$. . . . . . . . . . . . . . . . . . 37

8 Arcabouços cristalinos tipo sodalita: (a) zeólito A, (b) zeólito X ou Y . . . 38

9 (a) Primeira camada dos zeólitos ZSM-5 e ZSM-11, (b) subestrutura pentasil observada nos zeólitos ZSM-5 e ZSM-11, (c) indicação do PBU (vermelho) que permite gerar os zeólitos ZSM-5 e ZSM-11. . . . . . . . . . . . . . .

10 Representação das posições relativas dos anéis de 6 átomos "T"no arranjo hexagonal ..............................

11 Estrutura tipo sodalita dos cristais ZIF-8 (a) e ZIF-90 (b) com rede ordenada de poros. .........................

12 Estrutura das pontes Si-O-Si (a) e T-Im-T (b) onde é indicado o ângulo aproximado entre ligações de $145^{\circ}$. . . . . . . . . . . . . . . . . . . . . . 
13 Representação da reação química entre o Cátion-Zinco $\left(Z n^{2+}\right)$ e base conjugada do imidazol (Im) para formação das pontes Zinco-Imidazol-Zinco (ZnIm-Zn). O arcabouço cristalino obtido apresenta estrutura tipo sodalita. A abertura dos poros entre 6 anéis tem um diâmetros de $0,34 \mathrm{~nm}$ para o ZIF-8 e $0,35 \mathrm{~nm}$ para o ZIF-90 . . . . . . . . . . . . .

14 Evolução das facetas cristalinas do ZIF-8 em função do tempo de agitação na temperatura ambiente da mistura de zinco hexahidratado e 2-metilimidazol em metanol (antes da centrifugação, lavagem e se secagem): (a) 20 min; (b) $30 \mathrm{~min}$; (c) $40 \mathrm{~min}$; (d) $50 \mathrm{~min}$; (e) $60 \mathrm{~min}$; (f) $12 \mathrm{~h}$; (g) 24h. . . . . . . . .

15 Cinética de transformação do ZIF-8 em função do tempo. . . . . . . . . . .

16 Imagens TEM do ZIF-8 em função do tempo de síntese: (a) 10 min; (b) 30 $\min ;($ c) $40 \min ;($ d) $60 \min ;$ (e) $12 \mathrm{~h}$; (f) 24 h. . . . . . . . . . . . . . 52

17 Imagens de difração de elétrons para área selecionada (SAED) correspondentes às imagens TEM apresentadas na Figura 16: (a) 10 min; (b) 30 min; (c) 40 $\min ;($ d) $60 \min ;($ e) $12 \mathrm{~h} ;$ (f) $24 \mathrm{~h} . \ldots \ldots \ldots$

18 Espectro XRD típico do ZIF-8 onde está indicado todos os planos cristalinos da estrutura tipo sodalita. . . . . . . . . . . . . . . . 55

19 - Ilustração do processo de modificação do substrato . . . . . . . . . . . . 56

20 - (a) (b) Imagens SEM, respectivamente, de topo e de corte transversal de um filme contínuo de ZIF-8 obtido através da receita 1 (aproximadamente $20 \mu m$ de espessura), (c)(d), imagens SEM, respectivamente, de topo e de corte de um filme de ZIF-8 obtido através da receita 2 (aproximadamente $12 \mu \mathrm{m}$ de espessura). . . . . . . . . . . . . . . . . 58

21 Representação de um sistema com duas fases separadas por membrana. . . . 68 
22 - Diagrama esquemático de um feixe ${ }^{4} H^{2+}$ que incide numa dada amostra e sofre retroespalhamento num dado ângulo $\theta_{e}$ em direção ao detetor. . . . .

23 - Espectro RBS de um filme fino de ouro sobre substrato de silício. . . . . . 75

24 Espectros FTIR, respectivamente, do $\mathrm{CO}_{2}$ puro na pressão de $1 \mathrm{GPa}$, da amostra ZIF-8 com pressão de entrada do $C_{2}$ de $0,78 \mathrm{GPa}$ e, também da amostra ZIF-8, mas com 0,81GPa. A seta indica as posições do modo de estiramento da ligação $\mathrm{C}=\mathrm{C}$ da base conjugada imidazol, presente no ZIF-8. . . . . . . 78

25 (a) Espectros FTIR após compressão (subida da pressão de 0,47 GPa até 2,55 GPa), (b) Espectros FTIR após descompressão (descida da pressão de 2,65 $\mathrm{GPa}$ a 0$) \ldots \ldots \ldots \ldots \ldots \ldots$

26 Porcentagem de liberação de 5-FU em função do tempo para os $\mathrm{pH}$ de 5 e 7,4, respectivamente. O gráfico menor apresenta o processo de liberação nas primeiras 24 h. . . . . . . . . . . . . . .

27 (a) Foto do equipamento Biorad FTS 6000 onde está destacado o controle de injeção de nitrogênio ultrapuro no compartimento onde é colocado o portaamostras. (b) Detalhe da amostra de ZIF montada sobre o porta-amostras.

28 (a) Montagem empregada para condicionamento das amostras ZIF em diferentes pressões na faixa de 0 a 32psi e diferentes tempos de exposição $(0$ a 150min); (b) Detalhe da entrada de $\mathrm{CO}_{2}$ na câmara, do manômetro empregado para a medição da pressão interna e a da válvula agulha para ajuste fino da pressão. . . . . . . . . . . . . . . . . . . . . 9

29 : Espectros XRD típicos para as camadas preparadas com: (a)100ml de etanol e (b) $400 \mathrm{ml}$ de etanol. . . . . . . . . . . . . . . . . . . 
30 Espectro XRD típico para camadas depositadas por spinning $(2,5 \mathrm{ml}+2000 \mathrm{rpm})$ que passaram por secagem na temperatura ambiente por 24 horas. . . . . . . . . . . . . . . . . . . . . . . .

31 morfologia da superfície típica da camada ZIF contendo nanocristais com ta-

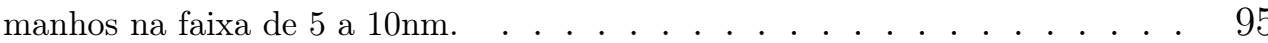

32 Micrografia FESEM transversal típica para camadas depositadas por casting (50ml) que passaram por tratamento na temperatura de $150^{\circ} \mathrm{C}$ por $48 \mathrm{~h}$ em nitrogênio ultrapuro. . . . . . . . . . . . . . . . . . . . . . . . 9

33 Micrografias FESEM típicas de superfície para camadas depositadas por casting $(50 \mathrm{ml})$ que passaram tratamento na temperatura de $150^{\circ} \mathrm{C}$ por $48 \mathrm{~h}$ em nitrogênio ultrapuro em diversos aumentos: (a) 50000x, (b) 100000x e 200000x. 97

34 Espectro XRD típico para as camadas ZIF preparada com a solução descrita no item 5.2.1 utilizando diluição em $800 \mathrm{ml}$ de etanol ........ . 98

35 Espectro RBS típico para as camadas ZIF preparada com a solução descrita no item 5.2.1 utilizando diluição em 800ml de etanol. . . . . . . . . . . . . 99

36 Espectro FTIR típico da camada ZIF após diferentes condicionamentos em $\mathrm{CO}_{2}$. (a) referência ZIF sem condicionamento, (b) 15 psi por $30 \mathrm{~min}$, (c) 32 psi por $30 \mathrm{~min}$ e (d) 32 psi por $150 \mathrm{~min}$

37 Espectro FTIR típico da camada ZIF em função do tempo, após condicionamento em $\mathrm{CO}_{2}$ em 32 psi durante 90 min. $\quad . \quad$. . . . . . . . . . . . . . . 102

38 Altura do pico em $2337 \mathrm{~cm}^{-1}$ em função do tempo após condicionamento da camada ZIF em $\mathrm{CO}_{2}$ em 32 psi durante 90 min seguido por imersão em $\mathrm{N}_{2}$ ultrapuro $(5 \mathrm{l} / \mathrm{min})$. . . . . . . . . . . . . . . . . . . . 104 
39 Espectros IR típicos da camada ZIF em função da pressão de condicionamento em $\mathrm{CO}_{2}$ em durante 10 min. A extração do espectro IR foi feita imediatamente após o condicionamento em ambiente de $N_{2}$ ultrapuro (5l/min). . . . . . . 106

40 Espectros IR típicos da camada ZIF em função do tempo de condicionamento em $\mathrm{CO}_{2}$ na pressão de 32 psi. A extração do espectro IR foi feita imediatamente após o condicionamento em ambiente de $N_{2}$ ultrapuro (5l/min). . . . 107

41 - Espectro FTIR típico da camada ZIF depositado por "casting" como função do tempo, após condicionamento em $\mathrm{CO}_{2}$, fluxo de $0,5 \mathrm{l} / \mathrm{min}$ na superfície do ZIF durante 10 min. . . . . . . . . . . . . . . . . . . . . . . 108 


\section{LISTA DE TABELAS}

1 Tamanho de poros característicos. . . . . . . . . . . . . . . 30

2 Propriedades de separação dos gases $\mathrm{CO}_{2} / \mathrm{CH}_{4}$ (constantes de permeação e seletividade) das membranas de ZIF-8 nas pressões de entrada do $\mathrm{CO}_{2}$ de 40 a 99,5 KPa, respectivamente.(SURENDAR; CARREON, 2009). . . . . . . . . 55 


\section{LISTA DE SIGLAS E ABREVIATURAS}

\begin{tabular}{|c|c|}
\hline $\mathrm{Al}$ & Alumínio \\
\hline Ar & Argônio \\
\hline $\mathrm{CO}_{2}$ & Gás Carbônico \\
\hline $\mathrm{CI}$ & Circuito Integrado \\
\hline DI & Deionizada \\
\hline FESEM & $\begin{array}{l}\text { Microscopia Eletrônica de Varredura por Emissão de Campo } \\
\text { (Field-Emission Scanning Electron Microscopy) }\end{array}$ \\
\hline FTIR & $\begin{array}{l}\text { Espectroscopia de Infravermelho por Transformada Rápida de Fou- } \\
\text { rier (Fourier Transform Infrared Spectroscopy) }\end{array}$ \\
\hline $\mathrm{HCl}$ & Ácido Clorídrico \\
\hline $\mathrm{HF}$ & Ácido Fluorídrico \\
\hline$H_{2}$ & Hidrogênio \\
\hline $\mathrm{H}_{2} \mathrm{O}$ & Água \\
\hline $\mathrm{H}_{2} \mathrm{O}_{2}$ & Peróxido de Hidrogênio \\
\hline IR & Infravermelho (Infrared) \\
\hline LAMFI & Laboratório de Análise de Materiais por Feixe Iônico \\
\hline MOF & arcabouço metal-orgânico (metal organic framework) \\
\hline$N_{2}$ & Nitrogênio \\
\hline $\mathrm{NH}_{4} \mathrm{OH}$ & Hidróxido de Amônia \\
\hline
\end{tabular}


$\mathrm{O}_{2} \quad$ Oxigênio

RCA Radio Corporation of América - nome da limpeza padrão

desenvolvida nos laboratórios RCA

RBS Espectroscopia de Retroespalhamento de Rutherford

(Rutherford Backscattering)

RF Radiofrequência

$\mathrm{SiO}_{2} \quad$ Óxido de Silício

MOS Metal-Óxido-Semicondutor

XRD Difração de raios X (X-Ray Diffraction)

ZIF Arcabouço cristalino zeolítico formado por cadeias de Zn e base

conjugada do imidazol (Zeolitic Imidalolate Framework)

ZIF-8 Arcabouço cristalino zeolítico formado por cadeias de Zn com uma base conjugada do imidazol $\left(\stackrel{N}{N}-_{N}^{E^{N}}\right)$, estrutura tipo sodalita, parâmetro de rede $\mathrm{a}=1,699 \mathrm{~nm}$.

ZIF-90 Arcabouço cristalino zeolítico formado por cadeias de Zn com uma base conjugada do imidazol ( $\left(\mathrm{N}^{-i}\right)$, estrutura tipo sodalita, parâmetro de rede $\mathrm{a}=1,727 \mathrm{~nm}$. 


\section{INTRODUÇÃO}

Os assuntos aquecimento global, emissão de gás carbônico, mudanças climáticas, estão sempre fazendo parte do nosso cotidiano. Notícias e conferências internacionais discutem esses assuntos tentando chegar a acordos para diminuir os problemas climáticos que podem estar sendo causados pela ação do homem.

A causa principal das mudanças climáticas tem sido atribuída ao fenômeno chamado efeito estufa. O efeito estufa é um fenômeno natural que tornou possível a vida no planeta Terra, mas é a sua intensidade que pode causar problemas ambientais. Relacionado a esse efeito, a detecção do dióxido de carbono presente na atmosfera passou a ter importância fundamental (BUCKERIDGE, 2013).

\subsection{Gases do efeito estufa e problemas causados pelo $\mathrm{CO}_{2}$ na Atmosfera}

Os gases que compõem a atmosfera terrestre são basicamente o nitrogênio (78,1\%), o oxigênio (21\%), vapor de água (entre 0 e 4\%), argônio(0,93\%), dióxido de carbono(0,3\%), neônio (abaixo dos 0,002\%), hélio(0,0005\%) e metano(0,0002\%). Quando há uma variação dos gases do efeito estufa, a temperatura da Terra é seriamente afetada. A distribuição porcentual atual relativa dos gases do efeito estufa consiste em $49 \%$ de dióxido de carbono , 18\% de metano, $14 \%$ de Clorofluorcarbonetos (CFC's), $6 \%$ de óxido nitroso e 13\% de outros gases (LAVARDA, 2012). 
O elemento carbono se encontra armazenado em diferentes reservatórios a saber : a) nos oceanos, b) nas reservas de combustíveis fósseis do subsolo e do fundo do mar, c) no solo, d) na atmosfera e d) na biomassa vegetal. O dióxido de carbono é o gás que mais contribui para o efeito estufa, ou seja, sua contribuição energética no período de 1765 a 1992 foi de 1,56W/m² (LAVARDA, 2012). Para estabilizar as concentrações de carbono que estão presentes hoje em dia, seria necessária uma redução de aproximadamente $60 \%$ da emissão global de dióxido de carbono. Com o intuito de solucionar o problema relativo ao aumento do dióxido de carbono foi criada a Framework Convention on Climate Change (FCCC), na Conferência das Nações Unidas sobre o Meio Ambiente e Desenvolvimento (ECO 92) realizada na cidade do Rio de Janeiro, que propôs um programa mundial para redução do $\mathrm{CO}_{2}$ e também desenvolveram-se métodos de proteção às fontes de renovação dos níveis de dióxido de carbono, como as florestas. O dióxido de carbono $\left(\mathrm{CO}_{2}\right)$ é um gás de grande importância em diversos processos que ocorrem na Terra, por exemplo, a fotossíntese. Desde o início da era industrial, a concentração de dióxido de carbono vem aumentando muito rapidamente. Podemos citar quatro principais mecanismos que participam das trocas do carbono a saber (LAVARDA, 2012):

- a fotossíntese das plantas;

- os oceanos;

- a queima de combustíveis fósseis;

- os desmatamentos das florestas.

Observa-se que os dois primeiros mecanismos descritos são naturais, enquanto os dois últimos são provocados por atividades humanas descontroladas que levam ao efeito estufa (LAVARDA, 2012). 


\subsection{Efeito Estufa}

O planeta Terra tem um raio de $6400 \mathrm{~km}$ e as camadas de gases que constituem a atmosfera têm uma espessura de aproximadamente 100 km (HEWITT, 2002). Estas camadas são relativamente muito finas quando comparadas com o raio da Terra. Com relação aos gases que compõem a atmosfera, 99\% desses gases estão abaixo de $30 \mathrm{~km}$ de altura. A primeira camada da atmosfera, que chega a altura de aproximadamente 10km, é denominada troposfera e é onde ocorrem fenômenos climáticos como os ventos e as chuvas (HEWITT, 2002). No pico do Everest, considerado o ponto mais alto da Terra, com altura de $8844 \mathrm{~m}$, o ar nesse local é muito rarefeito o que gera a necessidade do uso de máscaras para respirar. A atmosfera é composta por moléculas de gases, sendo o nitrogênio o gás mais abundante com cerca de $78 \%$, seguido do oxigênio com $21 \%$. Já o dióxido de carbono apresenta um percentual de apenas 0,03\%. A atmosfera contém além dos gases mencionados outros gases como, por exemplo: o ozônio, metano e o monóxido de carbono (HEWITT, 2002). Os vapores de água também estão presentes na atmosfera com um percentual entre 1 a $4 \%$. Esta quantidade de vapor d'água depende muito de alguns fatores como a pressão do ar e a presença de fontes de vapor. Estas fontes podem ser, por exemplo, a evaporação dos lagos, rios e a transpiração de vegetais e animais. Jean-Baptist Fourier, irlandês, formado em biologia e filosofia, foi o primeiro a formalizar, em 1827, uma teoria sobre o efeito estufa (FOURIER, 2001). Ele mostrou que o efeito de aquecimento do ar dentro de estufas de vidro, método utilizado para manter plantas de climas mais quentes em estações mais frias da Europa, ocorre também na atmosfera terrestre. Em 1960, o cientista John Tyndall mediu a absorção de calor pelo dióxido de carbono e pelo vapor d'água. John Tyndall foi o primeiro cientista britânico a introduzir a ideia de que as grandes variações na temperatura média na Terra, poderiam ser devidas as variações da quantidade de dióxido de carbono 
na atmosfera (FIGUEIREDO; ALVES; VECCHIA, 2012).

O efeito estufa é uma das maneiras que a Terra tem para manter a sua temperatura constante. Nossa atmosfera é altamente transparente à luz solar, e cerca de $35 \%$ da radiação que recebemos é refletida novamente para o espaço, ficando os outros $65 \%$ retidos na Terra. Esta retenção se deve principalmente à absorção dos raios infravermelhos de gases como o dióxido de carbono, metano, óxidos de azoto e ozônio presentes na atmosfera (USP, 2003).

Nos últimos anos, a concentração de dióxido de carbono, na atmosfera vem aumentando de forma não controlada. Esse aumento se deve à utilização de petróleo, gás e carvão e a destruição das florestas tropicais. Outros gases como o metano e os clorofluorcarbonetos, que também contribuem para o efeito estufa, aumentaram rapidamente. O efeito do dióxido de carbono junto com o metano e os clorofluorcarbonos pode causar um aumento da temperatura global nos próximos 100 anos. Nos últimos anos, a preocupação com o meio ambiente vem ganhando o espaço, notadamente no que se refere a (LAVARDA, 2012):

- Economia de água;

- Preservação de florestas;

- Redução da emissão dos gases do efeito estufa.

Como se sabe, o protocolo de Kyoto é o documento cujos países signatários se comprometem a reduzir a emissão dos gases responsáveis pelo efeito estufa, tentando frear o aquecimento global (CRUZ, 2012). Um desses gases ganha maior destaque por ser o gás que mais emitimos na atmosfera, o dióxido de carbono (gás carbônico ou $\mathrm{CO}_{2}$ ). Produzimos dióxido de carbono, até quando respiramos.

Nossas células se incumbem de absorver o oxigênio e promover uma reação com moléculas orgânicas para obtenção de energia. Na obtenção dessa energia, 
um dos produtos da reação é o gás carbônico o qual é eliminado do organismo.

Como as moléculas orgânicas são formadas basicamente por carbono e hidrogênio, a reação pode ser representada genericamente pela reação química (RAUPP; DEL-PINO, 2015).

$$
\mathrm{CnHm}+\mathrm{O}_{2} \rightarrow \mathrm{CO}_{2}+\mathrm{H}_{2} \mathrm{O}+\text { energia }
$$

Dessa equação, podemos destacar uma regra fundamental das reações orgânicas, ou seja, a queima total de hidrocarbonetos resulta em água e dióxido de carbono. Assim, percebemos que a redução de dióxido de carbono $\left(\mathrm{CO}_{2}\right)$ na atmosfera passa inevitavelmente pela mudança de nossa matriz energética. Daí a preocupação com fontes de energia que não liberem esse gás, energias limpas e renováveis, tais como a eólica, biomassas, energia dos mares e solar, entre outras (LI et al., 2011).

Por outro lado, mesmo se reduzirmos as emissões de dióxido de carbono na atmosfera, ela não voltará ao normal em curto e médio prazo (LI et al., 2011). O tempo de permanência do dióxido de carbono na atmosfera é de mais ou menos 150 anos. É importante também destacar que se fosse possível retirar todo o dióxido de carbono da atmosfera, a temperatura média de nosso planeta seria muito baixa, o que não daria suporte à vida. Portanto, o dióxido de carbono e o efeito estufa também são fundamentais para a manutenção da vida na Terra.

Normalmente o termo efeito estufa é utilizado de forma negativa, indicando que há problemas com a atmosfera, no entanto, a vida no planeta Terra também só é possível por causa desse efeito (BUCKERIDGE, 2013). Comparando a Terra com a Lua, verificamos que a camada de ar que envolve a Terra se encontra aproximadamente entre -10 e $50^{\circ} \mathrm{C}$, enquanto que a Lua possui seus extremos na faixa de $-150^{\circ} \mathrm{C}$ à noite e $100^{\circ} \mathrm{C}$ exposta ao sol. Essas diferenças existem porque a Terra possui uma camada de gases capazes de absorver parte da radiação emitida 
pelo sol. De toda a radiação que chega à Terra, apenas a luz visível e parte das ondas de rádio atingem a superfície da Terra sem interferência, enquanto a luz ultravioleta é absorvida pela estratosfera, provocando seu aquecimento (BUCKERIDGE, 2013).

Estudos realizados pelo centro de estudos em sustentabilidade da fundação Getúlio Vargas mostrou que em 2012, a emissão de gases devido ao efeito estufa foi de 71,6 milhões de toneladas de gás carbônico representando um aumento em relação ao ano anterior. (CRUZ, 2012).

O programa brasileiro GHG Protocol, desenvolvido pela fundação Getúlio Vargas, conta com a participação de 106 organizadores, dentre os quais se destacam os setores da indústria de transformação, financeiro; de seguros, de serviços relacionados à eletricidade, ao gás e à construção, totalizando 60\% das organizações. As emissões diretas de gases mais significativas são as provenientes de fontes controladas pela empresa, como por exemplo, combustão em caldeiras, fornos, veículos, emissões de processo produtivo, emissões de sistemas de ar condicionado e refrigeração (CRUZ, 2012).

Estudos mostram também que o volume das emissões indiretas no país, decorrem da energia proveniente das fontes elétrica e térmica, produzida no local. Em 2010, as emissões indiretas foram de 4,8 milhões de toneladas, já em 2011, a mesma fonte teve 8,1 milhões de toneladas de gás carbônico na atmosfera, portanto, 3,3 milhões a mais em relação ao ano anterior (CRUZ, 2012).

Segundo estudos, o aumento na emissão ocorre em função de recentes decisões de planejamento energético, ou seja, de incrementar a contribuição de fontes não renováveis de energia na matriz brasileira gerando assim um aumento nas emissões de gases associadas ao consumo elétrico. Pesquisas mostraram que as emissões indiretas, que são as atividades não controladas pela organização, mas que ocorrem em consequência de suas atividades, foram bem maior em 2012 
(CRUZ, 2012).

De toda radiação recebida pelo globo terrestre, $90 \%$ dessa energia é absorvida pela atmosfera, que por sua vez irradia $80 \%$ para a Terra, configurando o efeito estufa (LAVARDA, 2012).

Com o acúmulo de gases na atmosfera como dióxido de carbono, metano, e os clorofluorcarbonetos (CFC's), provenientes do uso de combustíveis fósseis e processos industriais, aumenta substancialmente a absorção de energia na atmosfera e, por consequência, aumenta o efeito estufa. De todos os gases mencionados acima, o principal é o metano, pois este tem a capacidade de absorver a radiação de infravermelho do sol. Com a industrialização, houve um aumento significativo nos níveis de dióxido de carbono na atmosfera os quais vêm se intensificando a cada dia. Com isso, passamos a ter um aumento na temperatura e como consequência, nas alterações climáticas globais. Embora saibamos que as erupções vulcânicas têm contribuído para o aumento de temperatura, acredita-se que as alterações climáticas dessas últimas décadas são decorrentes do acúmulo de gases causados pela atividade humana (LAVARDA, 2012). Sabemos que o efeito estufa é um processo natural, o que mantém um equilíbrio da temperatura da Terra, pois sem este efeito a Terra seria tão fria e não seria possível a existência de vida nela. O que gera uma grande preocupação entre os cientistas é o fato de que o efeito estufa vem expandindo muito nas últimas décadas, causando uma retenção maior da radiação de infravermelho do sol pela atmosfera, provocando assim alterações climáticas e desequilíbrio nos ecossistemas do planeta. Desde o início da era industrial, a concentração de dióxido de carbono na atmosfera tem crescido alcançando 390 ppm em 2010 (Figura 1) e, em março de 2015, ultrapassou 400 ppm. (EARTH, 2016).

$\mathrm{O}$ aumento da concentração de $\mathrm{CO}_{2}$ na atmosfera altera de forma significativa o balanço de entrada e saída de energia no sistema atmosférico, elevando dessa 
Figura 1: Concentração de $C_{2}$ na atmosfera entre os anos de 1958 e 2010.

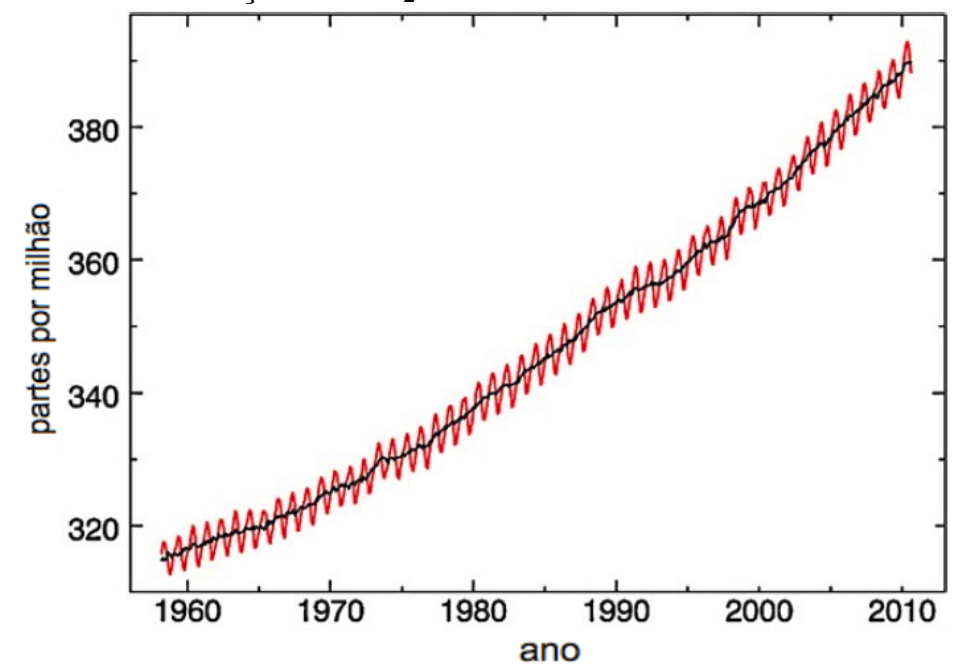

Fonte: ESRL, ESRL-s Global Monitoring Division, Trends in Atmospheric Carbon Dioxide, 2010.

maneira a temperatura média da superfície da Terra. Dessa forma, o $\mathrm{CO}_{2}$ é considerado como o principal gás antropogênico do efeito estufa, bem como o gás que é considerado o principal responsável por parte das mudanças climáticas (LI et al., 2011).

Embora existam ainda algumas dúvidas com relação aos problemas gerados pelo $\mathrm{CO}_{2}$, não há dúvidas que as estratégias para reduzir as emissões de $\mathrm{CO}_{2}$ são necessárias para minimizar as mudanças climáticas. Uma estimativa do painel intergovernamental sobre as mudanças climáticas (LI et al., 2014), mostrou que a emissão de $\mathrm{CO}_{2}$ poderia ser reduzida entre 80 a $90 \%$ por uma usina equipada com tecnologias modernas para a captura e armazenamento do dióxido de carbono, ou seja, Suitable Carbon Dioxide Capture and Storage (CCS) (SCOTTISH; AL, 2012).

O CCS é um processo que consiste em separar o $\mathrm{CO}_{2}$ de outros gases antes de entrar na atmosfera (SCOTTISH; AL, 2012). Entretanto, o custo relativo à captura do $\mathrm{CO}_{2}$ é aproximadamente $2 / 3$ do custo total de uma CCS, retardando assim a implantação de projetos comerciais de CCS (YAFENG et al., 2008). Na maior parte das tecnologias propostas, um ponto importante para um custo menor é a 
eficiência da separação dos gases que pode ser obtida por um material de captura (LI et al., 2011). Portanto, o estudo de novos materiais com elevada capacidade de separação de $\mathrm{CO}_{2}$ torna-se um dos maiores desafios dentre os quais podemos citar os materiais baseados em estruturas cristalinas zeolíticas tipo arcabouço para absorção das moléculas de $\mathrm{CO}_{2}$. Vários trabalhos têm sido publicados sobre este assunto, em que o conhecimento básico e novas perspectivas para CCS foram apresentadas por especialistas neste campo (RACKLEY, 2010), (ROOSA; JHAVERI, 2009) e (WILSON; GERARD, 2007).

\subsection{Objetivos e Organização do Trabalho}

O presente trabalho tem os seguintes objetivos:

- Estudar o processo de obtenção de camadas ZIF (Zeolitic Imidazolate Framework), utilizando os processos de spinning e casting;

- Propor uma nova solução de deposição de camadas ZIF através da utilização do solvente etanol em lugar do metanol, que é muito utilizado de acordo com a literatura;

- Estudar as camadas ZIF como pré-concentradores de $\mathrm{CO}_{2}$ para permitir sua detecção por Infravermelho.

Neste primeiro capítulo introdutório, foram apresentados: - o efeito estufa provocado pelo $\mathrm{CO}_{2}$, a importância da sua detecção, os problemas causados pelo $\mathrm{CO}_{2}$ na atmosfera e os objetivos gerais do trabalho. O segundo capítulo estuda uma parte fundamental sobre a estrutura cristalina dos zeólitos incluindo aspectos estruturais, composição química, unidades de construção de redes cristalinas, representação 2D de redes cristalinas complexas e tipos de zeólitos. O terceiro capítulo apresenta os dados bibliográficos que servem de base para o estudo realizado sobre arcabouços cristalinos zeolíticos formados por cadeias de Zinco (Zn) e 
base conjugada de imidazol (ZIF: Zeolitic Imidazolate Framework) com especial ênfase aos métodos de obtenção e a aplicação como membranas de separação. No capítulo quarto, são expostas as técnicas de análise por Retroespalhamento de Rutherford para obtenção da estequiometria das camadas e análise de concentração planar total de elementos químicos presentes, e a técnica de absorção de infravermelho, fundamental para detecção do $\mathrm{CO}_{2}$ armazenado nas camadas ZIF. No capítulo quinto, são elencados os procedimentos experimentais empregados na obtenção das camadas ZIF e as técnicas empregadas na sua caracterização física (FESEM, RBS e IR). O capítulo seis apresenta os resultados e discussões sobre a obtenção das camadas ZIF sobre os substratos de silício utilizando uma receita alternativa de deposição que emprega etanol como solvente ao invés de metanol através dos processos spinning e casting para deposição. Foi utilizada a técnica FESEM para caracterização da morfologia superficial e da espessura, e a técnica por difração de raio X (XRD) para caracterização da cristalinidade das camadas e RBS para caracterização da estequiometria. Adicionalmente foi empregada a técnica FTIR para caracterizar os processos de absorção e adsorção de $\mathrm{CO}_{2}$ nas camadas, visando permitir o armazenamento de $\mathrm{CO}_{2}$ para aplicações envolvendo não apenas a sua detecção, mas também a sua remoção do ambiente a fim de evitar o efeito estufa. O capítulo sete traz as conclusões sobre os resultados alcançados ao longo desse trabalho bem como algumas perspectivas futuras relacionadas ao tema. 


\section{ESTRUTURA CRISTALINA DOS ZEÓLITOS}

O primeiro zeólito mineral, a estilbita, foi descoberto pelo Barão Cronstedt no ano de 1756, porém, somente em 1926, suas características de adsorção foram atribuídas aos pequenos poros presentes com cerca de $0,5 \mathrm{~nm}$ de diâmetro, o que permitia a passagem seletiva de pequenas moléculas. Por essa razão, surgiu o termo "peneira molecular" (BRAGA; MORGON, 2007). Já no final da década de 40, surgiram os primeiros zeólitos sintéticos como a modernita e, em seguida, a produção dos zeólitos A ou LTA(Linde Type A), o zeólito X(Linde Type X) e o zeólito Y(Linde Type Y). A grande explosão dos zeólitos ocorreu nas décadas de 80 e 90, quando começaram a desenvolver zeólitos com microporos polimórficos, baseados em aluminofosfatos e metalosílica (BRAGA; MORGON, 2007).

As pesquisas sobre os zeólitos se preocupam em estudar estruturas capazes de "limpar" alguns processos de produção adequados às exigências ecológicas, tais como, limitar a porcentagem de enxofre nos combustíveis do tipo diesel ou ainda a conversão de hidrocarbonetos presentes nos gases como metano e etano em compostos aromáticos. O termo zeólito indica um grupo de aluminossilicatos cristalinos, que geralmente contém elementos alcalinos e alcalinos terrosos. Os zeólitos são constituídos de uma rede de poliedros com tetraedros, do tipo $\left[\mathrm{SiO}_{4}\right]^{4-}$ e $\left[\mathrm{AlO}_{4}\right]^{5-}$, ligados através de oxigênios, dando origem às unidades primárias. Para descrever as estruturas geométricas dos zeólitos, é preciso indicar o modelo e a disposição espacial das ligações. Por exemplo, o tetraedro $\left[\mathrm{SiO}_{4}\right]^{4-}$ 
pode ser ligado a um segundo tetraedro de maneira a formar uma cadeia linear sem ramificações ou uma estrutura ramificada, ou uma série não ramificada, mas com periodicidade diferente (BRAGA; MORGON, 2007). É interessante que, mesmo existindo zeólitos naturais, a indústria direciona seus investimentos na produção de catalisadores zeolíticos sintéticos. A razão dessa escolha se deve a três fatores importantes (BRAGA; MORGON, 2007):

- Os zeólitos naturais apresentam em sua grande maioria impurezas indesejáveis;

- A composição química desses minerais pode variar muito de um lugar para o outro e;

- Mesmo que a extração seja feita no mesmo local, é muito difícil a obtenção de zeólitos com a mesma composição.

As diferentes estruturas zeolíticas, com diferentes propriedades e características, podem ser obtidas através da manipulação de algumas das variáveis que participam do processo de síntese, como a temperatura, a pressão, o tempo, o pH, a concentração, dentre outros parâmetros. O tipo de cátion presente nessas estruturas pode orientá-las, agindo como se fosse um gabarito (template). Por exemplo, cátions de sódio facilitam a formação de estruturas com duplos anéis de seis membros, enquanto que grandes cátions orgânicos podem levar a um aumento do volume dos canais (BRAGA; MORGON, 2007).

No ano de 1962, as faujazitas sintéticas X e Y começaram a aparecer, em escala industrial, para catalisarem o craqueamento do óleo cru (BRAGA; MORGON, 2007).

Além das estruturas zeolíticas serem mais ativas cataliticamente que os processos em que usavam sílica-alumina amorfas, aquelas, por sua vez, proporcionavam a obtenção da gasolina em grande escala e com boa qualidade. Sem a 
utilização da catálise pelos zeólitos, o custo do refinamento do petróleo aumentaria em quase 10 bilhões de dólares por ano. Estima-se que, com apenas a melhoria do desempenho dos catalisadores atuais em 1\%, ocorreria uma redução na importação de cerca de 22 mil barris anuais. Dada a importância em se obter determinados zeólitos, o controle desses compostos durante a sua síntese deve considerar as seguintes propriedades (BRAGA; MORGON, 2007).

- os aspectos estruturais,

- a razão $\mathrm{Si} / \mathrm{Al}$,

- o tamanho dos poros e,

- a densidade da rede (número de átomos por cela unitária).

O tamanho dos poros em um zeólito corresponde a uma abertura bidimensional no cristal e é determinada pelo número de átomos tetraédricos ligados em sequência. As direções de visualização implicam em diferentes geometrias dos poros formando, assim, grandes cavidades internas e uma série de canais que atravessam todo o zeólito. A flexibilidade em gerar zeólitos, de acordo com a aplicação de interesse, é obtida promovendo-se o controle seletivo da passagem de certas moléculas conforme as formas, polaridades etc, o que eleva o interesse comercial na aplicação desses zeólitos (BRAGA; MORGON, 2007).

Os zeólitos podem ser divididos em três gerações: À primeira geração faz parte a modernita, caracterizada pela baixa relação entre o Silício e o Alumínio (Si/Al), o que confere uma elevada capacidade de troca iônica. Devido à polarização de suas pontes, por exemplo, a ponte $\mathrm{Si}-\mathrm{O}-\mathrm{Al}$, tem-se uma elevada higroscopia, sendo utilizada como dessecantes e em processos de separação e purificação. A segunda geração, representada pela estrutura ZSM-5 e pela sicalita, obtida com a aplicação de íons quaternários de amônio e cátions alcalinos durante a síntese, dá origem a 
novas estruturas e diferentes composições químicas com elevada relação Si/Al, geralmente utilizadas na adsorção de moléculas orgânicas (BRAGA; MORGON, 2007). A terceira geração é retratada por $\mathrm{AlPO}_{4}, \mathrm{SAPO}$ (Silico-Aluminophosphate) e MeAlPO. Estes fosfatos aluminosiliceto-metálicos são sintetizados sem a presença de cátions alcalinos, utilizando-se aminas orgânicas e compostos de amônio quaternário como elementos direcionadores. Os zeólitos podem ser representados com relação à sua célula unitária através da seguinte fórmula (BRAGA; MORGON, 2007):

$$
M \frac{x}{n}\left[\left(\mathrm{AlO}_{2}\right)_{x}\left(\mathrm{SiO}_{2}\right)_{y}\right] . w \mathrm{H}_{2} \mathrm{O}
$$

onde: $\mathrm{n}$ corresponde a valência do Cátion, $w$ é o número de moléculas de água e $x$ e y o número de estruturas $\mathrm{AlO}_{2}$ e $\mathrm{SiO}_{2}$, respectivamente. Através da estrutura básica tetraédrica pode-se formar redes tridimensionais muito diversificadas, com uma série de lacunas e espaços vazios, o que torna os zeólitos estruturas importantes em processos de adsorção, purificação, catálise, dentre outros.

\subsection{Estrutura dos Zeólitos e o tamanho de poros}

Os zeólitos são estruturas nanoporosas com diâmetros menores do que $2 \mathrm{~nm}$ e permitem a adsorção seletiva de moléculas e íons iguais ou menores que a abertura de seus poros como ilustra a Figura 2 (BRAGA; MORGON, 2007).

Figura 2: Diâmetro (nm) e átomo constituinte de poros característicos de alguns zeólitos

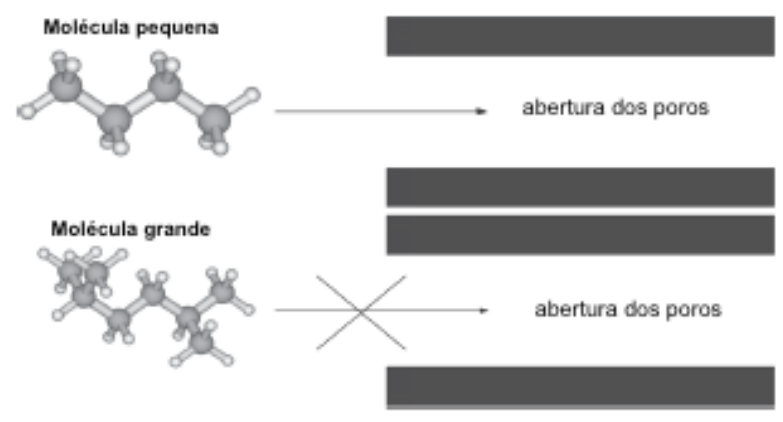

Fonte: BRAGA, A.A.C.; MORGON,N.H. Descrições estruturais cristalinas de zeólitos, Química Nova, v.30, p.178-188, 2007. 
A Tabela 1 a seguir mostra o tamanho característico dos poros e o número de átomos $\mathrm{Si}$ e $\mathrm{Al}$ que definem o perímetro de abertura do poro, de alguns zeólitos mais comuns (BRAGA; MORGON, 2007):

Tabela 1: Tamanho de poros característicos.

\begin{tabular}{c|c|c} 
Zeólito & diâmetro $(\mathrm{nm})$ & $\mathrm{N}^{\mathrm{o}}(\mathrm{Si}$ e $\mathrm{Al})$ \\
\hline $\mathrm{A}$ & 0,41 & 8 \\
\hline $\mathrm{Y}$ & 0,74 & 12
\end{tabular}

Fonte: BRAGA, A.A.C.; MORGON,N.H. Descrições estruturais cristalinas de zeólitos, Química Nova, v.30, p.178-188, 2007.

\subsection{Composição Química}

Uma grande parte das estruturas zeolíticas podem ser sintetizadas dentro de uma faixa bem ampla de razão silício/alumínio. No caso do ZSM-5, esse valor pode ser maior ou igual a 10 e atingir valor elevado. Mesmo após a realização da síntese, pode-se agir sobre os zeólitos, ao modificar sua composição química e, consequentemente, suas propriedades (BRAGA; MORGON, 2007).

\subsection{Troca Iônica}

A quantidade de alumínio na forma de cátions na estrutura do zeólito leva a determinar a quantidade de trocas iônicas $\mathrm{Al} / \mathrm{O}$ e, portanto, influi diretamente nas propriedades estruturais do material (BRAGA; MORGON, 2007).

\subsection{Interesse Ambiental}

Devido às características seletivas dos zeólitos, estes podem ser utilizados para controlar o nível de poluentes lançados no planeta como, por exemplo, a redução de óxido nítrico $\left(N O_{x}\right)$; o controle da emissão de compostos orgânicos voláteis, 
prejudiciais à camada de ozônio; o aperfeiçoamento de processos químicos industriais, substituindo ácidos como ácido fluorídrico $(\mathrm{HF})$, ácido cloridríco $(\mathrm{HCl})$ e ácido sulfúrico $\left(\mathrm{H}_{2} \mathrm{SO}_{4}\right)$ nos processos catalíticos (BRAGA; MORGON, 2007).

\subsection{Catálise}

Catálise é a mudança de velocidade de uma reação química devido à adição de uma substância (catalisador) que praticamente não se transforma ao final da reação. Os aditivos que reduzem a velocidade das reações se chamam inibidores e os catalisadores agem provocando um novo caminho reacional, no qual tem-se uma menor energia de ativação (BRAGA; MORGON, 2007).

Dentre os diversos tipos de catálises, podemos citar a heterogênea, em que se produz a adsorção dos reagentes na superfície do catalisador e é frequentemente bloqueada por impurezas denominadas "venenos". Como este tipo de catálise tem uma elevada aplicação nas indústrias, os zeólitos gozam de uma participação muito significativa nesses processos, tendo em vista a sua excelente capacidade catalítica. Sua atividade depende da estrutura da rede, assim como da densidade e força dos sítios ácidos. Experimentos com H-ZSM-5, forma protonada do ZSM-5 (HAAG; WEISZ, 1984), demonstram que a quantidade de sítios ácidos é diretamente proporcional à atividade catalítica. Com os trabalhos de Eugene Houdry em meados dos anos 20, foram introduzidas as técnicas de cracking catalítico, em que hidrocarbonetos de grandes cadeias podem ser quebrados em moléculas menores.

A indústria de petróleo, tem cada vez mais se aperfeiçoado com o intuito de tornar o refino mais atraente economicamente. Como se sabe, o petróleo cru contém uma quantidade significativa de contaminantes, sendo, dessa forma, necessária uma prévia purificação antes do seu processamento. Após uma série de medidas, o resultado é depositado em reservatórios ou processado novamente. A catálise costuma ser aplicada em dois estágios (BRAGA; MORGON, 2007): 
- no tratamento dos resíduos da destilação;

- no beneficiamento das frações constituídas de hidrocarbonetos leves.

Na parte principal da refinaria encontramos o Fluid Catalytic Cracker (FCC) responsável por introduzir os processos catalíticos no refinamento do petróleo (LERNER, 1998). O FCC pode ser dividido em duas partes: o zeólito e a matriz. O zeólito é uma esrutura cristalina contendo uma grande quantidade de poros, enquanto a matriz é um material amorfo, responsável pelo contato com as grandes moléculas. Além dos zeólitos participarem dos processos de refinamento do petróleo, possuem outras aplicações catalíticas tais como, desenvolvimento de processos para obtenção do metanol; obtenção de parafinas lineares; produção de oxigênio puro; como purificadores e além disso os zeólitos se encontram entre as camadas de vidro em janelas isolantes cujo uso resulta em economia energética. Ou seja, durante o aquecimento no decorrer do inverno e o resfriamento no verão, que pode resultar em uma contenção significativa de cerca de 450 milhões de barris de petróleo por ano (SHERMAN, 1999).

\subsection{Unidades de Construção}

A Figura 3 mostra algumas moléculas como silicato $\left(\left[\mathrm{SiO}_{4}\right]^{4-}\right)$ e aluminato $\left(\left[\mathrm{AlO}_{4}\right]^{5-}\right)$ com geometrias tetraédricas agrupados em subestruturas, onde os átomos de $\mathrm{Si}$ e $\mathrm{Al}$ correspondem aos átomos "T"e o "O"corresponde aos átomos indicados com menor tamanho fazendo ligações com os átomos "T"(BRAGA; MORGON, 2007). Nos vértices estão os átomos T(Si, Al) e as arestas representam as pontes T-O-T, onde o átomo de oxigênio está localizado a aproximadamente 0,03 - 0,07 nm de distância do átomo "T". Em cada vértice temos 4 ligações, denominadas de "4-ligadas", (quatro ligações) enquanto os oxigênios são "2-ligados"(duas ligações) (BRAGA; MORGON, 2007). Baseado nessa descrição, 
Figura 3: Redes tridimensionais 4:2 e sua representação em uma subunidade 2D. Os átomos de oxigênio situam-se nas arestas, entre os dois átomos $\mathrm{T}(\mathrm{Si}, \mathrm{Al})$ de cada vértice

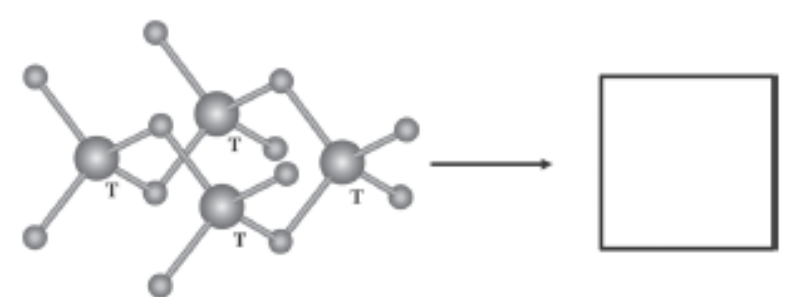

Fonte: BRAGA, A.A.C.; MORGON,N.H. Descrições estruturais cristalinas de zeólitos, Química Nova, v.30, p.178-188, 2007.

podemos representar a rede indicada na Figura 3 através de um quadrado onde o número de vértices (quatro) representa o número de átomos "T" da subestrutura e o número de lados conectados em cada vértice (dois) representa o número de ligações de cada átomo de oxigênio na forma de ponte T-O-T. Portanto, trata-se de uma rede 4:2 (BRAGA; MORGON, 2007).

\subsubsection{Unidades de Construção Secundárias - Secondary Building Units (SBU)}

Devido aos zeólitos possuírem diversas estruturas, foram criadas para a sua descrição e classificação estrutural, unidades finitas de construção secundária (SBU), como mostrado na Figura 4, observando que as unidades de construção primárias são os tetraedros $\mathrm{TO}_{4}$. Na maioria dos casos, podemos representar as redes cristalinas por uma unidade secundária com menos de 16 vértices, porém, em alguns casos podemos ter uma combinação de SBU's. As SBU's são unidades teóricas utilizadas para descrever a sua parte estrutural, não podendo ser confundidas com espécies precursoras presentes no processo de cristalização dos zeólitos. São utilizadas unidades finitas de construção secundária não quirais, de modo que cada estrutura seja formada por um único tipo de unidade secundária (BRAGA; MORGON, 2007). É importante lembrar que as SBU's não só compõem as estruturas zeolíticas, mas também estas vem sendo aplicadas em 
Figura 4: Unidades secundárias de construção (SBU's) encontradas em zeólitos e MOF's

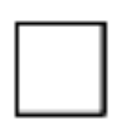

4

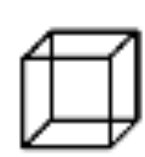

4- 4

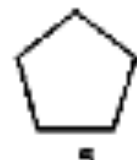

5
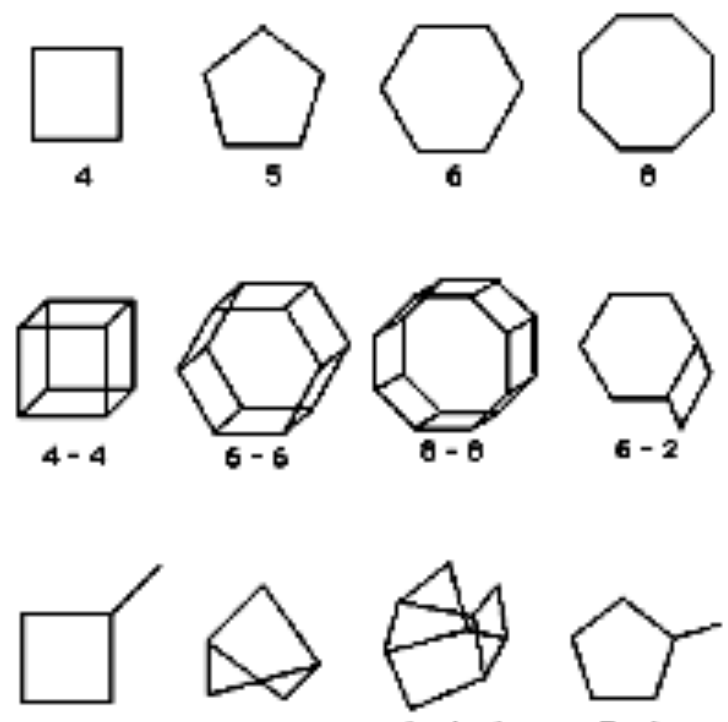

$\mathbf{4}=1$
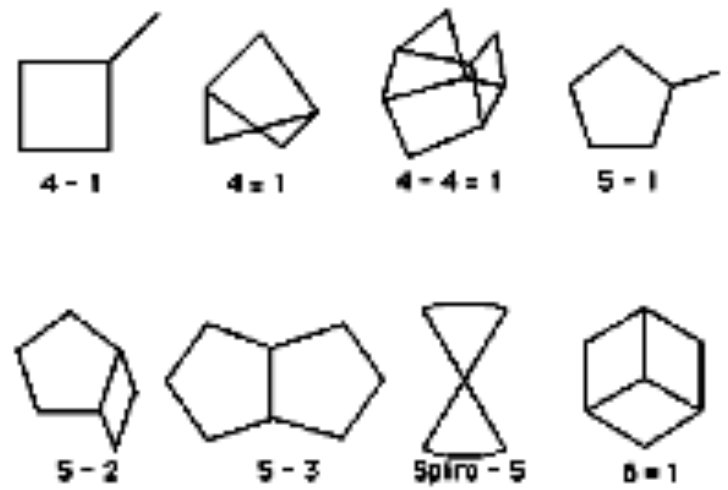

Fonte: BRAGA, A.A.C.; MORGON,N.H. Descrições estruturais cristalinas de zeólitos, Química Nova, v.30, p.178-188, 2007.

estudos de arcabouços cristalinos formados por redes metal-orgânicos, Metal Orgânics Frameworks (MOF'S), que são estruturas altamente porosas e estáveis (BRAGA; MORGON, 2007).

Os MOFs são sólidos híbridos orgânicos e inorgânicos com estrutura cristalina uniforme. Estes são constituídos por ligações de metal/orgânico formando estruturas microporosas, unidimensionais, bidimensionais e tridimensionais. Os MOFs são classes de materiais porosos com certas propriedades que vão além dos materiais tradicionais incluindo rigidez, funcionalidade, regularidade além de possuir elevada área superficial (BRAGA; MORGON, 2007).

O potencial desses materiais parece ser superior aos materiais tradicionais especialmente no que diz respeito à separação e purificação dos gases, catálise, adsorção e armazenamento de gases a alta pressão. Devido às excelentes carac- 
terísticas e propriedades dos MOF's, utilizados para separação de gases, estes têm sido alvo de muitos estudos (BRAGA; MORGON, 2007). As SBU's também podem ser descritas por outras unidades de construção, ou seja, por subunidades estruturais denominadas de, Strutural SubUnits (SSU) (BRAGA; MORGON, 2007).

\subsubsection{Sub-Unidades Estruturais - Strutural SubUnits (SSU)}

"Combinações de SBU's no espaço permitem uma série de construções de unidades "terciárias", mais complexas. Diversas formas de combinações são possíveis, envolvendo unidades finitas e infinitas, como cadeias simples, duplas e triplas, malhas 2D e poliedros. Por exemplo, a cavidade- $\beta$, um octaedro truncado, dá origem a vários zeólitos como se vê na Figura 5 (BRAGA; MORGON, 2007)".

Figura 5: Zeólitos correlacionados a cavidade- $\beta$ comuns (entre colchetes as vistas segundo os eixos $x y z)$

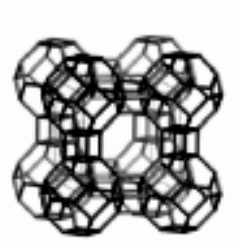

Zeólito A [001]

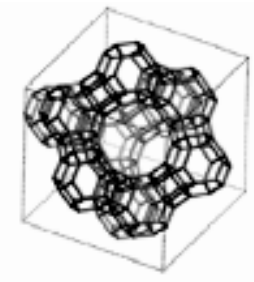

Zeólito X,Y [111]

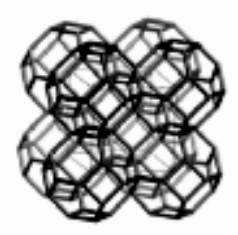

Zeólito Sodalita [100]

Fonte: BRAGA, A.A.C.; MORGON,N.H. Descrições estruturais cristalinas de zeólitos, Química Nova, v.30, p.178-188, 2007.

As unidades de construção do tipo SSU tem sido alvo de investimento, pois qualquer subunidade pode tornar-se um possível candidato promissor durante uma dada síntese. Ou seja, a combinação das subunidades pode resultar em novas estruturas que possam ser sintetizadas. Além disso, são importantes na classificação topológica das estruturas zeolíticas. Existem alguns conceitos básicos para compreender melhor o uso dos SSU's (BRAGA; MORGON, 2007). 


\subsubsection{Representação $2 \mathrm{D}$ de redes através das unidades de construção}

Como mencionado anteriormente sobre a Figura 3, existem unidades de construção que permitem representar uma dada rede através de polígonos 2D. Uma rede complexa pode ser representada através de polígonos diferentes entre si e com diferentes números de lados como ilustrado na Figura 6. Observa-se, na Figura 6, que a primeira rede é formada por polígonos com 4 e 8 lados interconectados entre si indicando a existência de dois tipos de subestruturas a saber: uma contendo 4 átomos "T"( por exemplo, $\mathrm{Al}$ ou $\mathrm{Si}$ ) e a outra contendo 8 átomos "T", e a frequência de polígonos em cada vértice (dois) é representada através de um número sobrescrito à direita. Portanto, trata-se de uma rede $4,8^{2}$. Já a segunda rede da Figura 6 é formada inteiramente apenas por polígonos de 6 lados onde a frequência de polígonos em cada vértice é 3 . Portanto, trata-se de uma rede $6^{3}$ (BRAGA; MORGON, 2007).

Figura 6: Exemplos de redes 3-conectados 2D

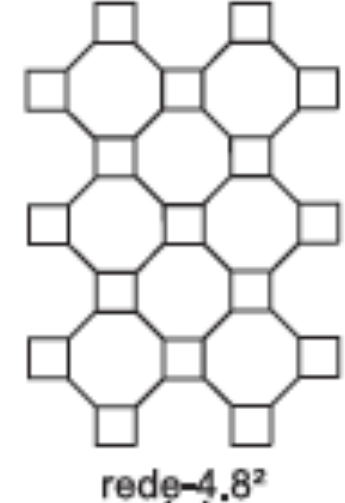

(a)

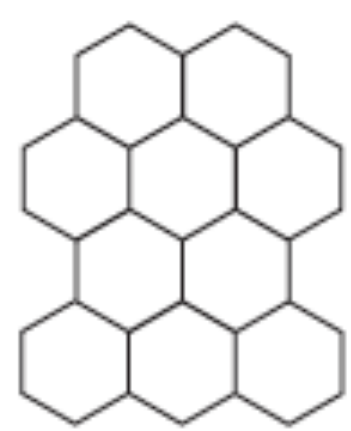

rede-6 - $^{3}$

(b)

Fonte: BRAGA, A.A.C.; MORGON,N.H. Descrições estruturais cristalinas de zeólitos, Química Nova, v.30, p.178-188, 2007.

\subsubsection{Transformação (sigma)}

A transformação sigma é uma ferramenta puramente conceitual que permite interrelacionar e construir tipos alternativos de arcabouços cristalinos zeolíticos 
já conhecidos ou apenas hipotéticos(SHOEMAKER; ROBSON; BROUSSARD, 1973). Por exemplo, estruturas conectadas tetraedricamente, assim como mostrado na Figura 3, podem ser expandidas se efetuarmos um corte através do plano formado por uma dada ponte $\mathrm{T}-\mathrm{O}-\mathrm{T}(\mathrm{T}=\mathrm{Al}$ ou $\mathrm{Si})$ resultando em duas pontes $\mathrm{T}-\mathrm{O}-\mathrm{T}$ paralelas e em uma nova estrutura com dois tetraedros adicionais. A Figura 7 ilustra duas transformações sigma sucessivas através dos planos de corte indicados sobre a representação 2D da estrutura apresentada na Figura 3. Observe que o corte simultâneo de duas pontes T-O-T no anel de 4 átomos T acaba gerando um anel com 6 átomos T interconectados através de átomos de oxigênio. O corte seguinte produz um outro anel com 8 átomos (BRAGA; MORGON, 2007).

Figura 7: Exemplo de transformação sigma para gerar anéis de 6 e 8 átomos T a partir de um anel de 4 átomos $\mathrm{T}(\mathrm{T}=\mathrm{Al}$ ou $\mathrm{Si}$ )

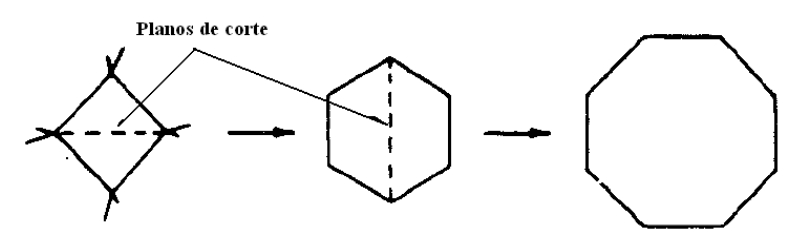

Fonte: BRAGA, A.A.C.; MORGON,N.H. Descrições estruturais cristalinas de zeólitos, Química Nova, v.30, p.178-188, 2007.

\subsubsection{Unidades de Construção Periódicas - Periodic Buil- ding Units (PBU)}

As unidades de construção periódicas (PBUs) são estruturas finitas (anéis simples e duplos, cadeias, tubos, malhas etc) que são usadas para construir a rede do zeólito por meio do menor número de conexões e operações de simetria como a translação, rotação e reflexão. Essas operações tem como objetivo descrever as 98 geometrias diferentes de redes $\mathrm{TO}_{4}$, onde $\mathrm{T}$ pode ser o $\mathrm{Si}, \mathrm{Al}, \mathrm{P}, \mathrm{Ga}, \mathrm{B}, \mathrm{Be}$, etc. (BRAGA; MORGON, 2007). 


\subsubsection{Zeólitos A, X e Y}

A literatura apresenta estruturas de arcabouço cristalino da sodalita conhecidos como zeólitos A, X e Y (Figura 8) que tem sido muito empregados em diversas aplicações. Para os zeólitos A, a unidade de construção PBU é uma cavidade- $\beta$, também conhecida como cavidade sodalita, com 24 átomos "T", seis anéis de 4 membros "T" e oito anéis de 6 membros "T". A estrutura resultante apresenta uma cavidade com 1,14 $\mathrm{nm}$, de diâmetro vazada por canais tridimensionais na forma de poros cilíndricos com 0,41 $\mathrm{nm}$ de diâmetro. A Figura 8a apresenta a estrutura tridimensional do zeólito LTA que acabamos de descrever (BRAGA; MORGON, 2007).

Figura 8: Arcabouços cristalinos tipo sodalita: (a) zeólito A, (b) zeólito X ou Y

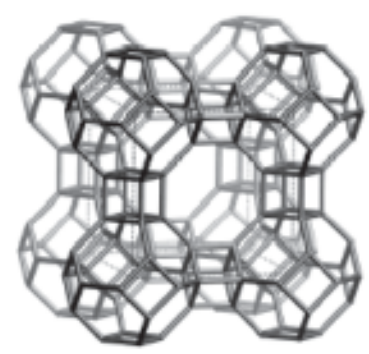

(a) LTA

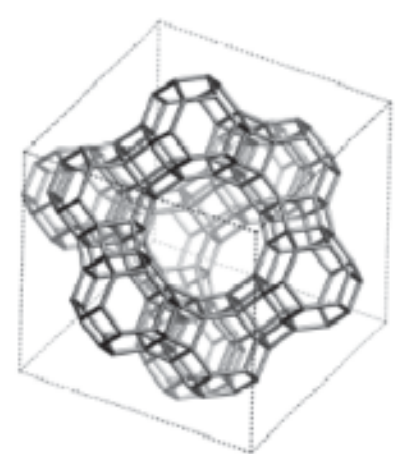

(b) $X / Y$

Fonte: BRAGA, A.A.C.; MORGON,N.H. Descrições estruturais cristalinas de zeólitos, Química Nova, v.30, p.178-188, 2007.

A estrutura tridimensional dos zeólitos X ou Y está ilustrada na Figura 8b. Esses zeólitos, também conhecidos como Linde $\mathrm{X}$ ou Linde $\mathrm{Y}$, têm estruturas idênticas. Na realidade o que diferencia uma estrutura da outra são suas razões Si/Al. Enquanto o zeólito X apresenta uma relação entre 1 e 1,5, o zeólito Y apresenta uma razão acima de 2,5. A estrutura é também uma cavidade sodalita, assim como o zeólito LTA, porém, estas cavidades são ligadas de forma distinta, pelas faces hexagonais com anéis duplos de 6 membros. Com relação às unidades secundárias de construção, existem 4 possibilidades: anéis 6-6, anéis 6-2, anel 
simples de 6 membros ou anel de 4 membros. O arranjo das unidades sodalitas leva à formação de uma cavidade bem maior, conhecida por supercavidade $\alpha$, com diâmetro interno de 1,18 $\mathrm{nm}$ formando entre as célas unitárias um sistema tridimensional de canais. Esta comunicação é feita através de anéis composto por 12 átomos de oxigênio, com diâmetro de 0,74nm e a combinação entre a supercavidade $\alpha$ com as unidades sodalitas, cujo diâmetro interno é de $0,65 \mathrm{~nm}$ e os anéis de 6 membros forma uma estrutura de canais secundários com um poro de aproximadamente 0,22 $\mathrm{nm}$, o que restringe o acesso de moléculas orgânicas e inorgânicas ao canal principal (BRAGA; MORGON, 2007).

\subsubsection{Modernita}

A unidade periódica de construção PBU da modernita é composta de 12 átomos "T", formada por duas cadeias em "zigzag" ligadas por um anel de 4 átomos "T". A razão $\mathrm{Si} / \mathrm{Al}$ apresenta valores entre 5 e 20, e esta característica confere à modernita uma resistência elevada a tratamentos térmicos e químicos. A modernita com razão por volta de 5 é caracterizada por uma simetria ortorrômbica, com 4 átomos T diferentes e pode ser construída por unidades secundárias 5-1 que caracterizam o grupo pentasil. Nos últimos anos, a modernita e as peneiras moleculares mesoporosas vem sendo usadas como matrizes para crescimento de clusters semicondutores, como por exemplo, aqueles formados por Sulfeto de Cádmio (CdS) (BRAGA; MORGON, 2007).

\subsubsection{ZSM-5 E ZSM-11}

Este tipo de zeólito é caracterizado pela elevada relação Si/Al, ou seja, maior que 15. A unidade periódica de construção (PBU) para os dois zeólitos está mostrada em negrito dentro do quadrado tracejado na Figura 9a. No caso dos 
zeólitos ZSM-5 e ZSM-11, a rede é gerada através da PBU de 12 vértices indicada no quadrado tracejado da Figura 9a, fazendo operações de translação na direção "c", rotação de $180^{\circ}$ e reflexão em relação a um plano perpendicular à direção "b". Na estrutura gerada, os vértices são tipicamente Al ou Si e demonstra que o oxigênio faz a ponte entre vértices através de duas ligações (BRAGA; MORGON, 2007).

Figura 9: (a) Primeira camada dos zeólitos ZSM-5 e ZSM-11, (b) subestrutura pentasil observada nos zeólitos ZSM-5 e ZSM-11, (c) indicação do PBU (vermelho) que permite gerar os zeólitos ZSM-5 e ZSM-11.

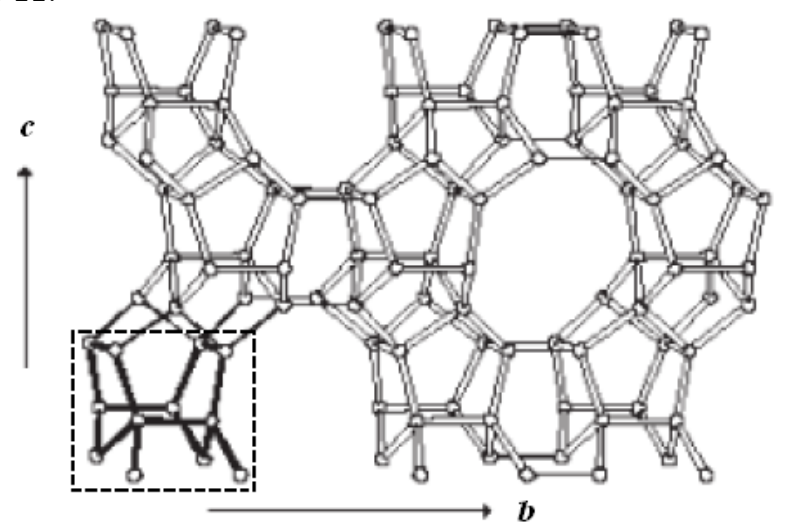

(A)

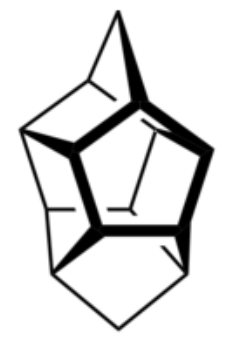

(B)

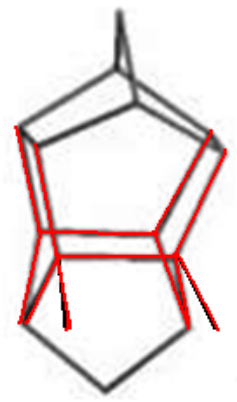

(C)

Fonte: BRAGA, A.A.C.; MORGON,N.H. Descrições estruturais cristalinas de zeólitos, Química Nova, v.30, p.178-188, 2007.

A Figura 9b mostra a subestrutura pentasil que fica aparente em todas as posições da primeira camada apresentada na Figura 9a para os zeólitos ZSM-5 e ZSM-11. Já a Figura 9c ilustra, em vermelho, sobre a subestrutura pentasil, a PBU que foi empregada para gerar a primeira camada dos zeólitos ZSM-5 e 
ZSM-11 (Figura 9a). A diferença entre esses zeólitos começa a partir da segunda camada. No caso do ZSM-5, a segunda camada é gerada sobre a primeira camada mostrada na Figura 9a através do encaixe da PBU rotacionada de $180^{\circ}$, ou seja, a conexão da primeira com a segunda camada é feita a partir de um centro de inversão. Por outro lado, no caso do ZSM-11, a segunda camada é gerada pelo encaixe direto da PBU posição a posição sem nenhuma rotação. Como resultado, os canais formados ao longo do eixo "a"perpendicular aos eixos "b"e "c"(saindo do papel) são do tipo zigzag no caso do ZSM-5; enquanto que, no caso ZSM-11, os canais ao longo do eixo "a" são diretos (BRAGA; MORGON, 2007).

Os canais em zigzag do zeólito ZSM-5 são ligeiramente elípticos, com dimensões de $0,53 \times 0,54 \mathrm{~nm}$ e são perpendiculares a canais diretos, também ligeiramente elípticos, com dimensões de 0,53 x 0,56 $\mathrm{nm}$. No cruzamento dos canais em zigzag com os canais diretos formam-se cavidades com diâmetro médio de 0,9nm. Baseado nessa estrutura característica, o ZSM-5 possui propriedades de adsorção e difusão diferenciadas, ou seja, o ZSM-5 é capaz de adsorver moléculas como 1, 2, 4-trimetilbenzeno, excluindo moléculas com diâmetro em torno de 0,1 nm maior, como 1, 3, 5- trimetilbenzeno (BRAGA; MORGON, 2007).

A dimensão dos canais também é importante durante a ação do ZSM-5 como catalisadores. Alterações na sua estrutura, com o intuito de aumentar a sua eficiência, vêm sendo estudadas, por exemplo, o tratamento alcalino $(\mathrm{NaOH})$ que pode alterar as partes amorfas do zeólito, criando mesoporos de tamanho uniforme e melhorando o desempenho catalítico, principalmente, devido ao aumento da capacidade de adsorção (BRAGA; MORGON, 2007).

\subsubsection{Erionita e Ofretita}

A Erionita e a Ofretita são estruturas pertencentes à família ABC-6, grupo este que engloba 15 zeólitos diferentes como cancrinita, chabazita e sodalita. Esta 
última é classificada como Clarato e apresenta poros de comunicação formados por anéis de 6 átomos "T", resultando em uma abertura muito pequena, que permite aplicações quando se deseja separar moléculas muito pequenas (BRAGA; MORGON, 2007).

A unidade periódica de construção (PBU) usada na família ABC-6 neste sistema consiste em um arranjo hexagonal de anéis de 6 membros não conectados como mostrado na Figura 10. Translações nos eixos "a"e "b"relacionam as PBU's a partir da posição $(0,0)$ no plano ab. Esta posição é conhecida como ponto A e as sucessivas posições transladadas e projetadas no plano "ab", vista [001], são chamadas de B e C conforme ilustra a Figura 10.

Figura 10: Representação das posições relativas dos anéis de 6 átomos "T"no arranjo hexagonal

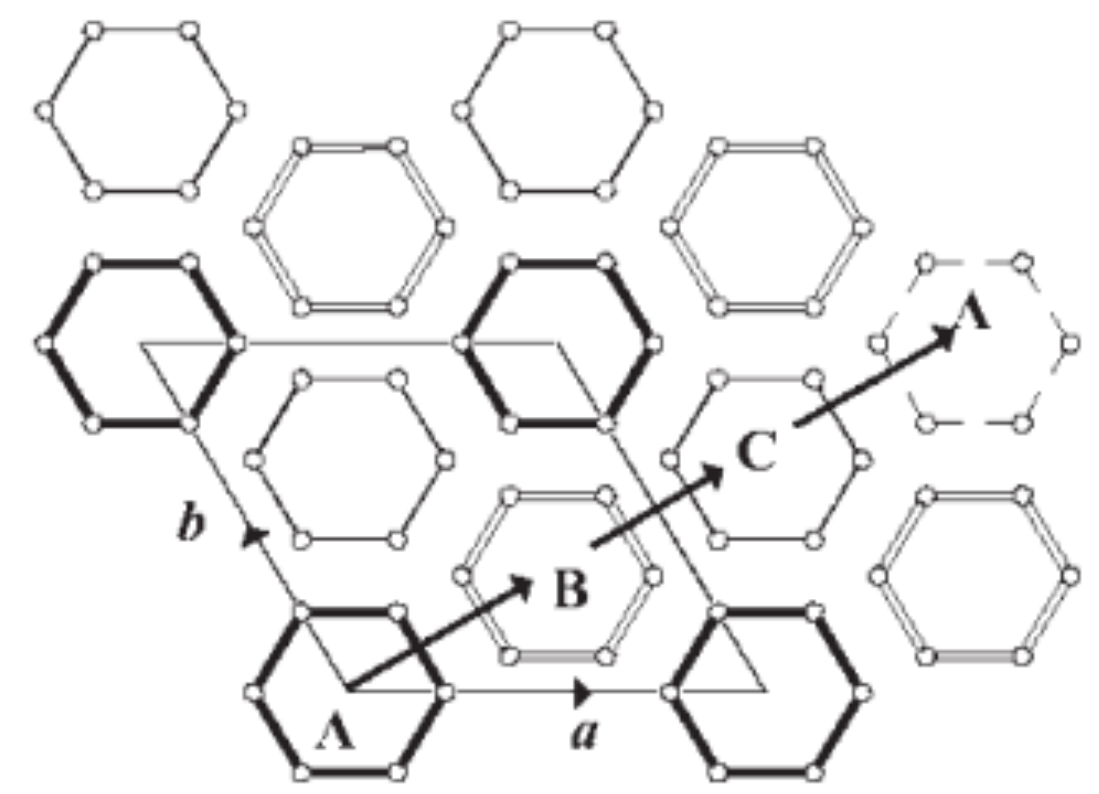

Fonte: BRAGA, A.A.C.; MORGON,N.H. Descrições estruturais cristalinas de zeólitos, Química Nova, v.30, p.178-188, 2007. 


\section{ARCABOUÇOS CRISTALINOS ZEOLÍTICOS FORMADOS POR REDES DE Zn E BASE CONJUGADA IMIDAZOL (ZIF: ZEOLITIC IMIDAZOLATE FRAMEWORK)}

Os zeólitos tipo ZIF ( Zeolitic Imidazolate Framework), cuja nomenclatura adotada em português foi "arcabouços cristalinos zeolíticos formados por redes de metal e base conjugada imidazol", têm sido amplamente empregados para absorver $\mathrm{CO}_{2}$ (NEWS, 2008). Um litro desse material pode armazenar aproximadamente 83 litros de dióxido de carbono $\left(\mathrm{CO}_{2}\right)$. Esse cristal não é tóxico e é resistente a tratamentos agressivos em meios ácidos e alcalinos, sendo assim um excelente recurso para capturar o dióxido de carbono e armazená-lo. Além disso, a estrutura porosa pode ser aquecida a altas temperaturas de aproximadamente $550^{\circ} \mathrm{C}$ sem decomposição bem como em água ou solventes por uma semana e permanecer estável, o que os torna adequados para usar em ambientes quentes. Os materiais tipo ZIF têm uma importância significativa na pesquisa científica e em aplicações industriais, devido a sua elevada estabilidade térmica e química são considerados excelentes para captura do dióxido de carbono $\left(\mathrm{CO}_{2}\right)($ NEWS, 2008).

O ZIF, material poroso, por sua excepcional estabilidade térmica e química tem atraído considerável atenção nos últimos anos para aplicações de armazenamento. Quando moléculas de gás são armazenadas em seu interior, o ZIF funciona 
como uma 'porta giratória' permitindo que determinadas moléculas, que neste caso são as de dióxido de carbono, atravessem-na e fiquem absorvidas, enquanto as moléculas maiores ou de forma diferentes são bloqueadas. Como sabemos, o dióxido de carbono é o principal responsável pela morte de recifes de corais e consequentemente da fauna marinha, danos estes irreversíveis, pelo menos por alguns ciclos. A captura do dióxido de carbono ajuda na produção de energia limpa, e isto pode ser feito quimicamente, pois temos a liberdade de escolher que tipo de 'porta giratória' podemos usar (SPOT, 2008).

Os materiais ZIF's são subclasses organometálicas dos MOFs, descritos no capítulo 2, que surgiram como um novo tipo de material cristalino poroso, já que radicais orgânicos (base conjugada do imidazol) estão interconectados entre si através de metais de transição. Estes podem interagir com o piriol e piridina ambos do grupo composto pela base conjugada do imidazol $\left(C_{3} H_{3} N_{2-}\right)$, dando lugar a uma formação de redes tridimensionais porosas e que combinam suas propriedades altamente desejáveis, tais como a cristalinidade, a microporosidade, a elevada área de superfície e a excelente estabilidade térmica (VENNA; JASINSKI; CARREON, 2010).

Como já mencionado, neste tipo de material, os radicais orgânicos (base conjugada do imidazol) estão conectados entre si através de íons metálicos, com a particularidade de que nos ZIF's essa ligação apresenta uma força muito maior devido à natureza da ligação química entre metal e radical orgânico com alta diferença de eletronegatividades o que confere ao material uma elevada estabilidade térmica (VENNA; JASINSKI; CARREON, 2010). 


\subsection{ZIF-8 e ZIF-90}

Os ZIF's podem formar uma grande variedade de estruturas 3D de zeólitos conforme apresentado no capítulo 2, porém com a vantagem sobre estes de que é possível ajustar o tamanho dos poros (VENNA; JASINSKI; CARREON, 2010). A Figura 11 mostra o arcabouço cristalino do ZIF-8 e ZIF-90 com cadeias Zn/radical orgânico que circundam uma cavidade formando um arcabouço cristalino do tipo sodalita cuja estrutura foi mostrada no item 2.6.6. É importante destacar que os átomos de Zn e os átomos que compõem a base conjugada do imidazol (C,N e H) estão indicados em diferentes cores. Um outro ponto importante de destaque é que os átomos de Zn (metal de transição) estão dispostos na forma de tetraedros e eles têm um papel semelhante ao alumínio ou ao silício nos zeólitos apresentados no capítulo 2, enquanto as bases conjugadas do imidazol correspondem aos átomos de oxigênio.

Figura 11: Estrutura tipo sodalita dos cristais ZIF-8 (a) e ZIF-90 (b) com rede ordenada de poros.

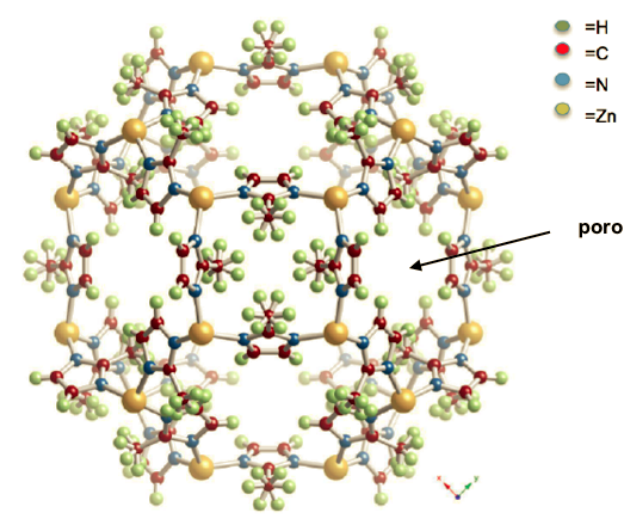

(a)

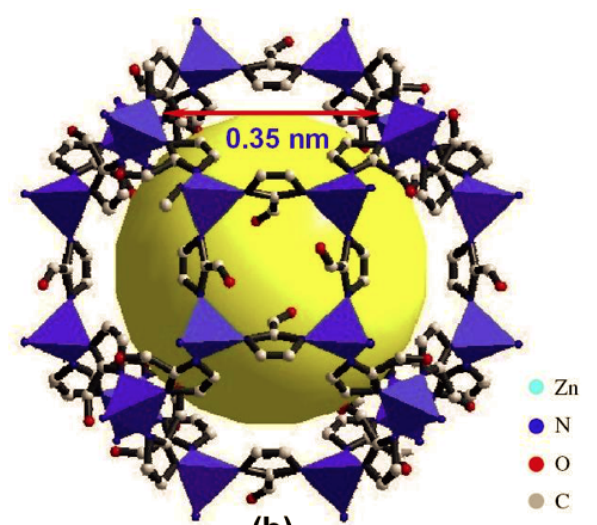

(b)

Fonte: YAN, M.P. Crystal growth of the metal-organic framework zif-8. December 2012. (a) HUANG, A.; LIU, Q.; WANG, N.; CARO, J. Microporous and Mesoporous Materials, V. 192, p. $18-22,2014$. (b)

Em particular, o ângulo metal-base conjugada do imidazol-metal é de aproximadamente $145^{\circ}$, muito próximo do ângulo Si-O-Si visto nos zeólitos apresentados 
no capítulo 2, o que faz com que as estruturas fiquem bem parecidas quanto à disposição tridimensional. As cadeias formadas por metais de transição e bases conjugadas do imidazol foram durante muitos anos objeto de pesquisa, no que diz respeito à sua estrutura cristalina e à síntese para sua obtenção. No entanto, no ano de 2004, a obtenção de estruturas análogas à dos zeólitos abriu um novo caminho para as pesquisas relacionadas aos polímeros. Atualmente há métodos de obtenção de estruturas estáveis que chegam até $400^{\circ} \mathrm{C}$, com áreas superficiais superiores à dos zeólitos e com elevadas capacidades de adsorção.

\subsubsection{Etapas na Síntese do ZIF-8 e ZIF-90}

Diversos grupos de pesquisa têm estudado as etapas de síntese do ZIF-8 e ZIF-90 em função do tempo na temperatura ambiente. Os pesquisadores têm reportado que existem alguns estágios que antecedem a formação do cristal como a nucleação, cristalização, crescimento e uma região estacionária. Também têm sido verificada a hipótese de que a transformação de semicristais para cristais pode ser realizada por meio de soluções e sólidos, como sugerido pela evolução de transformação de fase e a cinética de Avrami, (VENNA; JASINSKI; CARREON, 2010). É importante lembrar que o ZIF é uma subclasse da estrutura tipo arcabouço cristalino metalorgânico MOF: Metal Organic-Framework com propriedades importantes já vistas no capítulo 2, tais como a microporosidade, a cristalinidade, a elevada área superficial e uma excelente estabilidade química e térmica. Nos ZIF's, os átomos de metal de transição formam ligações químicas com átomos de nitrogênio, e ajudam a formar poros nanométricos cujo diâmetro depende do metal de transição empregado. Essas estruturas de ZIF se assemelham às estruturas de zeólitos formados por pontes $\mathrm{T}-\mathrm{O}-\mathrm{T}$, onde $\mathrm{T}=\mathrm{Si}$, Al, P que apresentam pontes $\mathrm{T}-\mathrm{Im}-\mathrm{T}$, onde $\mathrm{T}=\mathrm{Zn}$, Co e Im representa a base conjugada do imidazol, como ilustrado na Figura 12 (VENNA; JASINSKI; CARREON, 2010). 
Figura 12: Estrutura das pontes Si-O-Si (a) e T-Im-T (b) onde é indicado o ângulo aproximado entre ligações de $145^{\circ}$.

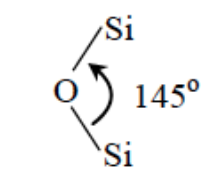

Si-O-Si

(a)

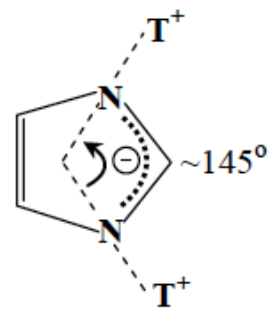

T-IM-T (b)

Fonte: YAN, M.P. Crystal growth of the metal-organic framework zif-8. December 2012. (a) HUANG, A.; LIU, Q.; WANG, N.; CARO, J. Microporous and Mesoporous Materials, V. 192, p. $18-22,2014$. (b)

Com relação às estruturas ZIF conhecidas, o ZIF-8 é uma das estruturas que têm sido mais estudadas, pois possui uma série de aplicações importantes tais como: separação de gases, sensoriamento e catálises, além de ser uma excelente estrutura para armazenamento de gás. O ZIF-8 é um material cujos arcabouços chegam a ter diâmetros de 1,16 nm que são acessíveis através de pequenas aberturas (poros) com diâmetros de 0,34 nm (YAN, 2012), como indicado na Figura 13a. Já o ZIF-90 Figura 13b apresenta estrutura muito semelhante, porém os poros têm diâmetros de $0,35 \mathrm{~nm}$

Um bom conhecimento do processo de formação dos ZIF's é de extrema importância para melhorar o controle estrutural e morfológico durante a síntese desses materiais. Com o intuito de aprimorar esse conhecimento, diversos grupos de pesquisa têm estudado a nucleação, a cristalização e o crescimento para este tipo particular de MOF (VENNA; JASINSKI; CARREON, 2010), (HUANG et al., 2014). A síntese do ZIF-8, tem sido realizada na temperatura ambiente através de nitrato de zinco hexahidratado $(\sim 0,3 g)$ e 2-metilimidazol $(\sim 0,7 g)$ previamente dissolvidos em metanol $(\sim 12 g)$ e, posteriormente, misturados através de agitação magnética durante algumas horas na temperatura ambiente.

Na sequência, as partículas cristalinas (cristais) obtidas a partir dessa receita 
Figura 13: Representação da reação química entre o Cátion-Zinco $\left(Z n^{2+}\right)$ e base conjugada do imidazol (Im) para formação das pontes Zinco-Imidazol-Zinco (Zn-Im-Zn). O arcabouço cristalino obtido apresenta estrutura tipo sodalita. A abertura dos poros entre 6 anéis tem um diâmetros de $0,34 \mathrm{~nm}$ para o ZIF-8 e 0,35 $\mathrm{nm}$ para o ZIF-90

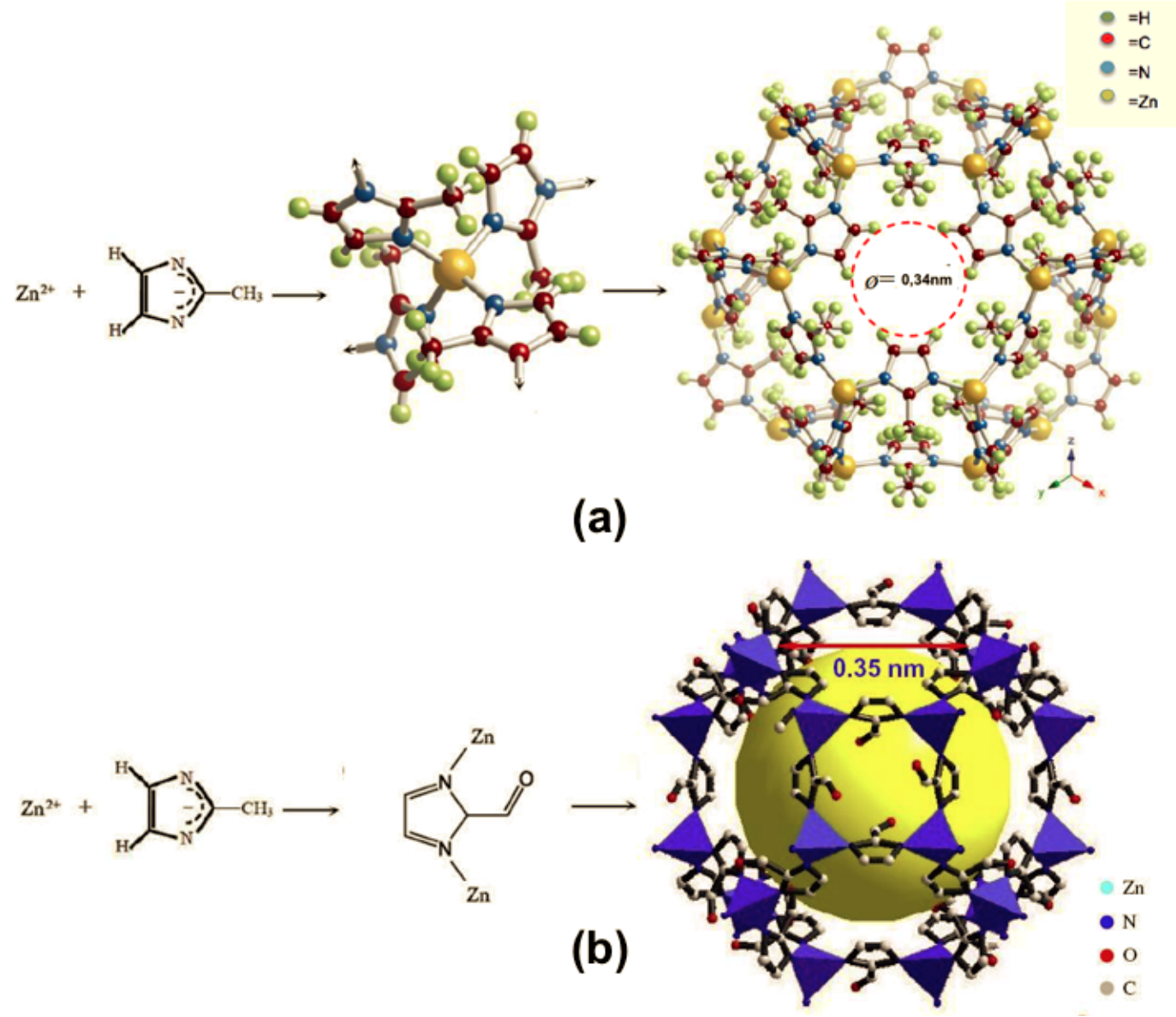

Fonte: YAN, M.P. Crystal growth of the metal-organic framework zif-8. December 2012. (a) HUANG, A.; LIU, Q.; WANG, N.; CARO, J. Microporous and Mesoporous Materials, V. 192, p. $18-22,2014$. (b)

típica de síntese devem passar por centrifugação em 4000 rpm e serem lavadas com metanol. Esse procedimento de centrifugação e lavagem deve ser repetido por pelo menos duas vezes. Finalmente, o material obtido na forma de pó, deve ser secado tipicamente por 12 horas a cerca de $75^{\circ} \mathrm{C}$.

A Figura 14 mostra e evolução das facetas cristalinas do ZIF-8 após a síntese descrita anteriormente para diversos tempos de agitação na temperatura ambiente da mistura de zinco hexahidratado e 2-metilimidazol em metanol (antes da centrifugação, lavagem e secagem) (VENNA; JASINSKI; CARREON, 2010). 
Figura 14: Evolução das facetas cristalinas do ZIF-8 em função do tempo de agitação na temperatura ambiente da mistura de zinco hexahidratado e 2-metilimidazol em metanol (antes da centrifugação, lavagem e se secagem): (a) $20 \mathrm{~min}$; (b) $30 \mathrm{~min}$; (c) $40 \mathrm{~min}$; (d) $50 \mathrm{~min}$; (e) 60 $\min ;(f) 12 \mathrm{~h}$; (g) $24 \mathrm{~h}$.

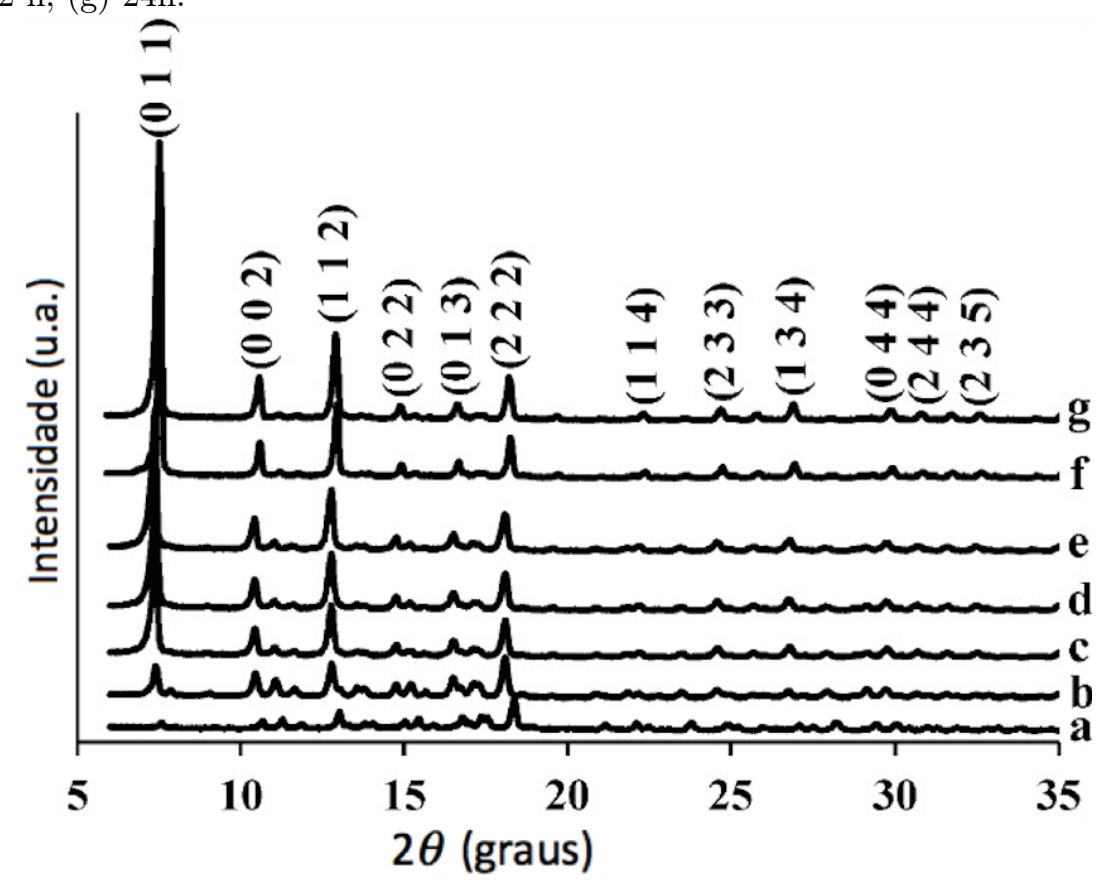

Fonte: VENNA, S.R.; JASINSKI, J.B.; CARREON, M.A. Strutural evolution of zeolitic imidazolate framework-8 J.Am.Chem.Soc.,v. 132,p.18030-18033,2010.

Como pode-se observar na Figura 14, a maioria dos picos aumentam de intensidade à medida que o tempo de síntese aumenta. Em particular, já existem picos para o tempo de 20 min o que sugere que o ZIF-8 evolui provavelmente a partir de uma fase metaestável. A soma das áreas dos picos para cada tempo de síntese é uma medida do grau de cristalinidade e observa-se que esse parâmetro aumenta lentamente na síntese com tempos de 20 e 30 min. Já para tempos acima de 40 min, observa-se um aumento rápido da soma das áreas dos picos. Finalmente, acima de 50 min, nota-se que a cristalinidade relativa do ZIF-8 permanece aproximadamente constante, acima de 90\%, e atinge o seu valor máximo em 24 horas. Observou-se também nesse experimento que após 48h, o grau de cristalização do material não sofreu alteração comparado com a síntese feita no tempo de 24 horas. A principal conclusão tirada desse experimento foi que a cristalinidade máxima é alcançada após um tempo de síntese de 24 horas (VENNA; JASINSKI; 
CARREON, 2010).

É importante também mencionar que as partículas cristalinas sintetizadas para tempos abaixo de 10 minutos, foram observadas, porém não foi possível fazer a análise XRD nesta etapa devido à quantidade extremamente pequena de material formado. Porém, utilizando-se de imagens TEM, foi possível observar algumas dessas partículas com tamanho de aproximadamente 50nm.

Como pode ser observado na Figura 15, a evolução estrutural do ZIF-8 em função do tempo pode ser separada em três regiões. Inicialmente para intervalos

Figura 15: Cinética de transformação do ZIF-8 em função do tempo.

I-Nucleação, II-Fase de Crescimento, III-Fase Estacionária

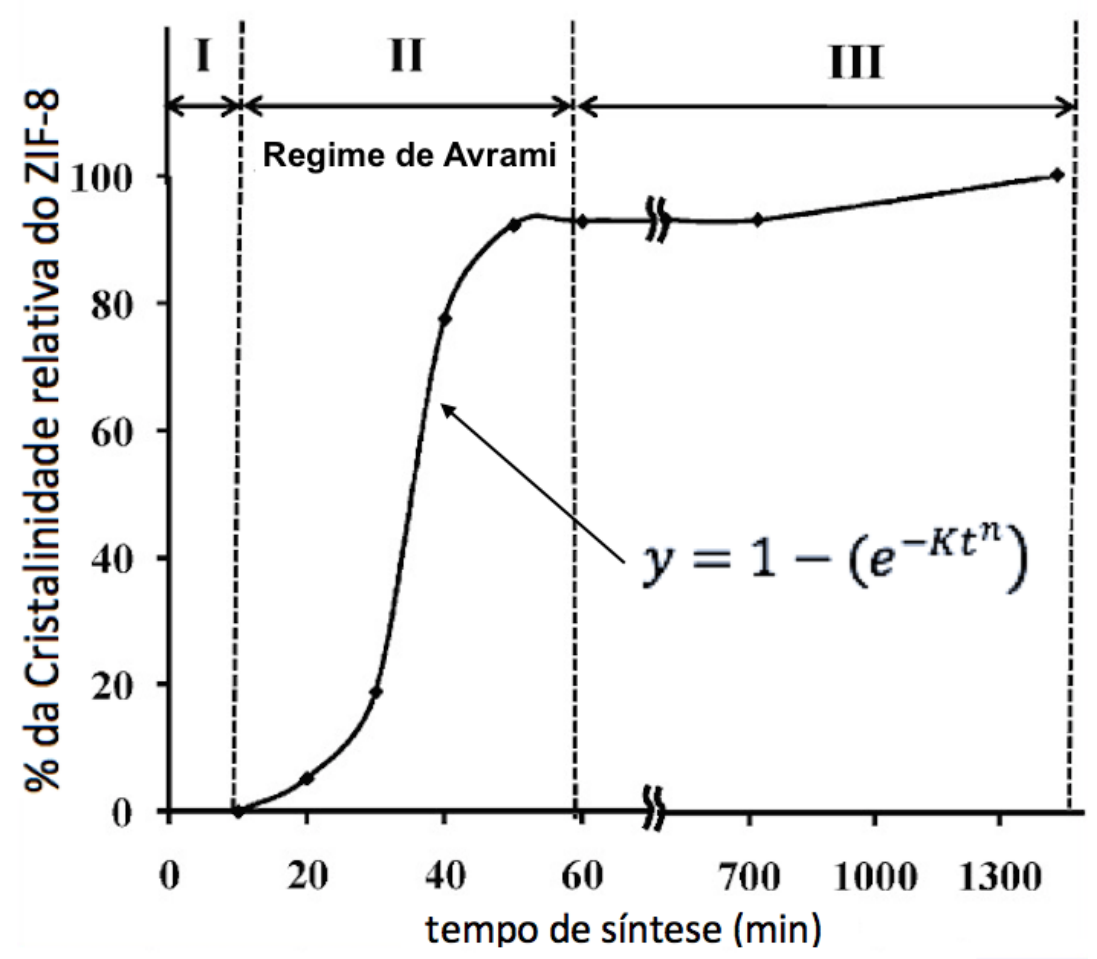

Fonte: VENNA, S.R.; JASINSKI, J.B.; CARREON, M.A. Strutural evolution of zeolitic imidazolate framework-8 J.Am.Chem.Soc.,v132,p.18030-18033,2010.

menores que 10 minutos temos o período de incubação necessário para a fase de nucleação correspondendo à etapa I. Após a nucleação, ocorre a etapa de crescimento (etapa II) durante a qual a cristalinidade relativa do material ZIF8 aumenta com o passar do tempo. Nessa região, a cristalinidade máxima é 
alcançada em aproximadamente $60 \mathrm{~min}$. Nessa etapa, a cinética de crescimento obedece o modelo clássico de Avrami, no qual a evolução da cristalinidade relativa (\%) do ZIF-8 em função do tempo pode ser expressa pela equação $y=1-e^{\left(-K t^{n}\right)}$, onde K é uma constante de escala e n é a constante de Avrami, y é a cristalinidade relativa e t é o tempo de síntese. Neste caso, $\mathrm{K}=5,1 \times 10^{-7}$ e $\mathrm{n} \approx 4$ (VENNA; JASINSKI; CARREON, 2010). O valor de n é muito importante, em relação ao processo de nucleação e crescimento, pois $n=4$ sugere que a fase randômica de nucleação é homogênea e que o crescimento ocorre na forma de superfícies esféricas (VENNA; JASINSKI; CARREON, 2010).

No início da fase estacionária (etapa III) para instantes maiores que $60 \mathrm{~min}$, a taxa de cristalização relativa do material ZIF-8 permanece constante como na fase metaestável. Além de todos esses parâmetros, o pH da solução foi também acompanhado como função do tempo. Verificou-se que inicialmente o pH da solução era de 7,8, diminuindo para 7,5, 7,4 e 7,3 em 10, 20 e 40 min respectivamente. Após 50 minutos o pH permaneceu constante em 7,2. Como resultado, verificouse que a cristalinidade do material é função do pH da solução, pois à medida que a cristalinidade do material aumentava, o seu pH se reduzia (VENNA; JASINSKI; CARREON, 2010).

A formação e crescimento do ZIF-8 foram confirmados pelas imagens TEM, como mostrado na Figura 16. Em 10 minutos, foram obtidas esferas com aproximadamente $50 \mathrm{~nm}$ de diâmetro e partículas facetadas que foram aumentando o tamanho com o aumento do tempo de síntese (VENNA; JASINSKI; CARREON, 2010).

A presença dessas partículas facetadas indica um estágio inicial de cristalização, de acordo com a Figura 16a. Após 30 min, o tamanho dessas partículas aumenta substancialmente e ainda alguns cristais mostraram-se facetados, como pode ser observado na Figura 16b. Já nas Figuras 16c e 16d, o tamanho dos 
Figura 16: Imagens TEM do ZIF-8 em função do tempo de síntese: (a) 10 min; (b) 30 min; (c) $40 \mathrm{~min}$; (d) $60 \mathrm{~min}$; (e) $12 \mathrm{~h}$; (f) $24 \mathrm{~h}$.

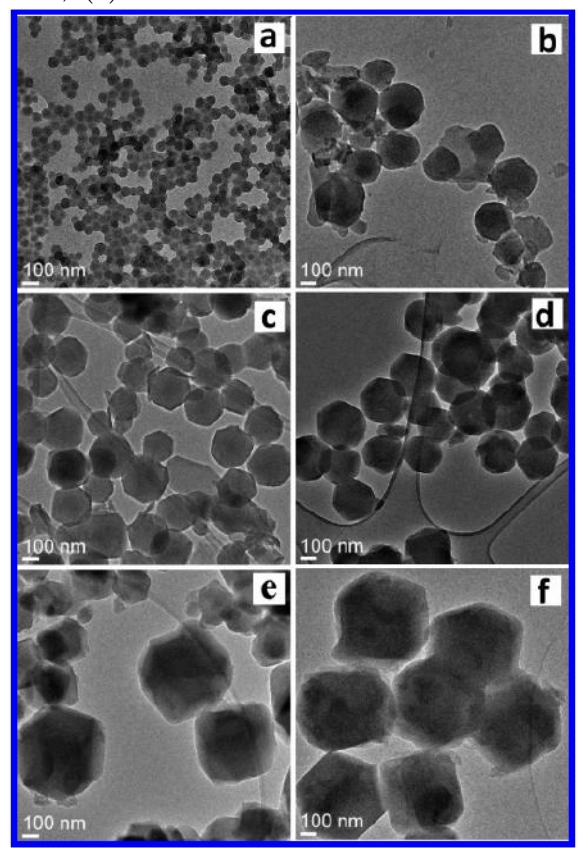

Fonte: VENNA, S.R.; JASINSKI, J.B.; CARREON, M.A. Structural evolution of zeolitic imidazolate framework-8. J. Am. Chem. Soc., v. 132, p. 18030-18033, 2010.

cristais permaneceu praticamente constante, embora mais cristais homogêneos facetados fossem observados. Após o tempo de 12 horas, o tamanho dos cristais aumentou ainda mais, porém não ficaram homogêneos, de acordo com a Figura 16e. E, finalmente, após 24 horas o tamanho dos cristais multifacetados chegaram a cerca de 500nm com uma distribuição de tamanhos relativamente homogênea, como se observa na Figura 16f (VENNA; JASINSKI; CARREON, 2010).

A Figura 17 mostra as imagens de difração de elétrons para área selecionada (SAED: Selected Area Electron Difraction) correspondentes às imagens TEM apresentadas na Figura 16. O resultado apresentado é semelhante à análise XRD já apresentada na Figura 14, porém a análise SAED permite identificar apenas os planos cristalinos correspondentes aos anéis de sinal mais evidente (VENNA; JASINSKI; CARREON, 2010). Como se pode verificar na Figura 17, o número de planos cristalinos aumenta à medida que o tempo de síntese aumenta. Em particular, já existem planos observados para o tempo de 10 min o que reforça 
Figura 17: Imagens de difração de elétrons para área selecionada (SAED) correspondentes às imagens TEM apresentadas na Figura 16: (a) $10 \mathrm{~min}$; (b) $30 \mathrm{~min}$; (c) $40 \mathrm{~min}$; (d) $60 \mathrm{~min}$; (e) $12 \mathrm{~h}$; (f) $24 \mathrm{~h}$.

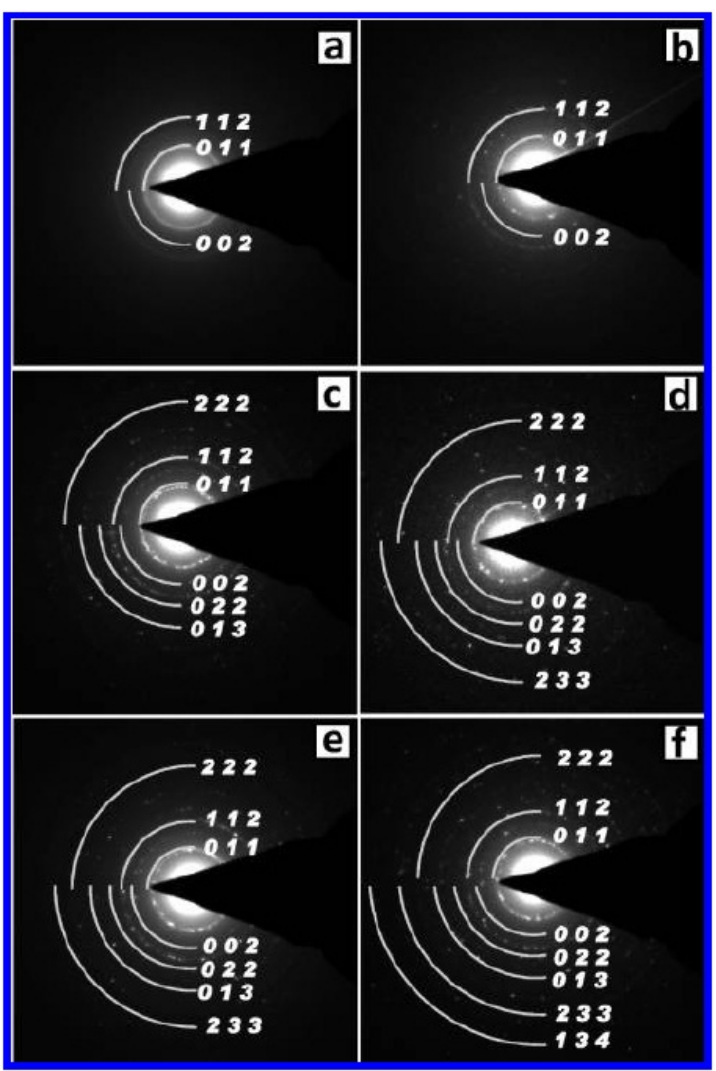

Fonte: VENNA, S.R.; JASINSKI, J.B.; CARREON, M.A. Strutural evolution of zeolitic imidazolate framework-8 J.Am.Chem.Soc.,v. 132, p. 18030-18033, 2010.

a ideia de que o ZIF-8 evolui provavelmente a partir de uma fase metaestável como já mencionado para as análises XRD. O aumento do número de planos constatados também é condizente com o fato descrito na Figura 17, isto é, com o aumento do tempo de síntese, aumenta o tamanho médio dos cristais o que permite evidenciar planos cristalinos, que antes não podiam ser detectados. É importante também destacar que na fase estacionária (estágio III da Figura 15), praticamente não aparecem novos planos cristalinos com exceção do plano 134 (SURENDAR; CARREON, 2009). 


\subsubsection{Métodos de Síntese do ZIF}

Existem vários métodos de síntese dos ZIFs a saber: hidrotérmico, solvotérmico, difusão lenta, em meio heterogêneo, eletroquímica, mecanoquímica, sonoquímica e, recentemente, métodos de síntese assistidos por micro-ondas (MCCARTHY et al., 2010). Porém, este capítulo contempla os métodos hidrotérmico e solvotérmico os quais estão relacionados com o presente trabalho conforme veremos a seguir.

\subsubsection{Método Hidrotérmico}

No método de síntese hidrotérmico utiliza-se pressões elevadas, permitindo ao solvente que se mantenha em estado líquido em temperaturas maiores que seu ponto de ebulição. Assim, tipicamente ocorre um aumento da solubilidade do precursor, ainda amorfo. Nas sínteses hidrotérmicas, a cristalização ocorre em temperaturas mais baixas do que as comuns de cristalização por calcinação. O padrão de Difração de Raios-X das sementes (grãos) de ZIF-8 por síntese hidrotérmica correspondem à estrutura tipo sodalita (SOD) e confirmam a formação da fase do ZIF-8 puro cristalino cujo espectro XRD típico está ilustrado na Figura 18 com os diversos planos cristalinos presentes. (SURENDAR; CARREON, 2009).

As membranas de ZIF-8 foram sintetizadas por cristalização "in situ" sobre suportes $\alpha$-alumina tubular porosa. As sementes iniciais obtidas por síntese hidrotérmica forneceram locais de nucleação para o crescimento das camadas. A eficiência de separação dos gases $\mathrm{CO}_{2} / \mathrm{CH}_{4}$ pelas camadas de ZIF-8 é mostrada na tabela 2. Na tabela 2, estão indicadas as constantes de permeação do $\mathrm{CO}_{2}$ no ZIF-8 para pressões de entrada, respectivamente de 99, 5 e $40 \mathrm{KPa}$ e a resultante seletividade obtida (SURENDAR; CARREON, 2009). 
Figura 18: Espectro XRD típico do ZIF-8 onde está indicado todos os planos cristalinos da estrutura tipo sodalita.

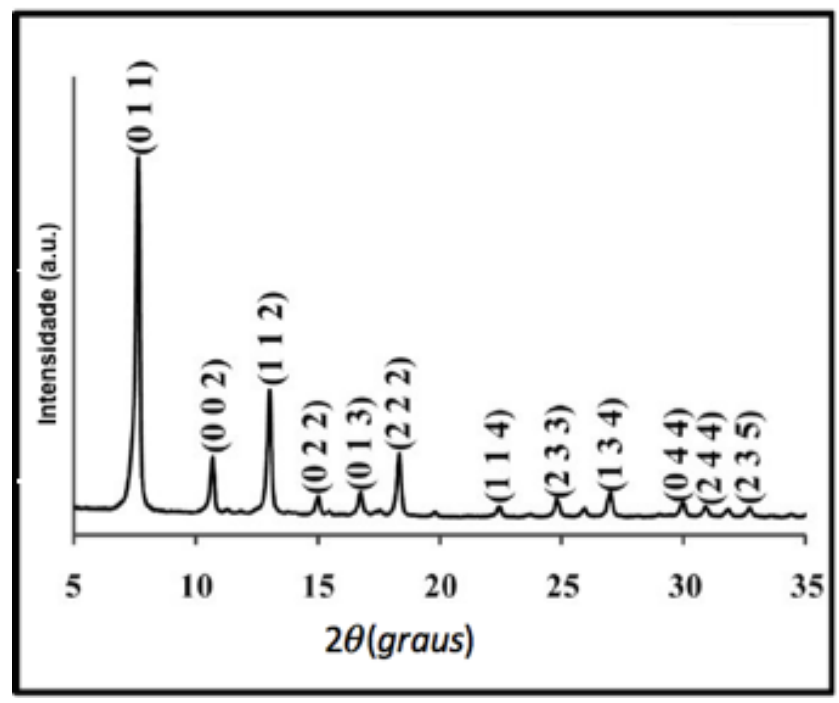

Fonte: VENNA, S.R.; JASINSKI, J.B.; CARREON, M.A. Strutural evolution of zeolitic imidazolate framework-8 J.Am.Chem.Soc.,v. 132, p.18030-18033, 2010.

Tabela 2: Propriedades de separação dos gases $\mathrm{CO}_{2} / \mathrm{CH}_{4}$ (constantes de permeação e seletividade) das membranas de ZIF-8 nas pressões de entrada do $\mathrm{CO}_{2}$ de 40 a $99,5 \mathrm{KPa}$, respectivamente.(SURENDAR; CARREON, 2009).

\begin{tabular}{cccc}
\hline $\begin{array}{c}\text { membrana } \\
I D^{a}\end{array}$ & $\begin{array}{c}\mathrm{PO}_{2}(40 \mathrm{KPa}) \\
\mathrm{mol} / \mathrm{m}^{2} s \mathrm{~Pa}\left(10^{6}\right)\end{array}$ & $\begin{array}{c}\mathrm{P}_{\mathrm{CO}_{2}}(99,5 \mathrm{KPa}) \\
\mathrm{mol} / \mathrm{m}^{2} \mathrm{~s} \mathrm{~Pa}\left(10^{6}\right)\end{array}$ & $\begin{array}{c}\mathrm{CO}_{2} / \mathrm{CH}_{4} \\
\text { seletividade }\end{array}$ \\
\hline $\mathrm{Z} 1$ & 2,43 & 4,72 & 5,1 \\
$\mathrm{Z} 2$ & 2,19 & 4,63 & 4,7 \\
$\mathrm{Z} 3$ & 2,11 & 5,17 & 4,1 \\
Z4 & 1,69 & 2,42 & 7,0
\end{tabular}

Fonte: VENNA, S.R.; JASINSKI, J.B.; CARREON, M.A. Strutural evolution of zeolitic imidazolate framework-8 J.Am.Chem.Soc.,v. v. 132, p. 18030-18033, 2010.

\subsubsection{Método Solvotérmico}

A Figura 19 ilustra o processo inicial de modificação de superfícies polidas de alpha-alumina antes de proceder a obtenção de camadas ZIF-8 (MCCARTHY et al., 2010). Inicialmente, a placa de alumina é aquecida até temperaturas de cerca de $200^{\circ} \mathrm{C}$, na sequência, uma solução de ligante (2-metilimidzol) derramada sobre a placa sofre evaporação e lavagem diversas vezes. Mais tarde, as amostras pré-condicionadas são imersas em solução de nitrato de zinco e 2-metilimidazol diluída em metanol, seguido de recozimento em temperaturas na faixa de $120^{\circ} \mathrm{C}$ a $200^{\circ} \mathrm{C}$. Os cristais de ZIF-8 assim obtidos são térmico e quimicamente estáveis 
Figura 19: - Ilustração do processo de modificação do substrato

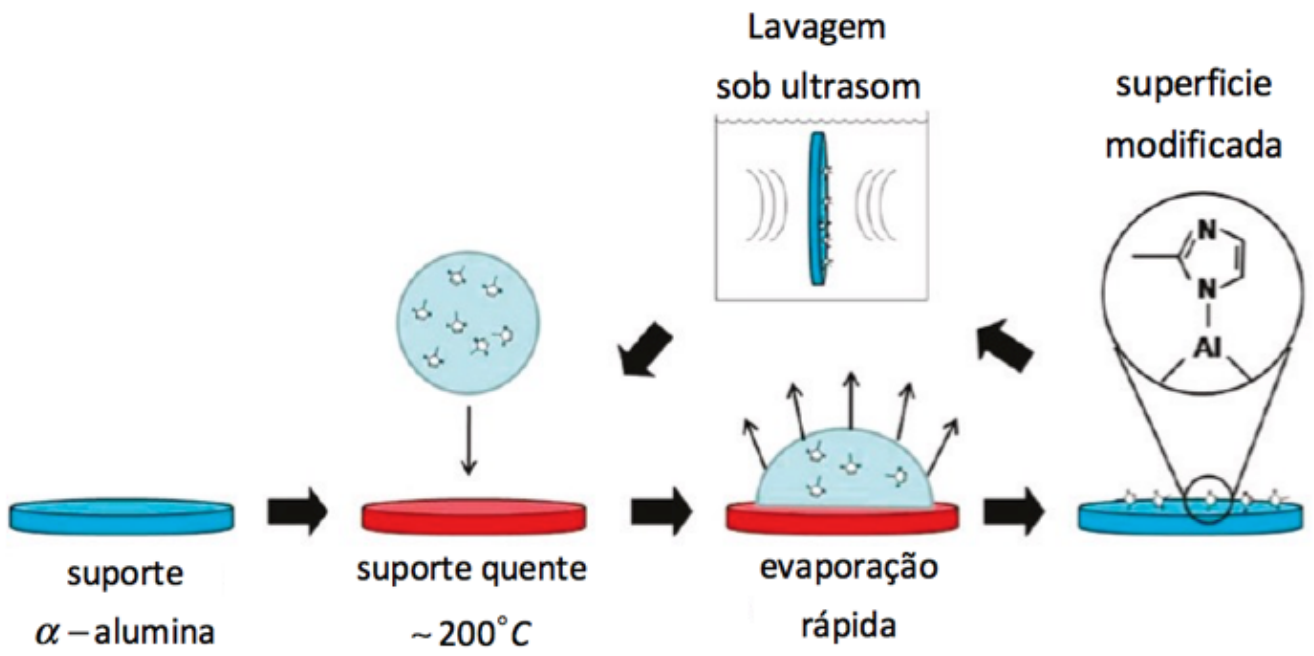

Fonte: MCCARTHY,M.C.; GUERREIRO,V.V.; BARNETT,G.V.; JEONG,H.K. Synthesis of zeolitic imidazolate framework films and membranes with controlled microstructures v. $26, \mathrm{n}$. 18 p. $14636-14641,2010$

e os tempos de síntese podem variar na faixa entre 1 hora a 1 mês, empregando diversas composições de solução sal de zinco+2-metilimidazol. Os cristais de ZIF-8 assim preparados apresentam tipicamente uma distribuição de partículas com tamanhos de micrômetros $(\sim 150 \mu \mathrm{m})$ até nanômetros $(\sim 50 \mathrm{~nm})$ e áreas de superfície na faixa de 900-1600 $\mathrm{m}^{2} / \mathrm{g}$. (SURENDAR; CARREON, 2009).

Um fato extremamente relevante a destacar é que a síntese solvotérmica não ocorre na temperatura ambiente. A necessidade de temperatura mais elevada implica que os ligantes (base conjugada do imidazol) são presos à superfície do suporte por meio de um processo ativado, isto é, para formar ligações fortes do tipo iônica (por exemplo, Al-N, como mostrado na ilustração da Figura 19). Outra evidência disso foi mostrada pelos resultados de condicionamento inicial da superfície polida de alpha-alumina a $200^{\circ} \mathrm{C}$ onde uma solução de ligante (2metilimidazol) diluída em metanol foi derramada e seca durante 20 minutos subsequente a banho ultrassônico em metanol durante 30 segundos. Após repetir a etapa de condicionamento diversas vezes, a superfície adquiriu uma cor marrom escuro indicando que os ligantes ficaram fortemente presos após o processo de 
modificação da superfície (MCCARTHY et al., 2010).

Por outro lado, a síntese solvotérmica convencional pode também ser empregada para obter MOFs luminescentes (KRENO et al., 2012).

A Figura 20 mostra as imagens SEM típicas de superfície e de corte transversal para filmes contínuos de ZIF-8 produzidos, pelo método solvotérmico em superfícies polidas de alpha-alumina utilizando duas receitas: (1) imersão em solução de cloreto de zinco + formiato de sódio +2 -metilimidazol diluídos em metanol seguido de recozimento a $120^{\circ} \mathrm{C}$ durante 4 horas; e (2) imersão em solução de nitrato de zinco e 2-metilimidazol diluídos em metanol seguido de recozimento a $120^{\circ} \mathrm{C}$ durante 30 horas. A estrutura de cristal desses filmes foi confirmada com a ajuda da análise XRD. Embora ambas as películas, obtidas respectivamente pelas receitas 1 (Figuras 20a e 20b) e 2 (Figuras 20c e 20d), sejam inteiramente de cristais de ZIF -8, elas exibem grandes diferenças microestruturais (MCCARTHY et al., 2010).

A microestrutura compacta obtida através da receita 1 (Figura 20a e 20b) para o filme ZIF-8 torna-o adequado para aplicações de separação de gases, por exemplo, a separação do $\mathrm{CO}_{2}$ do $\mathrm{CH}_{4}$ em misturas de gás pobre com alto teor de $\mathrm{CO}_{2}$. Por outro lado, a microestrutura obtida através da receita 2 (Figuras 20c e 20d) apresenta diversos interstícios o que o torna inadequado para a aplicação de separação de gases. No entanto, apesar desta limitação, os filmes de ZIF-8 obtidos através da receita 2 ainda podem ser empregados como sensor químico por apresentar excelente capacidade de absorção do $\mathrm{CO}_{2}$ (MCCARTHY et al., 2010). 
Figura 20: - (a) (b) Imagens SEM, respectivamente, de topo e de corte transversal de um filme contínuo de ZIF-8 obtido através da receita 1 (aproximadamente $20 \mu m$ de espessura), (c)(d), imagens SEM, respectivamente, de topo e de corte de um filme de ZIF-8 obtido através da receita 2 (aproximadamente $12 \mu m$ de espessura).
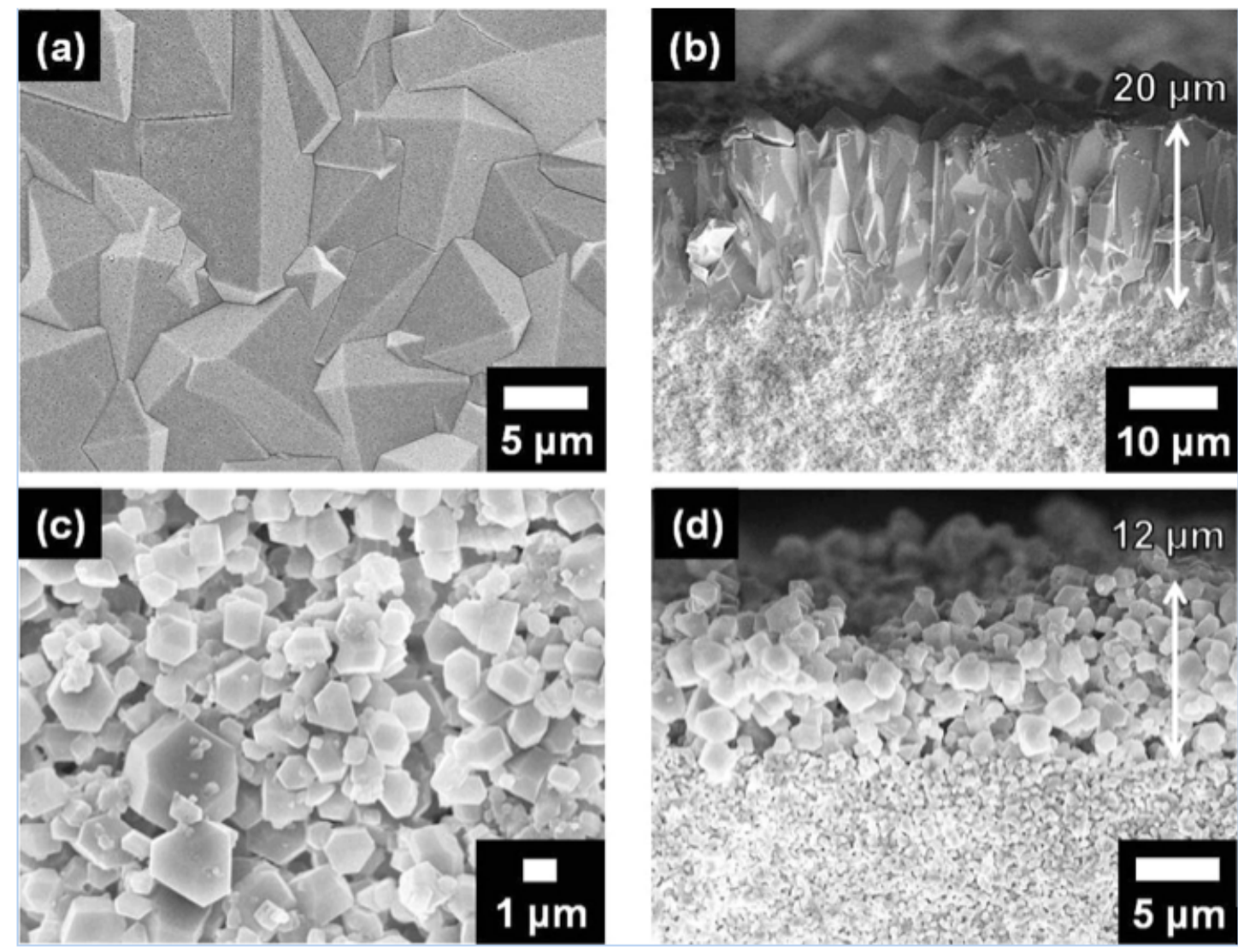

Fonte: MCCARTHY,M.C.; GUERREIRO,V.V.; BARNETT,G.V.; JEONG,H.K. Synthesis of zeolitic imidazolate framework films and membranes with controlled microstructures v $26, \mathrm{n}$.

18 p. $14636-14641,2010$

\subsection{Membranas de Separação Fabricadas com Es- truturas MOF e ZIF}

As estruturas cristalinas do tipo ZIF são uma subclasse das estruturas cristalinas do tipo MOF e surgiram como um tipo recente de material poroso cristalino que combina propriedades altamente desejáveis, assim como as estruturas MOF que possui elevada microporosidade, grandes áreas de superfície, e excelente estabilidade térmica e química (SURENDAR; CARREON, 2009). A estrutura geral dos MOFs consiste de átomos de metal ou grupos atômicos unidos a ligantes orgâni- 
cos em redes cristalinas microporosas (MCCARTHY et al., 2010). Entre as classes de materiais altamente porosos, as estruturas metalorgânicas (MOFs) apresentam um alto grau de flexibilidade e diversidade estrutural, bem como uma ampla gama de propriedades químicas e físicas. Os MOFs são estruturas cristalinas estendidas em que cátions metálicos ou grupo de cátions ("nós") são conectados por "base"orgânica ou íons ligantes ou moléculas. A variedade de íons de metal, ligantes orgânicos, (KRENO et al., 2012) e sequências estruturais proporcionam essencialmente um número infinito de possíveis combinações (KRENO et al., 2012). Ou seja, as propriedades das redes metalorgânicas dependem parcialmente das propriedades dos ligantes orgânicos e da forma com que eles estão coordenados ao metal. Assim, novas propriedades podem ser dadas a estes materiais através de alterações prévias do ligante orgânico obtido por diferentes rotas sintéticas.

O potencial dos MOFs como membranas tem sido reconhecido por extensos estudos (SURENDAR; CARREON, 2009), dada a versatilidade tanto no projeto da arquitetura da estrutura como na sua funcionalização (BUX et al., 2009).

Os MOFs são frequentemente comparados aos zeólitos de forma geral devido às suas grandes áreas de superfície, grande porosidade, e elevado grau de cristalinidade (KRENO et al., 2012). Os MOFs obtidos sinteticamente têm mostrado aplicações em catálise, separação e armazenamento de gás, também como uma alternativa para capturar $\mathrm{CO}_{2}$, imagiologia biomédica, dosador de droga (LI et al., 2014) liberação controlada de fármacos e troca iônica (SUN et al., 2012).

A possibilidade de modificação pós-sintética acrescenta uma dimensão à variável fabricação sintética. O estudo das afinidades da estrutura do MOF com moléculas adsorvidas na superfície ou absorvidas no corpo do material, aponta para a perspectiva de estruturas pré-moldadas que tenham as propriedades desejadas (MCCARTHY et al., 2010).

Os ZIFs, como já mencionado, apresentam característica zeolítica e são cons- 
tituídos por tetraedros de átomos de metal ligados entre si através da base conjugada imidazol (MCCARTHY et al., 2010). A estrutura dos materiais tipo ZIF é idêntica a estrutura dos zeólitos, isto é, as ligações T-O-T ( $\mathrm{T}=\mathrm{Si}, \mathrm{Al}, \mathrm{P})$ nos zeólitos são substituídas por ligações M-Im - M (M = Zn, Co, Cu), tal que os ângulos T-O-T e M-Im-M também são praticamente iguais (SURENDAR; CARREON, 2009).

Também, como já mencionado, as estruturas dos zeólitos são formadas por unidades tetraédricas $\mathrm{Si}(\mathrm{Al}) \mathrm{O}_{4}$, sendo possível produzir até 150 tipos diferentes de estrutura. Porém, existe ainda o desafio de tentar incorporar íons metálicos de transição e as unidades orgânicas dentro dos poros do zeólito, tornando-os uma parte integrante da sua estrutura (PARK et al., 2006).

Essa capacidade seria útil em muitas aplicações envolvendo catálise, porque os poros seriam revestidos com uma alta concentração de íons de metais de transição, permitindo a funcionalização das ligações orgânicas. No entanto, a visão de alcançar este zeólito que combina essas características em grande parte não se concretizou até agora (PARK et al., 2006).

Em particular, ZIF-8 é um dos materiais tipo ZIF mais estudados, devido às suas importantes aplicações em armazenamento de gás $\left(\mathrm{CO}_{2}, \mathrm{H}_{2}\right.$, e acetileno), catálise, e separações de gases. O ZIF-8 tem poros com 1, $16 \mathrm{~nm}$ de diâmetro que são acessíveis através de pequenas aberturas de $0,34 \mathrm{~nm}$, e que tem uma rede cúbica, com dimensões de célula unitária de 1,632 nm. Tem a estrutura tipo sodalita (SOD) com o tamanho dos poros cerca de duas vezes maior do que os correspondentes materiais zeólitos naturais (SURENDAR; CARREON, 2009).

Essas informações são úteis sobre os tipos de estruturas de poros que são adequadas para separação de gases e os ZIFs se tornam referência como uma dessas composições (SURENDAR; CARREON, 2009). Suas propriedades notáveis permitem sua utilização em várias aplicações (BUX et al., 2009). Um segmento notável 
da economia global ( $\$ 350$ bilhões) baseia-se no uso de zeólitos microporosos cristalinos na área petroquímica, para aplicações na troca iônica para purificação de água e na separação de gases (PARK et al., 2006). Nos ZIFs, os átomos de metais, tais como Zn, Co, Cu estão ligados aos átomos de nitrogênio das bases conjugada Imidazol, formando estruturas neutras e fornecendo poros nanométricos ajustáveis por grupos tetraédricos produzindo anéis de quatro, seis, oito, doze membros M-Im (SURENDAR; CARREON, 2009).

A estrutura porosa dos materiais zeólitos, cuja superfície interna é muito grande em relação à externa, permite-lhes a transferência de massa entre o espaço cristalino e o meio externo, mas que pode ser limitada pelo diâmetro dos poros da estrutura zeolítica. Os zeólitos, devido à sua estrutura rígida, apresentam alta estabilidade aquosa, e têm sido amplamente utilizados em aplicações de química industrial. Ao passo que, o seu desempenho é limitado pela rigidez da estrutura, cujo tamanho dos poros e funcionalidade da superfície não são facilmente modificados através do processo de autoarranjo (auto-assembly). As membranas microporosas possuem um grande potencial para o desenvolvimento de métodos de separação de misturas de gases ambientalmente benéficas e com eficiência energética. Com relação à síntese da membrana, os problemas associados à densidade das camadas e valor de espessura sobre cerâmica porosa ou suportes metálicos têm sido resolvidos de forma a apresentar estabilidade térmica e química (BUX et al., 2009). Outro desafio a ser vencido no desenvolvimento de membranas de separação é o controle da microestrutura do filme que impactam diretamente nas propriedades de transporte dos gases (MCCARTHY et al., 2010).

As películas finas de MOF têm sido fabricadas utilizando as mais variadas técnicas de síntese incluindo o crescimento "in situ"após a modificação da superfície de substrato, crescimento camada por camada, deposição térmica induzida por micro-ondas, síntese eletroquímica, e evaporação de solvente (MCCARTHY et 
al., 2010).

\subsubsection{SEPARAÇÃO DE GASES}

As principais aplicações do processo de separação de gases (PSG) encontramse na área da petroquímica com destaque para (SURENDAR; CARREON, 2009):

1. separação dos componentes do ar - produção de nitrogênio nos processos de combustão;

2. recuperação de hidrogênio - operações de craqueamento nas refinarias;

3. tratamento do gás natural - remoção de outros gases ou impurezas.

Além dessas aplicações, a separação do $\mathrm{CO}_{2}$ é de extrema importância, pois as emissões desse gás no mundo, em 2005, foram estimadas em 28.051 milhões de toneladas métricas (MMT) e projetadas para 42.325 MMT para 2030 (SURENDAR; CARREON, 2009). Além disso, o $\mathrm{CO}_{2}$ é uma impureza indesejável em reservatórios de gás natural, chegando a concentrações tão elevadas a 70\%. Além disso, o $\mathrm{CO}_{2}$ deve ser separado do $\mathrm{CH}_{4}$ porque este reduz o poder de combustão do gás natural, é ácido e corrosivo na presença de água (SURENDAR; CARREON, 2009).

Quimicamente estável na presença de água, o ZIF (ZIF-8 ou ZIF-90) torna-se uma composição exclusiva e potencialmente útil para a separação do $\mathrm{CO}_{2}$ do $\mathrm{CH}_{4}$ e de alguns hidrocarbonetos aromáticos, tais como benzeno, que são impurezas típicas do gás natural (SURENDAR; CARREON, 2009)(HUANG et al., 2014).

Atualmente, menos de 5\% das unidades de transformação de gás natural empregam tecnologia de membrana, que é usado principalmente para a remoção de dióxido de carbono (HUNGER et al., 2012). O gás natural é composto principalmente de metano (75\% - 90\%) e alguns hidrocarbonetos superiores. Infelizmente, um número significativo de recursos de gás natural não pode ser explorada devido 
à alta quantidade de $\mathrm{CO}_{2}$ (até $30 \%$ ) e outras impurezas indesejáveis (água, nitrogênio, sulfeto de hidrogênio, etc) contidas na mistura, uma vez que conduzem a corrosão dos gasodutos. As especificações para entrega de gás natural para a rede de gasodutos dos Estados Unidos exigem conteúdo de menos de $2 \%$ de $\mathrm{CO}_{2}$ (HUNGER et al., 2012).

A partir de 1970, surgiram novos procedimentos de fabricação de membranas sintéticas economicamente viáveis à área industrial (HUNGER et al., 2012).

De acordo com as características da superfície das membranas que está em contato com a solução a ser separada, é que se verifica a aplicabilidade delas e, assim, classificá-las em densas ou porosas. Estas sinalizam quando o transporte ocorre através das próprias membranas devido à diferença de tamanho entre as substâncias e os poros das membranas (MCCARTHY et al., 2010).

A estabilidade térmica e química dos materiais ZIF combinada com suas estruturas microporosas regulares os torna muito atraentes para separações de gases em ambientes industriais. Apesar disso, existem poucas investigações sobre as membranas de ZIF, (MCCARTHY et al., 2010).

Por outro lado, as membranas já possuem aplicações na remoção de $\mathrm{CO}_{2}$ do gás natural, desidratação de solventes orgânicos, a dessalinização, a remoção de componentes polares de baixo peso molecular em reações de equilíbrio, de enriquecimento de oxigênio ou nitrogênio do ar, bem como em sistemas de recuperação de vapor e vários outros (HUNGER et al., 2012). Além do tratamento de gás natural, a separação de compostos aromáticos e alifáticos é um campo promissor para aplicação de tecnologia de membranas de difusão por solução. Legalmente na Europa, a percentagem de benzeno nos combustíveis é limitado a 1\% em volume (HUNGER et al., 2012).

O transporte de uma substância através de uma membrana acontece se houver 
a existência de uma força motriz agindo sobre ela. Além disso, são determinantes ao processo a permeabilidade, o fluxo de um componente através da membrana, e a seletividade da membrana em permitir a passagem de um componente a outro. O material da membrana pode ser adequado à separação, quando a permeabilidade e seletividade são elevados (HUNGER et al., 2012).

Infelizmente, a melhoria da permeabilidade, muitas vezes, é adquirida em conjunto com uma perda de seletividade, ou ao contrário. Em vários policarbonatos, poli (sulfona éter) e poliimidas as seletividades de solubilidade para $\mathrm{O}_{2} /$ $\mathrm{N}_{2}$ e $\mathrm{CO}_{2} / \mathrm{CH}_{4}$ encontradas são muito semelhantes, independentes da estrutura do polímero, enquanto que a seletividade variava significativamente. Isso implica, que a seletividade da difusão (Dx / Dy) é de maior importância na separação de gás do que na seletividade da solubilidade $(\mathrm{Sx} / \mathrm{Sy})$, de acordo com a equação: (HUNGER et al., 2012).

$$
\alpha=\frac{S x}{S y} \frac{D x}{D y}
$$

O MOF à base de tetracianoquinodimetano (TCNQ) mostra forte adsorção de oxigênio em contraste com outras moléculas de gás, incluindo o dióxido de carbono. Atribui-se isso à maior facilidade de transferência de elétrons do oxigênio, em comparação com outras moléculas de gás. O oxigênio pode ser submetido à transferência de carga com a doação de elétrons ao TCNQ presente na estrutura composta MOF/TCNQ, resultando em elevada seletividade para adsorção de oxigênio (MCCARTHY et al., 2010).

O metanol pode ser separado do solvente dimetilformamida (DMF), pois o metanol tem menor diâmetro cinético do que o DMF. A isoterma de adsorção do metanol pelo ZIF-8 exibe uma forma incomum, indicando que o metanol polar apenas interage de maneira fraca com a estrutura de ZIF-8. Portanto, o metanol pode ser removido mais facilmente da rede do poro do que o DMF (BUX et al., 2009). Um outro fato importante associado à permeação dos gases através de 
membranas é que o transporte ocorre de forma preferencialmente convectiva em membranas porosas com poros (grandes) entre 0,1 e $10 \mu \mathrm{m}$. Se o poro for menor que 0,1 1 m, tem-se a difusão de Knudsen (HABERT; BORGES; NOBREGA, 2006. 180 p.).

Quando os poros são extremamente pequenos, ou seja, de 0,5 - $2 \mathrm{~nm}$, a estrutura atua como peneira molecular. Em membranas densas, a adsorção-difusão é o modelo que explica a permeação dos componentes através das membranas. As aplicações industriais são divididas em seis subgrupos, baseadas nos processos de transporte que podem ocorrer: microfiltragem, ultrafiltração, osmose inversa, eletrodiálise, pervaporação e permeação dos gases. Eis alguns casos em nossa literatura:

Em particular, as membranas de separação para misturas $\mathrm{CH}_{4} / \mathrm{CO}_{2}$ construídas a partir de ZIF-8 com espessura de 5-9 $\mu \mathrm{m}$ sobre alumina porosa, demonstraram permeação de $\sim 2,4.10^{-5} \mathrm{~mol} / \mathrm{m}^{2} s P a$ com a seletividade de separação de $\sim 4 a 7$ e os índices de separação na faixa de $\sim 6,5$ a 10 em $295 \mathrm{~K}$ e uma pressão de alimentação de $139,5 \mathrm{kPa}$. O principal desafio dos pesquisadores tem sido a modificação dos parâmetros químicos (composições, natureza dos reagentes) e de processamento (número de camadas, tempo de síntese e temperatura) para preparar membranas mais robustas e mais seletivas capazes de segurar as pressões de alimentação mais elevadas para separação de $\mathrm{CO}_{2} / C H_{4}$ visando aplicações industriais (SURENDAR; CARREON, 2009).

Como mencionado anteriormente, o tamanho da abertura dos poros de ZIF-8 é $0,34 \mathrm{~nm}$, o que faz com que apresente boa seletividade para moléculas pequenas (por exemplo, hidrogênio) comparado com moléculas maiores (por exemplo, metano e nitrogênio). No caso do ZIF-8, a seletividade para $H_{2} / N_{2}$ é da ordem de 11,6 e para $\mathrm{H}_{2} / \mathrm{CH}_{4}$ é da ordem de 13,0. Estes valores foram obtidos a partir de testes de permeação de gás de três diferentes membranas (testado três 
vezes cada) e são comparáveis às primeiras membranas de ZIF-8 (MCCARTHY et al., 2010).

Como relatado anteriormente, estas membranas de ZIF-8 exibiram peneiramento molecular, favorecendo a permeação de moléculas muito pequenas e, em particular, do $\mathrm{CO}_{2}$ e $\mathrm{O}_{2}$ que não são tão pequenas. A permeabilidade de oxigênio é maior do que a de dióxido de carbono, o que pode ser atribuído ao fato de que o oxigênio pode ter uma maior afinidade com ZIF-8 em comparação com dióxido de carbono (MCCARTHY et al., 2010).

As membranas de separação de gás utilizadas em aplicações industriais são geralmente integradas como fibras ocas ou folhas planas embalados como módulos enrolados em espiral. Elas são compostas de uma fina camada não porosa seletiva ao gás de interesse ( tipicamente menos do que $0,5 \mu \mathrm{m}$ ) depositadas sobre uma camada de suporte altamente porosa. O material de suporte aumenta a estabilidade mecânica da membrana, sem influenciar as características de separação (HUNGER et al., 2012).

Quando se trata de separação em meio líquido, alguns analitos podem ser preferencialmente adsorvidos se eles interagirem favoravelmente com sítios de metal no MOF. Estes podem envolver interações reversíveis de ligação, por exemplo, NO ligando-se ao Co (II), Cu (II), ou Ni (II), ou podem basear-se em interações puramente eletrostáticas (KRENO et al., 2012). Recentemente, as membranas de polímero ZIF-8 têm sido usadas para separações em fase líquida. Elas têm exibido altas taxas de permeação do $\mathrm{CO}_{2}$ e índices relativamente altos de separação de misturas equimolares de $\mathrm{CO}_{2}$ e $\mathrm{CH}_{4}$ (SURENDAR; CARREON, 2009).

A compatibilidade entre MOFs e polímeros como membranas de matriz mista tem sido muito boa. Em princípio, é possível fabricar membranas de MOF sobre polímeros flexíveis devido a interações favoráveis entre ligantes orgânicos de MOFs e polímeros. Estes filmes/membranas flexíveis oferecem grandes oportunidades 
para novas aplicações em sensores, separação de gás e fósforo (YAO et al., 2011).

As primeiras membranas poliméricas para a remoção de $\mathrm{CO}_{2}$ do gás natural consistiam de membranas de acetato de celulose. As membranas de acetato de celulose têm uma seletividade de $\mathrm{CO}_{2} / \mathrm{CH}_{4}$ de cerca de $12-15$ sob as condições normais de funcionamento, o que não é suficiente para aplicação industrial. Hoje cada vez mais poliamidas são usadas como material de membrana, em vez de derivados de celulose, dado que as seletividades obtidas são melhores (seletividade de 20-25). No entanto, a baixa durabilidade das membranas de poliimida ainda tem sido um problema sério a ser superado (HUNGER et al., 2012).

\subsection{Membranas para Separação de Gases Cons- tituídas por Metal Organic Framework (MOF)}

Normalmente, os processos utilizados na captura do $\mathrm{CO}_{2}$ são a absorção, adsorção e a destilação criogênica. Na indústria, o processo mais utilizado para a captura do $\mathrm{CO}_{2}$ é a absorção gasosa utilizando aminas, sendo que essa técnica apresenta algumas desvantagens em sistemas de pós-combustão como, por exemplo, a degradação de aminas devido à presença de oxigênio (LI et al., 2011).

Dessa forma, é importante encontrar alternativas mais eficientes e economicamente viáveis e, portanto, a captura de $\mathrm{CO}_{2}$ por membranas pode ser uma alternativa mais válida para compensar as limitações e desvantagens às tecnologias tradicionais (LI et al., 2011).

A separação do $\mathrm{CO}_{2}$ utilizando membranas não só leva vantagem pela diferença de solubilidade dos produtos, mas também pela diferença de difusividade, podendo assim atingir maior seletividade para certa separação. Devido ao seu baixo custo e baixo consumo de energia, as membranas foram indicadas como 
alternativas principais para o meio industrial (SANAEEPUR et al., 2011).

Para separação do $\mathrm{CO}_{2}$ nas correntes de pós-combustão, são utilizadas membranas inorgânicas e poliméricas. As membranas inorgânicas possuem melhor desempenho, pois suas estruturas são bem definidas, poros rígidos e estabilidade química e térmica comparadas com as membranas poliméricas. A Figura 21 ilustra o processo de separação de partículas utilizando membranas (LI et al., 2011).

Figura 21: Representação de um sistema com duas fases separadas por membrana.

Fase 1 membrana Fase 2

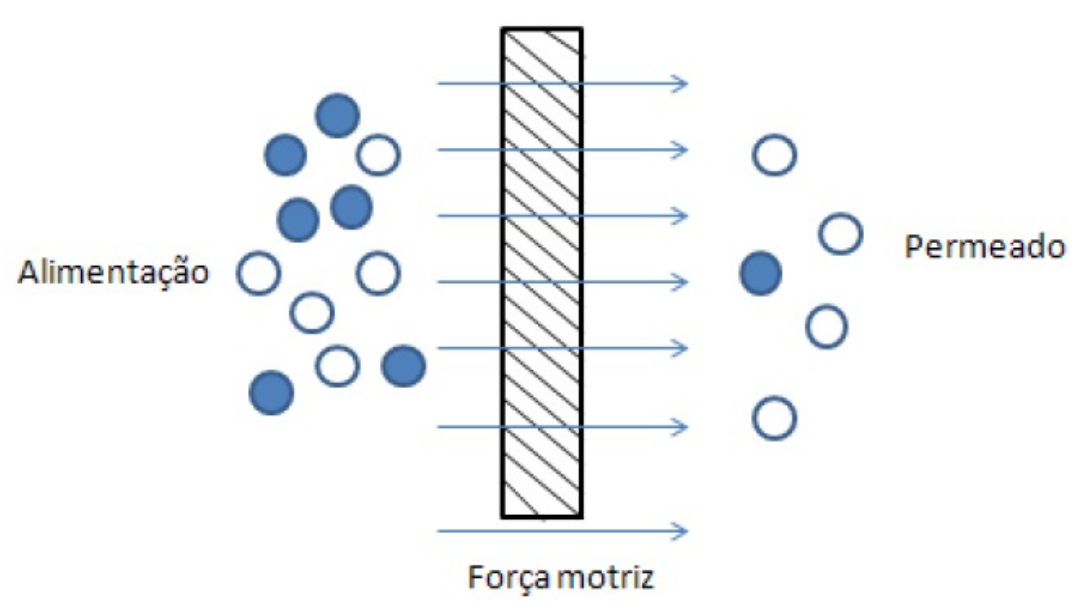

Fonte: MULDER, M. Basic principles of membrane technology. Kluver academic, second edition, 1996 .

Apesar de novas técnicas aplicadas em materiais para a captura do $\mathrm{CO}_{2}$, a baixa seletividade e a baixa permeabilidade nos leva a desenvolver novos materiais para que possamos separar o $\mathrm{CO}_{2}$ com mais eficácia. Levando em conta a seletividade e a permeabilidade de materiais, mostrou-se necessária a utilização de novos materiais como o Metal Organic Frameworks (MOF) que possui características interessantes para a captura do $\mathrm{CO}_{2}$ (LI et al., 2011).

Subhankar Basu empregou membranas densas e assimétricas para estudar três tipos de MOFs, sendo eles o $\mathrm{Cu}_{3}(\mathrm{BTC})_{2}$, MI-53 e o ZIF-8 para separação de misturas como $\mathrm{CO}_{2} / \mathrm{CH}_{4}$ e $\mathrm{CO}_{2} / \mathrm{N}_{2}$ (BASU; CANO-ODENA; VANKELECON, 2011). 
Foi verificado que as interações eletrostáticas entre o MIL-53 e o $\mathrm{CO}_{2}$ eram superiores em comparação com os outros gases e que a permeabilidade do $\mathrm{CO}_{2}$ é superior ao $\mathrm{CH}_{4}$ e ao $\mathrm{N}_{2}$.

Zhang realizou alguns experimentos de permeação com gases puros utilizando membranas Matrimid ${ }^{\circledR}$ contendo o MOF CuBPY-HFS com diferentes concentrações e observou que a permeabilidade aumenta com o aumento da concentração de entrada no MOF (YAFENG et al., 2008).

V. Perez desenvolveu membranas de Matrimid ${ }^{\circledR}$ com MOF-5 e essas membranas foram utilizadas para separação de gases puros e misturas binárias. Experimentos mostraram que a permeabilidade dos gases $\mathrm{H}_{2}, \mathrm{~N}_{2}, \mathrm{O}_{2}, \mathrm{CH}_{4}$ e $\mathrm{CO}_{2}$ aumentaram com o aumento da concentração de MOF-5. Também foi constatado que a adsorção desses gases não foi significativa para pressões entre 3 e 4 atm, porém a adsorção do $\mathrm{CO}_{2}$ aumenta com pressões superiores a 3 atm (PEREZ et al., 2009).

As membranas constituídas por MOFs utilizadas para separação de gases são hoje uma área crescente no mercado, porém, com pouquíssimas informações sobre a permeação de gás (LI et al., 2011).

Desafios ligados à fabricação de membranas com MOF, tais como interação substrato MOF (RANJAN; TSAPATISS, 2009), e formação de fissuras microscópicas e macroscópicas (GUERRERO et al., 2010) ainda são obstáculos no estudo desses materiais como membranas para captura de $\mathrm{CO}_{2}$.

Estes desafios, de um modo geral podem ser atribuídos às ligações da própria estrutura MOF. Em geral as ligações metal-ligante não são fortes como as ligações covalentes, resultando em possíveis tensões mecânicas entre camadas e formação de fissuras. As técnicas utilizadas na síntese de membranas com MOF podem ser divididas em duas categorias: a) síntese local e b) crescimento seme- 
ado (secundário). Na técnica de crescimento local, é realizado apenas um passo para a produção de membranas, porém, nessa técnica não há o mesmo controle de microestruturas e independência de substratos que o crescimento secundário proporciona. Já no método do crescimento secundário, o passo mais importante é a nucleação inicial de sementes, a funcionalização e condicionamento inicial da superfície do substrato que serve como suporte antes da síntese da membrana solvotérmica. Foi também relatado que os métodos de fixação de sementes de cristal incluem deposições térmicas induzidas por micro-ondas (YOO; LAI; JEONG, 2009), fixação com aglutinantes poliméricos (RANJAN; TSAPATISS, 2009), (LI et al., 2014), e fixação de sementes utilizando deposição térmica (GUERRERO et al., 2010). 


\section{TÉCNICAS DE ANÁLISE}

Neste capítulo, dada a importância, vamos descrever algumas técnicas de análise que foram empregadas na caracterização das amostras produzidas neste trabalho de doutorado.

\subsection{Espectrometria de Retroespalhamento de Rutherford}

O modelo do átomo mais aceito atualmente consiste de um núcleo positivamente carregado ao redor do qual está presente uma nuvem de elétrons. As medidas de caracterização do espalhamento de partículas $\alpha$ após a colisão com núcleos positivamente carregados não apenas ajudou desenvolver tal visão do átomo mas também serviu de base para a técnica de espectrometria de retroespalhamento de Rutherford (RBS) (CHU et al., 1973).

Nesta técnica, um feixe colimado de partículas ( tipicamente íons ${ }^{4} H e^{2+}$ ) de alta energia (1-2 MeV) colide com uma amostra dentro de uma câmara de vácuo $\left(10^{-5}\right.$ a $10^{-6}$ Pascal $)$ e sofre espalhamento elástico desde a superfície até uma dada profundidade máxima de penetração. As partículas retroespalhadas num dado ângulo $\theta_{e}$ são então detectadas por um detetor que fornece um sinal proporcional à energia delas (Figura 22). Este sinal é amplificado e processado eletronicamente, de forma a gerar um histograma contendo o número de partículas retroespalhadas (número de pulsos emitidos pelo detetor) em função de sua energia resultando, 
portanto, num espectro em energia (CHU et al., 1973).

Considerando-se, por exemplo, uma partícula qualquer do feixe incidente com massa $\mathrm{m}$ e energia $E_{0}$ colidindo elasticamente com uma partícula estacionária (por exemplo um átomo da amostra) de massa $M$ e sendo espalhada segundo um ângulo $\theta_{e}$, temos que imediatamente após o choque, esta partícula de massa M apresentará uma energia $K_{m} \cdot E_{0}$, a qual é menor do que a energia $E_{0}$ incidente original. O parâmetro $K_{m}$, também denominado de fator cinemático, é obtido através da seguinte expressão 4.1 (CHU et al., 1973):

$$
K_{m}=\left[\frac{\left(M^{2}-m^{2} \operatorname{sen}^{2} \theta_{e}\right)^{1 / 2}+m \cos \theta_{e}}{M+m}\right]^{2}
$$

Verifica-se por inspeção na expressão 4.1 acima que o fator cinemático depende exclusivamente das massas $\mathrm{M}$ e m e do ângulo de espalhamento $\theta_{e}$.

Quando a partícula incidente penetra no corpo da amostra, ela perde energia principalmente nas colisões inelásticas com as nuvens eletrônicas dos átomos da amostra. Esta perda é expressa pela seção de choque de freamento $\left(\varepsilon^{\prime}\right)$ descrita pela seguinte expressão (CHU et al., 1973):

$$
\varepsilon^{\prime}=\frac{1}{N^{V}} \frac{d E}{d x}
$$

onde $N^{V}$ é a densidade volumétrica atômica.

Na Figura 22, a largura do espectro equivalente a $\triangle E=K_{m} E_{0}-E_{1}$ corresponde à energia total perdida pelas partículas incidentes (devido a colisões com núcleos da amostra) em seus caminhos de entrada e saída da camada analisada. A relação entre a largura em energia $\Delta E$ e a espessura t da camada em análise (Figura 22) é dada por (CHU et al., 1973):

$$
\triangle E=N^{V}[\varepsilon] . t
$$

onde $[\varepsilon]$ é o fator de freamento o qual pode ser obtido através da seguinte expressão 
Figura 22: - Diagrama esquemático de um feixe ${ }^{4} \mathrm{H}^{2+}$ que incide numa dada amostra e sofre retroespalhamento num dado ângulo $\theta_{e}$ em direção ao detetor.

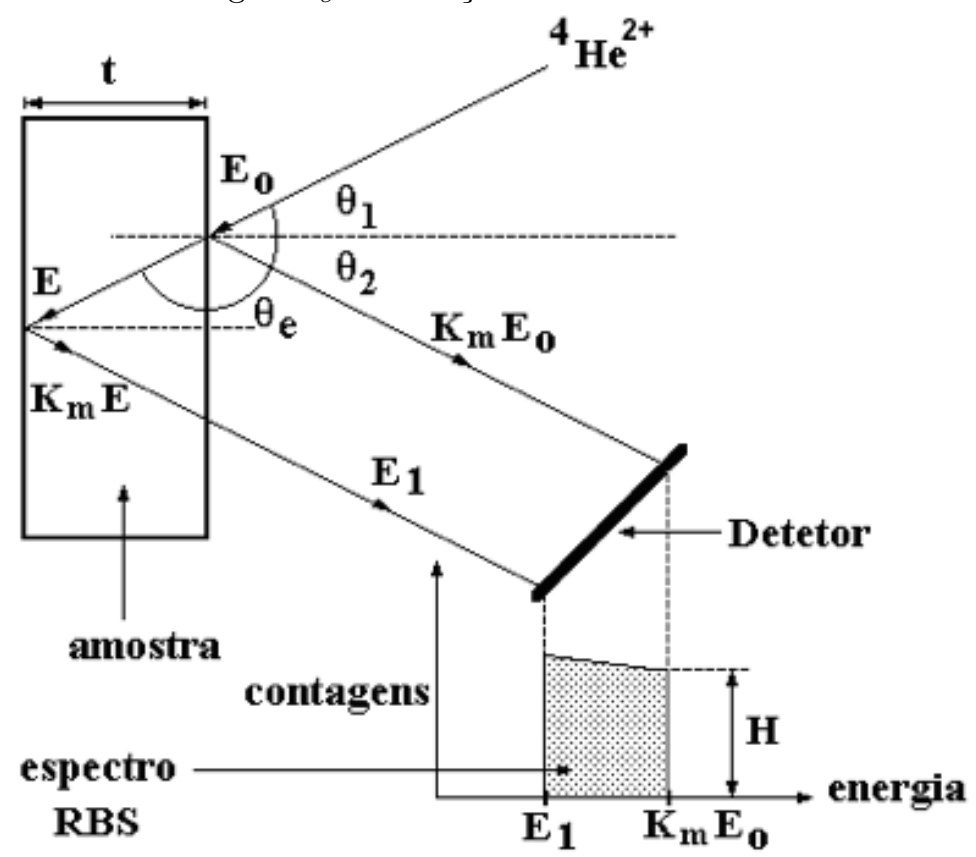

Fonte: CHU, W. K.; MAYER, J. W.; NICOLET, M. A.; BUCK, T. M.; AMSEL,G.; EISEN,

E. Principles and applications of ion beam techniques for the analysis of solids and thin films.v.17, p.1-47,1973.

(CHU et al., 1973):

$$
[\varepsilon]=\frac{K_{m}}{\cos \theta_{1}} \varepsilon^{\prime}\left|E=E_{0}+\frac{1}{\cos \theta_{2}} \varepsilon^{\prime}\right| E=K_{m} E_{0}
$$

onde $\varepsilon^{\prime}$ é dado pela expressão 4.2 .

Para amostras cuja composição compreende dois ou mais elementos, é válida a expressão 4.4 anterior, desde que se considere o princípio da aditividade das seções de choque de freamento de cada elemento (CHU et al., 1973). Por outro lado, um outro parâmetro importante é a seção de choque diferencial $\sigma$ que representa a probabilidade de ocorrer espalhamento da partícula de massa m pelo alvo composto de partículas cada uma com massa M. A seção de choque diferencial pode ser obtida através da fórmula de Rutherford conforme segue (CHU et al., 1973):

$$
\sigma=\left(Z_{1} Z_{2} q^{2} / E\right)^{2}\left(\operatorname{sen}^{4} \theta_{e} / 2\right)^{-1}
$$


onde $Z_{1}$ e $Z_{2}$ são respectivamente os números atômicos dos íons incidentes (Z1 $=2$ para partículas $\alpha$ ) e dos átomos do alvo, q é carga elementar, E é a energia do feixe incidente a uma dada profundidade $\mathrm{X}$ e $\theta_{e}$ é o ângulo de espalhamento. Para se determinar a relação entre as concentrações atômicas de dois elementos A e B presentes numa dada amostra a partir do espectro RBS, pode-se utilizar como primeira aproximação, por exemplo, as alturas relativas tomadas à mesma profundidade e as correspondentes seções de choque como segue (CHU et al., 1973):

$$
\frac{A}{B}=\frac{H_{A}}{H_{B}} \frac{\sigma_{B}}{\sigma_{A}}
$$

Os sistemas RBS permitem a medida direta de rendimento (contagens) em função do de um dado conjunto de canais onde o total de canais pode variar de sistema para sistema, mas em geral pode ser 512, 1024 ou 2048. O número associado a cada um desses canais é proporcional à energia da partícula espalhada detectada naquele canal. Utilizando-se amostras em que se conhece previamente os elementos que a compõem (portanto com fatores cinemáticos conhecidos para cada elemento), pode-se levantar a reta de calibração da energia em função do número do canal (CHU; MAYER; NICOLET, 1978).

Por outro lado, se quisermos determinar o valor absoluto da altura H expressa em contagens por canal (Figura 22), podemos utilizar a seguinte expressão (CHU et al., 1973):

$$
H(\text { contagens } / \text { canal })=Q_{R B S} \Omega \sigma N^{V} t_{c}
$$

sendo que $t_{c}$ é a espessura associada a um único canal a qual pode ser descrita em termos de energia por:

$$
t_{c}=\frac{\delta E}{N^{V}[\varepsilon]}
$$

onde $\delta E$ é a largura em energia de um único dado canal sendo normalmente fixada pelo ganho do sistema RBS de medida. 
A Figura 23, por exemplo, apresenta o espectro RBS de um filme fino de ouro depositado sobre um substrato de silício. Uma ideia fundamental associada à análise de RBS é justamente o fato de que a área sob um dado pico é proporcional ao número total de átomos por centímetro quadrado $\left(N^{P}\right)$ de um dado elemento presente ao longo de toda a profundidade da amostra (CHU et al., 1973). Portanto, no caso do espectro apresentado na Figura 23, a concentração planar total (integrada ao longo da profundidade do filme) de ouro é proporcional à área $A_{A u}$ indicada (CHU et al., 1973).

Figura 23: - Espectro RBS de um filme fino de ouro sobre substrato de silício.

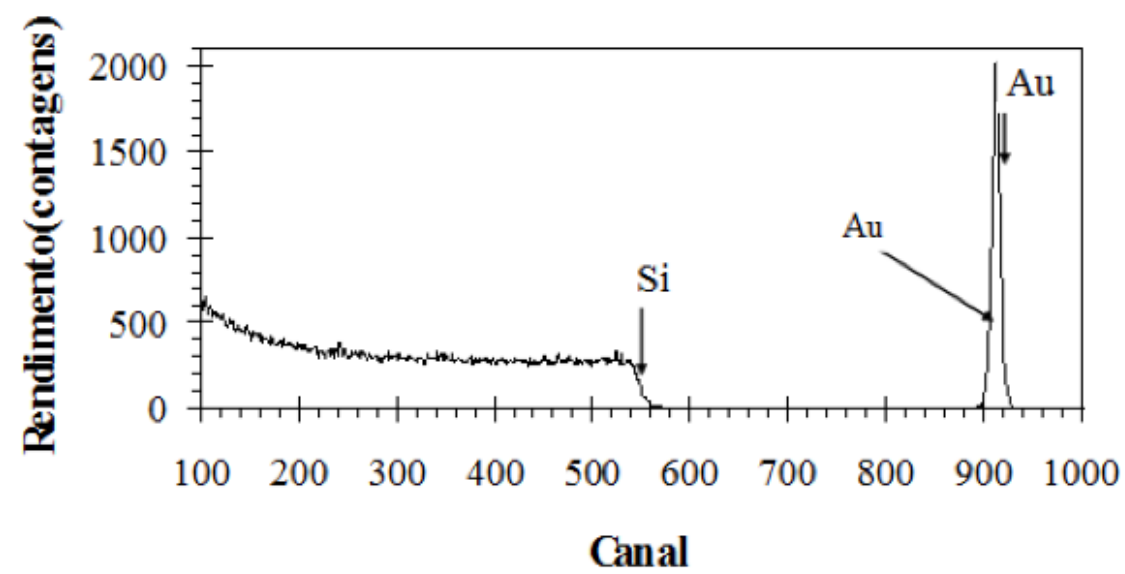

Fonte: CHU, W.K.; MAYER,J.W.; NICOLET, M.A.; BUCK, T.M.; AMSEL, G.; EISEN, E.

Principles and applications of íns bean techniques for the analysis of solids and thin films.Thin Solid Films, v. 17, p. 1-47,1973.

Dada essa particular característica da medida de retroespalhamento, o que se faz costumeiramente é determinar com precisão o número total de átomos por centímetro quadrado na amostra $\left(N^{P}\right)$ o que equivale ao produto $\left(N^{V} t\right)$ onde $N^{V}$ é o número de átomos por centímetro cúbico e t é a espessura da camada em análise. Portanto se conhecermos o valor de $N^{V}$, podemos até extrair o valor da espessura da camada em análise. Para uma carga integrada " $Q_{R B S}$ "de íons ${ }^{4} H e^{2+}$ e um ângulo sólido de detecção $\Omega$, a área total (em contagens) sob um 
dado pico é dada por (CHU et al., 1973):

$$
A=Q_{R B S} \Omega \sigma N^{P}
$$

A espectrometria de retroespalhamento de Rutherford tem sido largamente empregada nos mais diferentes tipos de aplicações entre as quais podemos citar a análise de filmes finos sobre superfícies e a análise de defeitos e contaminações nos mais diferentes tipos de substratos (CHU et al., 1973).

\subsection{Espectroscopia Infravermelho com Transfor- mada de Fourier (FTIR).}

$\mathrm{Na}$ grande família de ZIF, $\left[\mathrm{Zn}(\mathrm{MeIm})_{2}, \mathrm{MeIm}=2-\right.$ metilimidazolato $]$, o ZIF-8, um dos Zeólitos mais analisados, apresenta uma rede cúbica e estrutura do tipo sodalita (SOD), topologia com cavidades com diâmetro de 1, $16 \mathrm{~nm}$ diretamente conectadas a anéis de seis membros, sendo que os diâmetros livres das aberturas desses anéis são de apenas $0,34 \mathrm{~nm}$ e as aberturas consistem de anéis com 4 membros T-Im (HU et al., 2013).

Assim, devido ao pequeno tamanho da janela, espera-se que o ZIF-8 separe o hidrogênio $(0,289 \mathrm{~nm}$ diâmetro cinético) de moléculas maiores, tais como metano $(0,38 \mathrm{~nm})$ e nitrogênio $(0,36 \mathrm{~nm})$. No entanto, as moléculas de metano e nitrogênio, teoricamente, são grandes para passarem através das janelas da estrutura, que é rígida (CHU et al., 1973).

A adsorção de moléculas grandes e a sua difusividade implicam flexibilidade durante o processo de adsorção. Esta flexibilidade nas estruturas ZIF é de fundamental importância, uma vez que modifica a difusividade de gases através da rede porosa. Uma compreensão desse comportamento é um pré-requisito para explorar a tecnologia de adsorção (CHU et al., 1973). Em virtude do diâmetro cinético 
do $\mathrm{CO}_{2}(0,33 \mathrm{~nm})$ ser ligeiramente menor que o tamanho dos canais hexagonais do ZIF-8 (0,34 $\mathrm{nm})$ e do ZIF-90 (0,35 $\mathrm{nm})$, e da estrutura do ZIF ter boa estabilidade, deve ser possível inserir mais $\mathrm{CO}_{2}$ em estruturas em pressões na faixa gigapascal para aumentar substancialmente a capacidade de armazenamento (HU et al., 2013).

Utilizando a espectroscopia FTIR "in situ", a literatura reporta que tem sido possível investigar o desempenho de ZIF-8 para adsorção de $\mathrm{CO}_{2}$ e as evidências das interações da estrutura aumentada com o $\mathrm{CO}_{2}$ em pressões externas elevadas.

A Figura 24 mostra os espectros FTIR, respectivamente, do $\mathrm{CO}_{2}$ puro na pressão de $1 \mathrm{GPa}$, da amostra ZIF-8 com pressão de entrada do $\mathrm{CO}_{2}$ de $0,78 \mathrm{GPa}$ e, também da amostra ZIF-8, mas com 0,81GPa. Para número de onda na faixa de 600 a $1800 \mathrm{~cm}^{-1}$, aparece uma série de bandas correspondente à estrutura ZIF-8 tipo sodalita comparado ao caso $\mathrm{CO}_{2}$ puro (HU et al., 2013).

As mudanças devido à presença do $\mathrm{CO}_{2}$ na estrutura do ZIF-8 ocorrem na faixa de 3500 a $3800 \mathrm{~cm}^{-1}$ (veja os correspondentes espectros em escala ampliada na Figura 24). Mudanças apreciáveis não foram observadas na faixa de 1800 a $3000 \mathrm{~cm}^{-1}$ (não mostrado na Figura 24) (HU et al., 2011).

A observação mais impressionante na faixa de $3500 a_{3800 \mathrm{~cm}^{-1}}$ é o modo de absorção muito diferente das bandas (Figura 24), observa-se que cada uma das duas faixas presente no $\mathrm{CO}_{2}$ puro divide-se em um par: a banda $v 3+v 1$ originalmente em $3708 \mathrm{~cm}^{-1}$ exibe um par em 3700 e $3720 \mathrm{~cm}^{-1}$, enquanto a banda $v 3+2 v 2$ também se divide. Para cada par, o componente de baixa frequência se assemelha ao perfil original do $\mathrm{CO}_{2}$ puro, enquanto que o componente de mais alta frequência torna-se nítido e intenso (HU et al., 2013).

A intensidade fortemente contrastada e a largura da linha dos dois componentes para cada par demonstram que há dois tipos diferentes de moléculas de 
Figura 24: Espectros FTIR, respectivamente, do $\mathrm{CO}_{2}$ puro na pressão de 1GPa, da amostra ZIF-8 com pressão de entrada do $\mathrm{CO}_{2}$ de $0,78 \mathrm{GPa}$ e, também da amostra ZIF-8, mas com $0,81 \mathrm{GPa}$. A seta indica as posições do modo de estiramento da ligação $\mathrm{C}=\mathrm{C}$ da base conjugada imidazol, presente no ZIF-8.

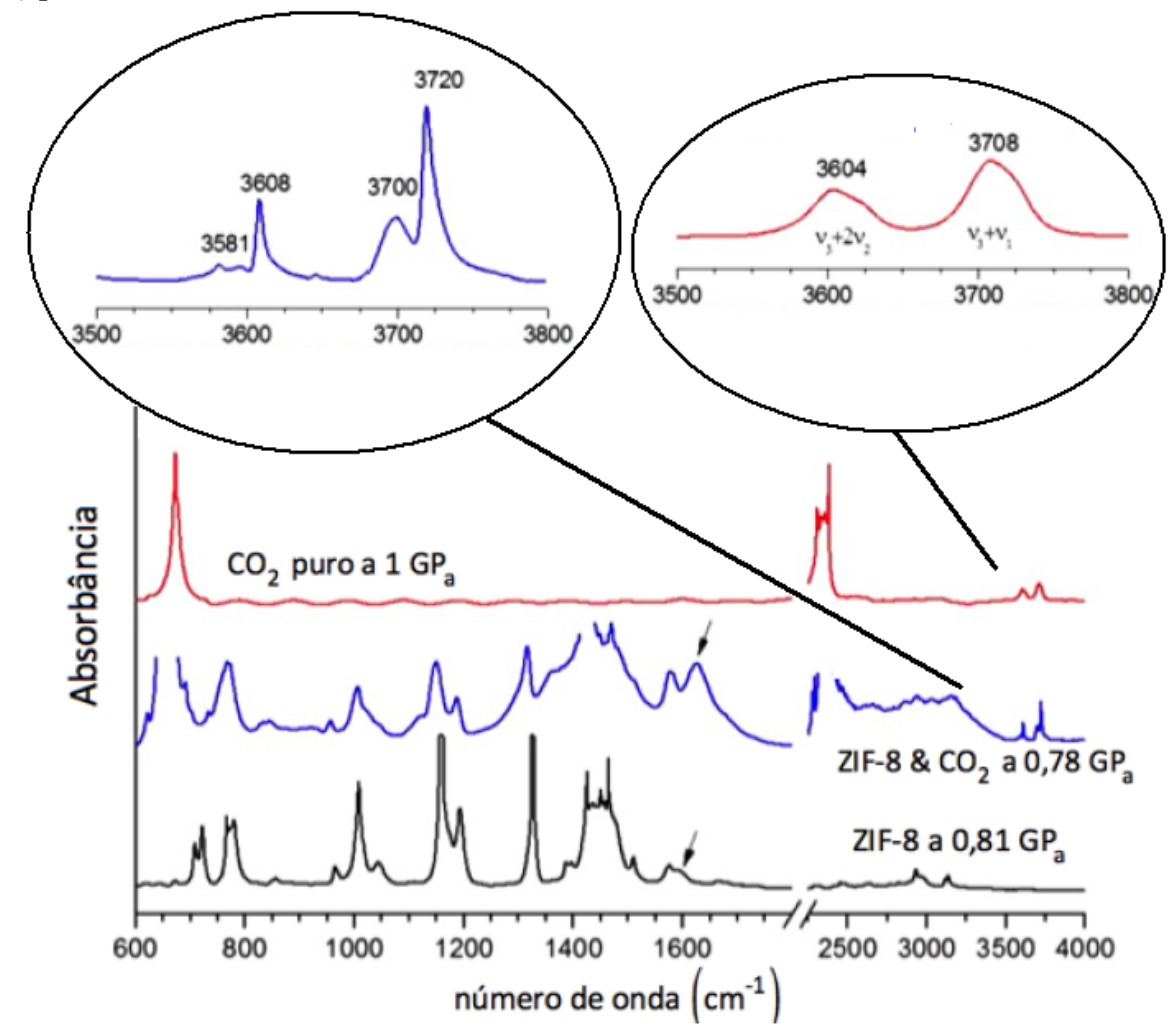

Fonte adaptada de: HU,Y.; LIU,Z.; XU,J.; HUANG,Y.; SONG,Y. Evidence of pressure enhanced $\mathrm{CO}_{2}$ storage in zif-8 probed by FTIR spectroscopy J.Am.Chem.Soc.,v.135, p.9287-9290, 2013.

$\mathrm{CO}_{2}$. Ou seja, o componente de baixa frequência com perfil semelhante ao $\mathrm{CO}_{2}$ puro sugere que a porção de $\mathrm{CO}_{2}$ carregado com esta característica está fora da estrutura com excessiva pressão média. O componente de alta frequência pode ser analisado como uma porção substancial das moléculas de $\mathrm{CO}_{2}$ que foi absorvido na estrutura ZIF-8 sob condições atuais de pressão-temperatura (HU et al., 2013). Além disso, a Figura 25 mostra o espectro de absorção de Infravermelho dos dois modos de combinação de $\mathrm{CO}_{2}$ carregado com ZIF-8 mediante compressão (Figura 25a: subida progressiva da pressão de 0,47GPa a 2,55GPa) e descompressão (Figura 25b: descida progressiva da pressão de 2,65GPa a 0). Quando inicialmente carregado em $0,47 G P a$, um espectro de Infravermelho mostra um perfil 
com duas bandas, uma em $3590 \mathrm{~cm}^{-1}$ e a outra em $3700 \mathrm{~cm}^{-1}$, idêntica ao espectro do $\mathrm{CO}_{2}$ puro. Quando comprimida acima de $0,78 \mathrm{GPa}$, foi observada uma nova banda associada com $\mathrm{CO}_{2}$ aprisionado no interior da estrutura $\left(3720 \mathrm{~cm}^{-1}\right)$ e um deslocamento da banda de $3590 \mathrm{~cm}^{-1}$ para a direita. Se comprimido de forma contínua a pressões mais elevadas (por exemplo, 2, 65GPa ou mais) resulta no deslocamento para a linha azul do espectro de todos os modos (Figuras 25a). Ao tirar a pressão, o par $3700 \mathrm{~cm}^{-1} / 3720 \mathrm{~cm}^{-1}$ começa a fundir-se em um só a 0,47GPa (Figura 25b) , indicando que as moléculas de $\mathrm{CO}_{2}$ migram para fora da estrutura. Quando a pressão é completamente liberada, as moléculas de $\mathrm{CO}_{2}$ no interior do estrutura escapam totalmente das cavidades internas do ZIF-8 (ver parte inferior do espectro na Figura 25b) (HU et al., 2013).

Os ciclos de compressão - descompressão podem ser repetidos várias vezes de forma reversível com pouca histerese, e a separação no par $3700 \mathrm{~cm}^{-1} / 3720 \mathrm{~cm}^{-1}$ ocorre sempre na faixa de 0,4 a 0,8GPa. Além disso, com base na intensidade de absorção dos dois componentes do modo $3700 \mathrm{~cm}^{-1} / 3720 \mathrm{~cm}^{-1}$, estimou-se que até $\sim 68 \%$ do $\mathrm{CO}_{2}$ carregado foi inserido na estrutura sobre a compressão (Figura 25a) e , pelo menos, $45 \%$ de $\mathrm{CO}_{2}$ permanece preso após a descompressão (Figura 25b) (HU et al., 2013).

Diversos fatores devem ser considerados para a compreensão do mecanismo de inserção de $\mathrm{CO}_{2}$ na estrutura em altas pressões, tais como, a pressão para a inserção/extrusão de $\mathrm{CO}_{2}$ na estrutura do ZIF-8 relativamente baixa ( < 0, 8GPa à temperatura ambiente) em relação àquela para o natrolito ${ }^{1}(1,5 G P a$ a alta temperatura), o que sugere que o $\mathrm{CO}_{2}$ deve estar em estado superfluido para a difusão eficaz em condições de compressão; além das características únicas de pressão de ZIF -8, em termos de flexibilidade da estrutura e alargamento

\footnotetext{
${ }^{1} \mathrm{O}$ natrólito é um zeólito com uma estrutura tridimensional contendo poros separados regularmente. Esta estrutura inclui moléculas de alumínio, silício e oxigênio que quando submetida a uma pressão entre 0,8 e 1,5GPa, o cristal se expande. Em 1,5GPa a alta temperatura, permite armazenar $\mathrm{CO}_{2}$.
} 
Figura 25: (a) Espectros FTIR após compressão (subida da pressão de 0,47 GPa até 2,55 GPa), (b) Espectros FTIR após descompressão (descida da pressão de 2,65 GPa a 0)
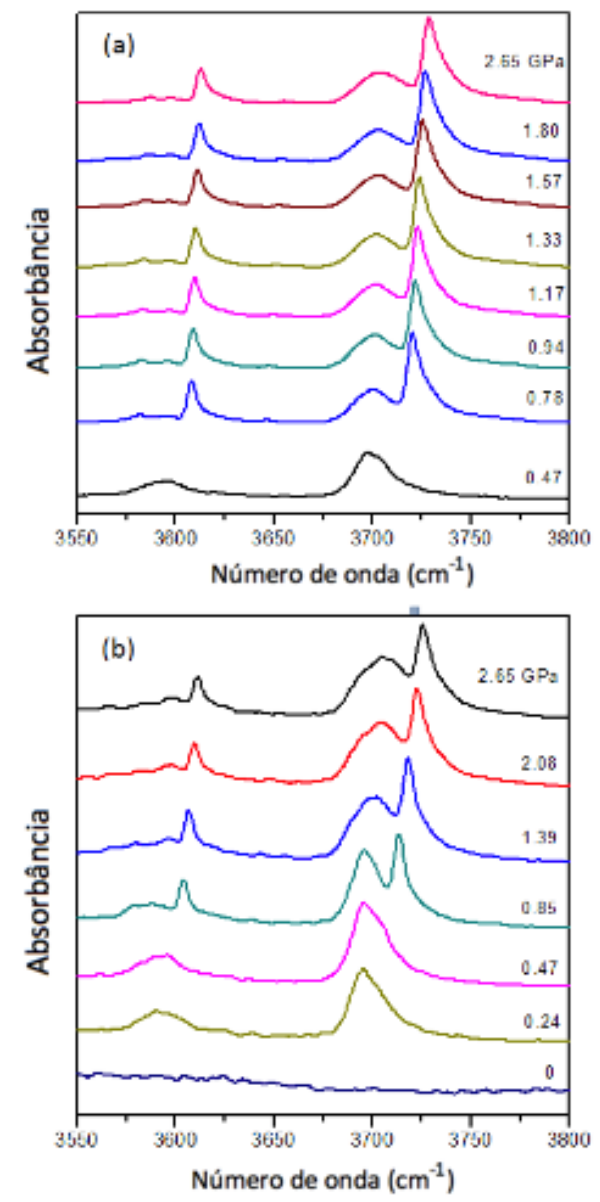

Fonte: HU,Y.; LIU,Z.; XU,J.; HUANG,Y.; SONG,Y. Evidence of pressure enhanced $\mathrm{CO}_{2}$ storage in zif-8 probed by FTIR spectroscopy J.Am.Chem.Soc.,v135, p.9287-9290, 2013.

induzido por pressão de abertura do poro e volume, que desempenham um papel importante na facilitação da inserção de $\mathrm{CO}_{2}$ a altas pressões (HU et al., 2013).

A flexibilidade dos ligantes compostos de base conjugada de imidazol é fundamental na dinâmica de transporte do $\mathrm{CO}_{2}$. Mais recentemente, comprovou-se que a flexibilidade da estrutura do ZIF-8 facilita a adsorção de $N_{2}$, adotando a estrutura de alta pressão muito embora a pressão da carga seja substancialmente menor que o nível GPa (HU et al., 2013).

Assim, através da espectroscopia de infravermelho sugere-se que a abertura dos poros, a flexibilidade da estrutura, e difusividade do $\mathrm{CO}_{2}$ são significativos à 
migração do $\mathrm{CO}_{2}$ através da estrutura do ZIF-8. Esta interação - o $\mathrm{CO}_{2}$ e a estrutura - é ainda mais evidenciada pelas características diferentes do Infravermelho do ZIF-8 carregado com $\mathrm{CO}_{2}$ em comparação com a da estrutura vazia (Figura 24a). A diferença mais importante, por exemplo, é o aparecimento de uma banda de absorção intensa a cerca de $1620 \mathrm{~cm}^{-1}$ no espectro do ZIF-8 carregado com $\mathrm{CO}_{2}$, o que pode ser atribuído ao modo de estiramento $C=C$ do anel imidazol. Conclui-se que os principais sítios de interação da estrutura de ZIF -8 e $\mathrm{CO}_{2}$ são os ligantes orgânicos (HU et al., 2013).

\subsection{A espectroscopia de absorção de ultravioleta visível (UV-Vis)}

Sabe-se que ZIF -8 contém muita água e é estável em solução alcalina de hidróxido de sódio. No entanto, quando se coloca o ZIF-8 em solução ácida, ele começa a se decompor rapidamente. A sua propriedade de dissolução mediada por pH foi examinada através da sua suspensão em tampão de fosfato salino (PBS), pH 7,4 e em tampão de acetato $(\mathrm{pH} 5,0)$ a $37^{\circ} C$. Após 30 min, o material era completamente solúvel em tampão acetato. Esses resultados sugerem que ZIF-8 possui uma propriedade de dissolução sensível ao pH que pode ser explorada como um veículo de liberação de drogas em condições controladas e moderadamente ácidas (SUN et al., 2012).

Desde que se comprovou que ZIF-8 é um veículo de liberação de drogas, pois responde adequadamente ao $\mathrm{pH}$, as suas características de armazenamento de medicamentos foram avaliadas ao utilizar 5-fluorouracil (5-FU) como uma droga modelo. O 5-FU foi escolhido especificamente pelo seu pequeno tamanho, bem como por ser amplamente utilizado como um medicamento de quimioterapia anticâncer colorretal, de mama e de cabeça e pescoço.

A espectroscopia de absorção UV-Vis pode ser empregada para determinar 
a efetiva capacidade de armazenamento de 5-FU. Em primeiro lugar, o término do 5-FU adsorvido depende da afinidade relativa entre o solvente, 5-FU e a superfície interna porosa. Devido à polaridade diferente, as quantidades de 5-FU necessitam de metanol em vez de água como solvente. O tempo de contato é também importante, a capacidade de carregamento aumentou e atingiu o valor máximo de 0,660g por grama de ZIF-8 em 2 dias, e depois diminui lentamente e chega a um valor equilibrado de cerca de $0,518 g$ por grama de ZIF-8. A estrutura zeólita imidazolato (ZIF-8) demonstra uma capacidade notável para a droga anticancerígena 5-fluorouracil (5-FU), cerca de 0,660g de 5-FU por grama de ZIF-8 e demonstra que um pH ativado controlou a propriedade de liberação da droga. A Figura 26 apresenta os espectros de absorção de UV-Vis de solução de metanol 5-FU antes e após a interação com ZIF-8 . A intensidade da absorção de 5-FU diminuiu após a interação com a dissolução do ZIF-8, indicando a diminuição significativa da concentração de droga em solução, ou seja, o armazenamento de 5-FU é eficiente (SUN et al., 2012).

Os melhores resultados foram obtidos quando ZIF-8 foram embebidos durante 2 dias em uma solução de metanol contendo $6 \mathrm{mg} \mathrm{mL}^{-1}$ de 5 -FU na proporção de 3:2 de 5-FU para ZIF-8. A análise química indicou que ZIF-8 em dissolução adsorve em torno de 45,4\% em peso de 5-FU, o que corresponde a $0,660 \mathrm{~g}$ de 5-FU por grama de ZIF-8 (SUN et al., 2012). 
Figura 26: Porcentagem de liberação de 5-FU em função do tempo para os pH de 5 e 7,4, respectivamente. O gráfico menor apresenta o processo de liberação nas primeiras $24 \mathrm{~h}$.

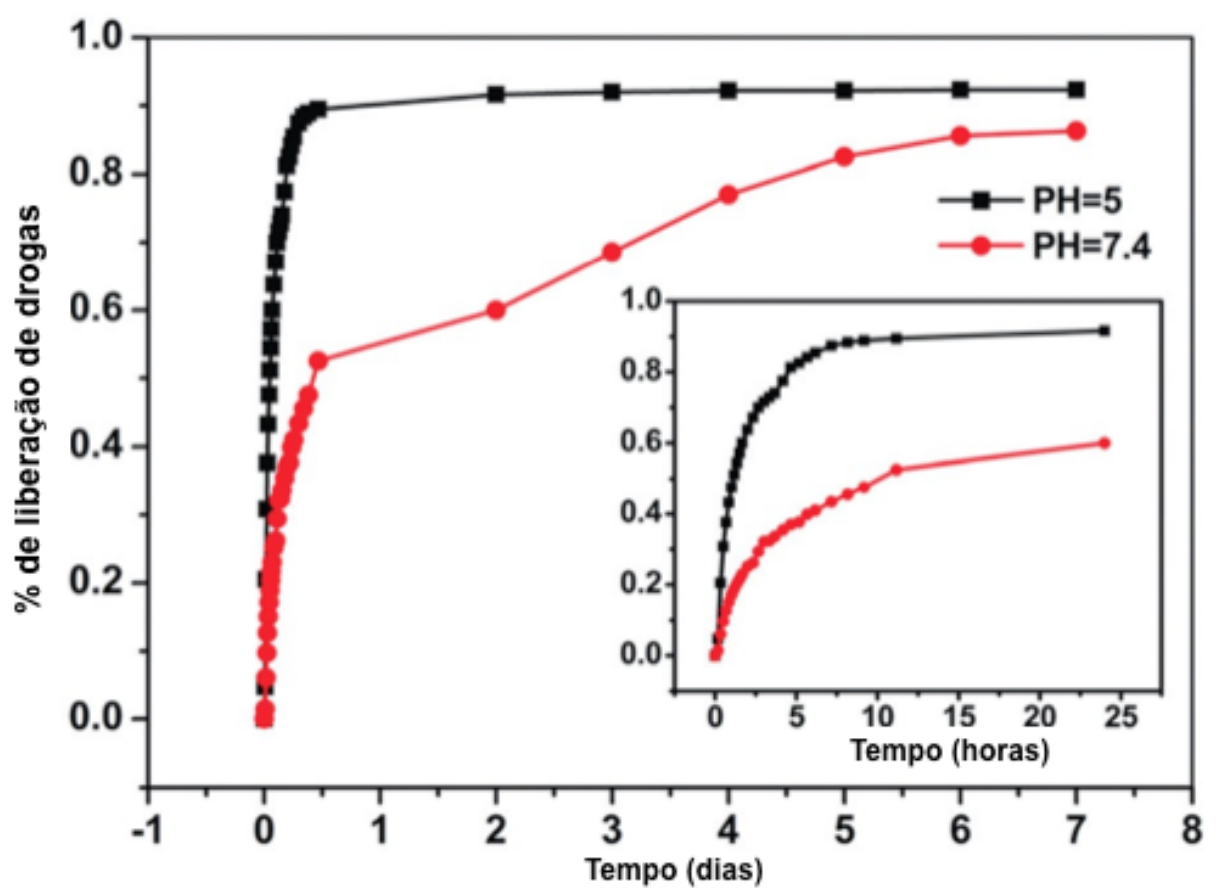

Fonte: SUN,C.Y.; QIN,C.; WANG,X.L.; YANG,G.S.; SHAO,K.Z.; LAN,Y.Q.; SU,Z.M.; HUANG,P.; WANG,C.G.; WANG,E.B. Zeolitic imidazolate framework-8 as efficient pH-sensitive drug delivery vehicle. Dalton Trans., v 41, p. 6906-6909,2012. 


\section{PROCEDIMENTOS EXPERIMENTAIS}

Neste capítulo serão apresentados os procedimentos experimentais adotados na deposição dos filmes ZIF sobre os substratos de silício assim como as técnicas empregadas para caracterizá-los fisicamente.

O procedimento de obtenção dos filmes ZIF vem sendo desenvolvido e aprimorado pelo grupo de superfícies, interfaces e deposição eletroquímica (GSIDE/LSI/EPUSP). Esses filmes, como mencionado no capítulo 1, podem permitir o armazenamento de $\mathrm{CO}_{2}$ para aplicações envolvendo não apenas a sua deteç̧ão, mas também a sua remoção do ambiente a fim de evitar o efeito estufa.

\subsection{Limpeza de Materiais}

A seguir serão descritos os procedimentos para limpeza dos substratos de silício e dos materiais utilizados na parte experimental.

\subsubsection{Limpeza dos substratos de silício}

Os substratos empregados para deposição dos filmes de ZIF foram lâminas de silício com 3 polegadas de diâmetro, tipo P, dopadas com boro, com espessura de $(380 \pm 25) \mu m$, orientação $<100>$ e resistividade na faixa de $1-10 \Omega c m$. Inicialmente, estas lâminas de silício foram limpas quimicamente a fim de remover a contaminação por metais $\left(<10^{-10} \mathrm{~cm}^{-2}\right)$ e o material particulado $\left(<10 \mathrm{~cm}^{-2}\right)$ sem alterar substancialmente a rugosidade superficial inicial $(<0,05 n m R M S)$. (KERN, 
New Jersey: Noyes Publicatins, 1993),(SANTOS-FILHO et al., 1995a),(SANTOSFILHO; HASENACK, 1995b),(SANTOS-FILHO et al., 1995c),(SANTOS-FILHO, 1996). Foi adotada uma limpeza RCA seguida de uma imersão em solução diluída de ácido fluorídrico ("dip"em d-HF) (KERN; PUOTINEN, 1970),(KERN, 1990),(KERN, New Jersey: Noyes Publicatins, 1993),(KERN; REINHARDT, 2008). O detalhamento do processo de limpeza $(\mathrm{RCA}+\mathrm{d}-\mathrm{HF})$ pode ser visto de acordo com as etapas que seguem.

- Enxágue em água deionizada (DI) por 5 min em fluxo constante e temperatura ambiente;

- Imersão em solução de $4 \mathrm{H}_{2} \mathrm{O}+1 \mathrm{H}_{2} \mathrm{O}_{2}(30 \%)+0,5 \mathrm{NH} \mathrm{H}_{4} \mathrm{OH}$ (35\%) por 15 min na temperatura de $90^{\circ} \mathrm{C}$ (Etapa RCA-1);

- Enxágue em água deionizada (DI) por 5 min em fluxo constante e temperatura ambiente;

- Imersão em solução de $4 \mathrm{H}_{2} \mathrm{O}+1 \mathrm{HCl}(36.5 \%)$ por 15 min na temperatura de $90^{\circ} \mathrm{C}$ (Etapa RCA-2);

- Enxágue em água deionizada (DI) por 5 min em fluxo constante na temperatura ambiente;

- Imersão em solução $80 \mathrm{H}_{2} \mathrm{O}+1 \mathrm{HF}$ (49\%) durante 100 s na temperatura ambiente;

- Enxágue em água deionizada (DI) por 3 min em fluxo constante na temperatura ambiente;

- Secagem com jato de nitrogênio $\left(N_{2}\right)$ ultrapuro.

Vale ressaltar que todo o processo de limpeza foi feito em uma capela química (com exaustão e fluxo de ar laminar) localizada dentro da sala limpa do LSI garantindo um ambiente adequado (classe 100) para o processo. 


\subsubsection{Limpeza de béqueres e tupperwares}

Os béqueres empregados na preparação das soluções para deposição do ZIF sobre as lâminas de silício foram previamente limpos com a solução RCA-I indicada no item 5.1.1 anterior. As etapas empregadas foram as seguintes:

- Enxágue em álcool isopropílico por 5 min na temperatura ambiente;

- Enxágue em água deionizada (DI) por 5 min em fluxo constante e temperatura ambiente;

- Imersão em solução de $4 \mathrm{H}_{2} \mathrm{O}+1 \mathrm{H}_{2} \mathrm{O}_{2}(30 \%)+0,5 \mathrm{NH}_{4} \mathrm{OH}(35 \%)$ por 15 min na temperatura de $90^{\circ} \mathrm{C}$ (Etapa RCA-1);

- Enxágue em água deionizada (DI) por 5 min em fluxo constante e temperatura ambiente;

- Secagem em nitrogênio ultrapuro.

A limpeza dos "tupperwares"para o acondicionamento dos béqueres previamente limpos seguiu as mesmas etapas anteriores descritas para limpeza de béqueres.

\subsection{Deposição das camadas ZIF sobre substratos de silício}

A seguir serão descritos os procedimentos para preparação da solução química de deposição, bem como as técnicas de deposição e tratamentos térmicos empregados. 


\subsubsection{Preparação da solução química de deposição}

Como mencionado no item 3.1.1, é usual a síntese do ZIF-8 com estrutura sodalita tetragonal na temperatura ambiente utilizando solução química de nitrato de zinco e 2-metilimidazol diluídos em metanol (VENNA; JASINSKI; CARREON, 2010). No presente trabalho, desenvolvemos uma receita alternativa com etanol em vez de metanol, para com o objetivo de simplificar o manuseio ao utilizar um produto de menor toxidade para o ser humano e, ao mesmo tempo, produzir uma receita para produção em massa dos filmes ZIF. Por outro lado, vimos também no item 3.1.1 que o pH da solução química mencionada tinha um papel fundamental na cristalinidade dos filmes ZIF-8 obtidos, sendo que esta aumentava com a diminuição do pH de 7,8 para valores em torno de 7,2 resultado da maior diluição em metanol.

Neste trabalho, além de mudar o solvente para etanol, também monitoramos o pH da solução química de nitrato de zinco com 2-metilimidazol a fim de verificar a sua influência na cristalinidade dos filmes ZIF obtidos.

As soluções empregadas na deposição dos filmes ZIF foram preparadas como segue:

- Dissolução de 4,3g de nitrato de zinco hexahidratado em $25 \mathrm{ml}$ de etanol sob agitação da solução através de barra magnética (stirrer);

- Dissolução de 9,7g de 2-metilimidazol em 25ml de etanol sob agitação da solução através de barra magnética (stirrer);

- Mistura das duas soluções previamente dissolvidas;

- Diluição da solução de nitrato de zinco hexahidratado e 2metilimidazol em etanol até perfazer os volumes de 100,400ml e 800ml;

- Medida do pH das soluções preparadas nas diferentes diluições. 


\subsubsection{Técnicas de deposição e tratamentos térmicos empre- gados}

Para deposição dos filmes ZIF sobre as superfícies dos substratos de silício, foram empregadas duas técnicas: a) spinning através do derramamento de volumes variáveis (10 a 200ml) de solução sobre a superfície seguido de rotação da lâmina na faixa de 2000 a 3000 rpm e b) casting através do simples derramamento de solução com volumes na faixa de 50 a $200 \mathrm{ml}$ seguido de secagem.

O processo de secagem consistiu em deixar o solvente evaporar por cerca de $2 \mathrm{~h}$ na temperatura ambiente seguido de tratamento térmico na temperatura de $150^{\circ} \mathrm{C}$ em nitrogênio ultrapuro para tempos variando na faixa de 1 a $48 \mathrm{~h}$.

\subsection{Técnicas de Caracterização Física}

A técnica de microscopia eletrônica de varredura por emissão de campo (FESEM: Field-emission scanning electron microscope) com equipamento da FEI modelo NanoSEM 400 FEG, foi empregada para obter informações da morfologia superficial das camadas depositadas e, também, estimativas de espessura através de imagens transversais após o processo de clivagem das amostras.

Os espectros RBS foram extraídos por um acelerador Pelletron - Tanden, model $55 \mathrm{DH} / \mathrm{NEC}$, com feixe $\mathrm{He}^{+}$em incidência normal, energia de 2,4 MeV e ângulo de espalhamento de $80^{\circ}$. Através do programa de simulação SIMRA (MAYER, 1997. 62p.), foi possível ajustar a curva teórica sobre a curva experimental por intermédio dos parâmetros físicos que melhor descrevem os elementos contidos nos filmes, tais como estequiometria e concentração (veja item 4.1). A técnica de difração de raios X (XRD: X-Ray Difraction), com difratômetro PIXCEL 3D Panalytical (radiação $C u H \alpha(\lambda=1.54059 \AA$ ) $), 40 \mathrm{kV}$ e $40 \mathrm{~mA}$ ), foi aplicada para determinar a estrutura cristalina das camadas ZIF depositadas. A 
técnica de absorção de infravermelho (IR: InfraRed absorption), com equipamento Biorad FTS 6000 na faixa de 400 a $3000 \mathrm{~cm}^{-1}$, foi utilizada para analisar absorção de $\mathrm{CO}_{2}$ pelas camadas ZIF depositadas. Os espectros IR foram obtidos na temperatura ambiente em condição controlada de baixa umidade, por meio de fluxo ultrapuro de nitrogênio durante a medida. A Figura 27a ilustra o ajuste do fluxo de nitrogênio sobre a amostra que é colocada em um compartimento isolado com baixo conteúdo de umidade dentro do equipamento Biorad FTS 6000. A Figura 27b ilustra a amostra ZIF montada sobre o porta-amostras imediatamente antes de ser inserida no equipamento.

Para caracterizar os processos de absorção e adsorção de $\mathrm{CO}_{2}$ pelas camadas ZIF depositadas, foi utilizada a montagem indicada na Figura 28a composta de uma câmara de $\mathrm{CO}_{2}$ com pressão ajustável na faixa de 0 a 32 psi e um cilindro de $\mathrm{CO}_{2}$ ultrapuro com regulador de saída. A Figura 28b mostra detalhe da entrada de $\mathrm{CO}_{2}$ na câmara, o manômetro empregado para a medição da pressão interna da câmara e a válvula agulha para ajuste fino da pressão.

Após o condicionamento das amostras ZIF em diferentes pressões e tempos de exposição ao $\mathrm{CO}_{2}$, foi feita a caracterização da evolução temporal das bandas de $\mathrm{CO}_{2}$ nos espectros IR extraídos com a ajuda do equipamento Biorad FTS 6000 em ambiente de nitrogênio ultrapuro. 
Figura 27: (a) Foto do equipamento Biorad FTS 6000 onde está destacado o controle de injeção de nitrogênio ultrapuro no compartimento onde é colocado o porta-amostras. (b) Detalhe da amostra de ZIF montada sobre o porta-amostras.

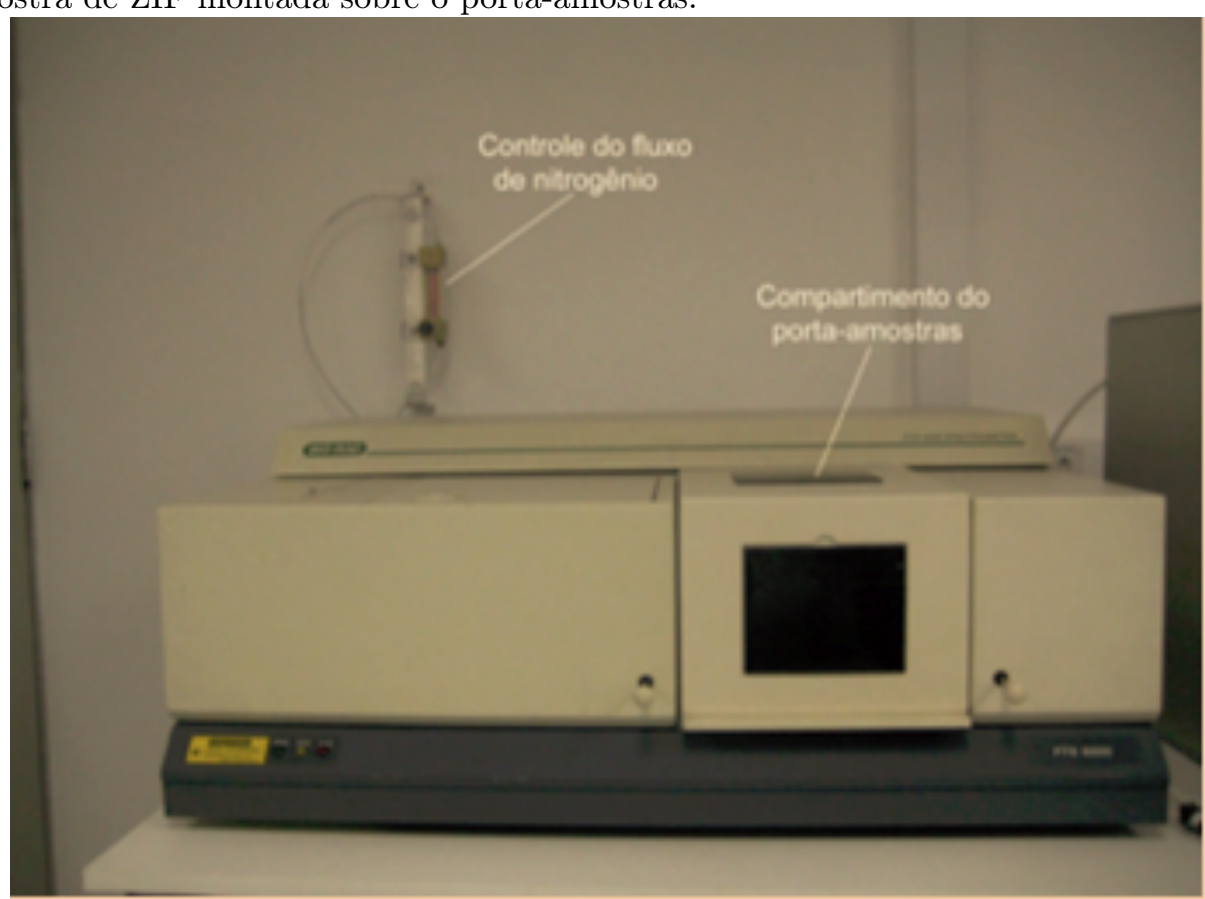

(a)

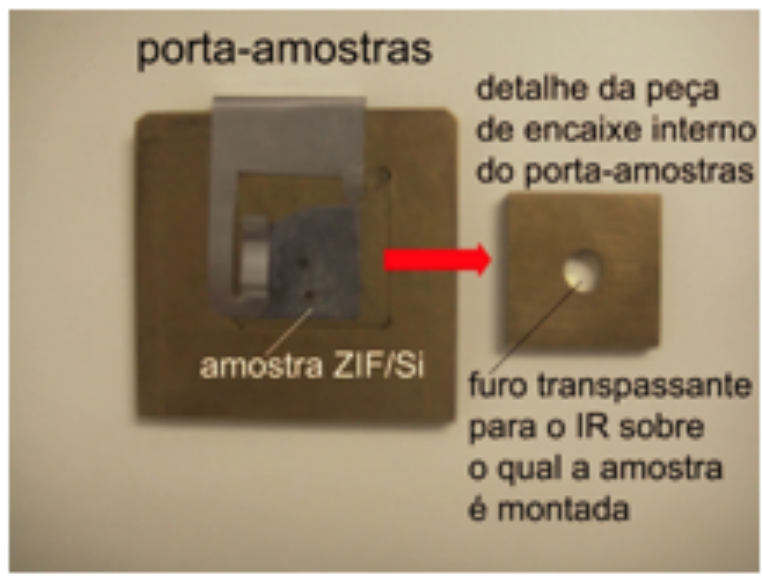

(b)

Fonte: Autor 
Figura 28: (a) Montagem empregada para condicionamento das amostras ZIF em diferentes pressões na faixa de 0 a 32psi e diferentes tempos de exposição (0 a 150min); (b) Detalhe da entrada de $\mathrm{CO}_{2}$ na câmara, do manômetro empregado para a medição da pressão interna e a da válvula agulha para ajuste fino da pressão.

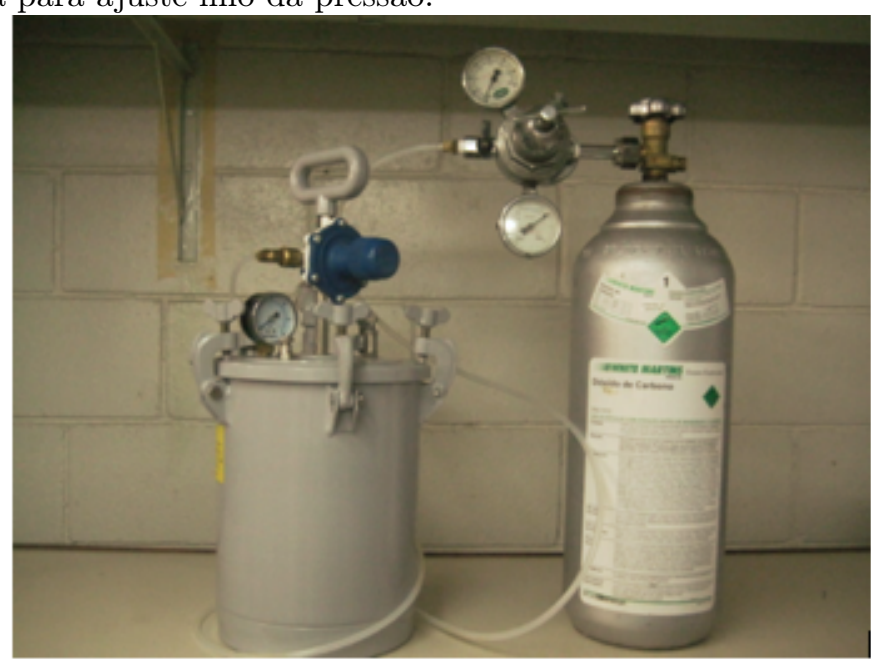

(a)

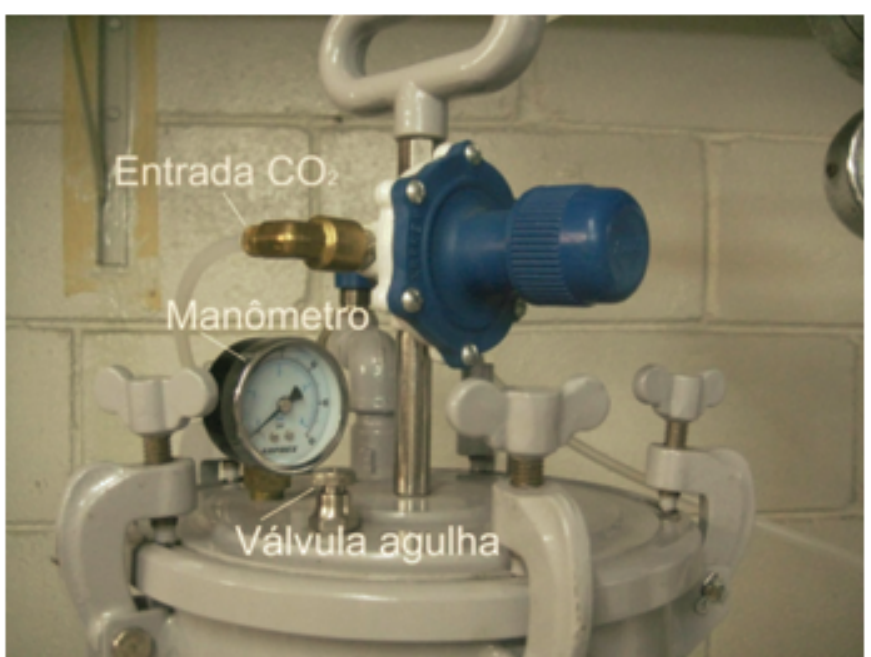

(b)

Fonte: Autor 


\section{RESULTADOS E DISCUSSÃO}

Neste capítulo, serão expostos e discutidos os resultados experimentais sobre a obtenção das camadas ZIF sobre os substratos utilizando uma receita alternativa de deposição que emprega etanol como solvente em vez de metanol através dos processos spinning e casting para deposição. Foi utilizada a técnica FESEM para caracterização da morfologia superficial e da espessura, a técnica XRD para caracterização da cristalinidade das camadas e RBS para caracterização da estequiometria. Adicionalmente foi empregada a técnica FTIR para caracterizar os processos de absorção e adsorção de $\mathrm{CO}_{2}$ nas camadas, visando permitir o armazenamento de $\mathrm{CO}_{2}$ para aplicações envolvendo não apenas a sua detecção, mas também a sua remoção do ambiente a fim de evitar o efeito estufa.

\subsection{Influência do pH e do processo de deposição}

Conforme descrito no item 5.2.1, para deposição das camadas ZIF foi utilizada uma solução química de zinco hexahidratado e 2-metilimidazol com diferentes diluições em etanol ultrapuro $(100 \mathrm{ml}, 400 \mathrm{ml}$ e $800 \mathrm{ml})$ a fim de permitir a variação do pH da solução na faixa de 7,2 a 8,2. Para deposição dos filmes ZIF sobre as superfícies dos substratos de silício, foram empregadas as técnicas: a) spinning através do derramamento de volumes variáveis (10 a 200ml) de solução sobre a superfície seguido de rotação da lâmina na faixa de 2000 a 3000 rpm e b) casting 
através do simples derramamento de solução com volumes na faixa de 50 a $200 \mathrm{ml}$ seguido de secagem. Adicionalmente foi realizado, ou não, tratamento térmico na temperatura de $150^{\circ} \mathrm{C}$ em nitrogênio ultrapuro para tempos variando na faixa de 1 a 48 h.

A utilização das soluções químicas com diluições em 100ml e 400ml resultaram em valores de pH, respectivamente, de 8,2 e 7,6. Nesses casos, não foi possível obter as camadas ZIF cristalinas seja pelo processo casting, seja por spinning. A Figura 29 ilustra os espectros XRD para camadas preparadas, respectivamente, com 100ml e 400ml de etanol pelo processo casting. Em nenhum caso, incluindo a deposição

Figura 29: : Espectros XRD típicos para as camadas preparadas com: (a)100ml de etanol e (b) $400 \mathrm{ml}$ de etanol.
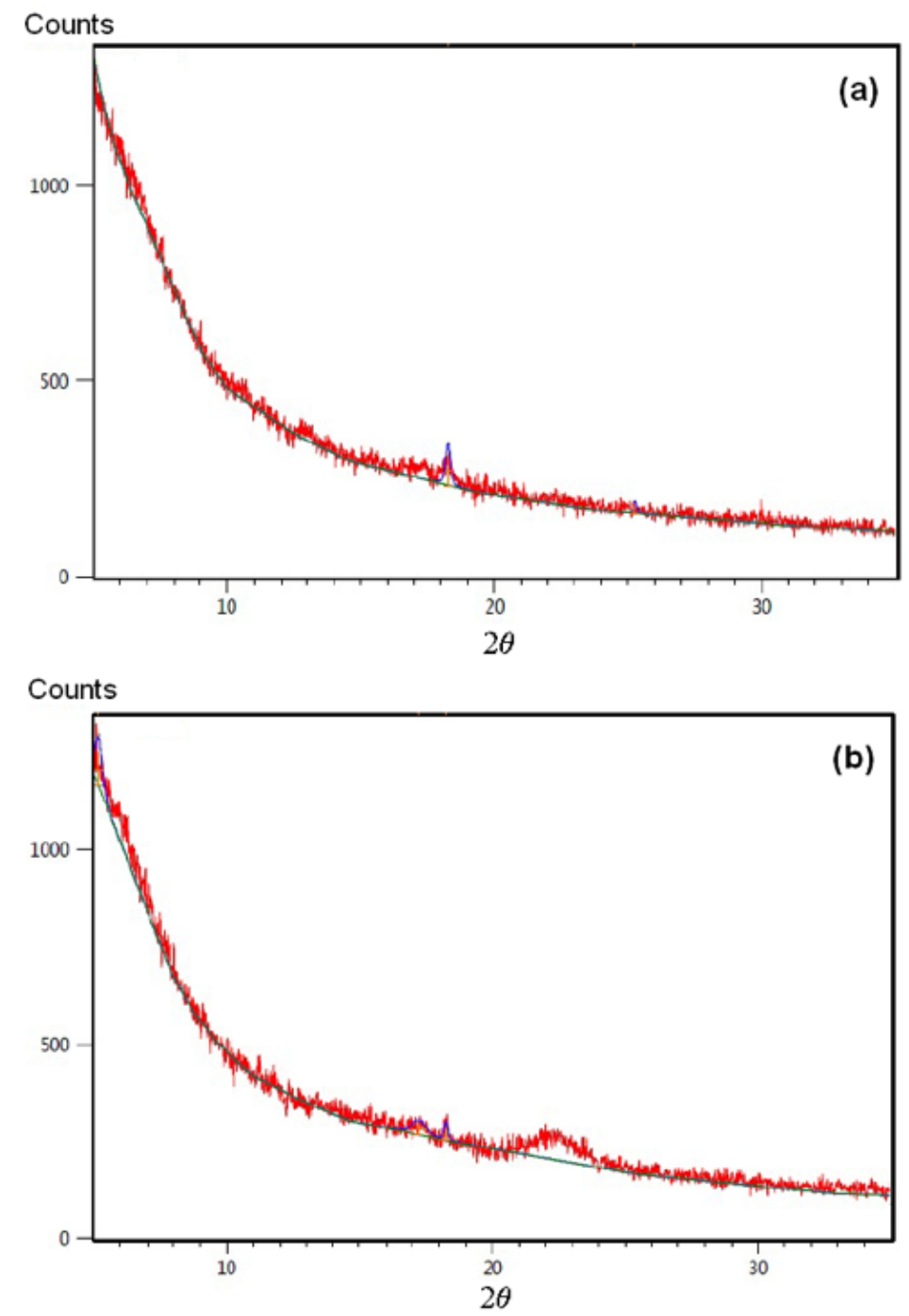

Fonte: Autor 
por spinning, foram obtidas fases cristalinas correspondentes a estrutura ZIF como descrito no capítulo 3.

Por outro lado, todas as deposições realizadas a partir da química de zinco hexahidratado e 2-metilimidazol com diluição em 800ml de etanol resultaram em fases cristalinas que indicaram a formação da estrutura ZIF como descrita no capítulo 3. No caso da deposição por spinning, foi realizada a tentativa de depositar diversas camadas (coberturas), utilizando o equipamento spinner em diversas etapas com $5 \mathrm{ml}$ de solução sobre lâminas de 3 polegadas de diâmetro e rotação de 2000 ou $3000 \mathrm{rpm}$ seguido por intervalo de secagem de 5 min na temperatura ambiente. A tentativa de fazer diversas camadas (até 16) não teve sucesso, ao contrário, os filmes obtidos através de várias etapas de spinning ficaram demasiadamente desuniformes, inclusive com regiões sem deposição, tanto na face polida. Esse resultado negativo foi atribuído a uma aderência pobre das camadas em relação ao substrato polido, sendo que até mesmo o recozimento a $150^{\circ} \mathrm{C}$ descolou as partes remanescentes dos filmes que ficaram desuniformes.

A Figura 30 ilustra o espectro XRD de uma camada depositada por spinning $(2,5 \mathrm{ml}+2000 \mathrm{rpm})$ que passou por secagem na temperatura ambiente durante 24 horas. Verifica-se que existe a fase ZIF-8 dado que foram identificadas pelo menos 11 facetas cristalinas $\left(7,56^{\circ} ; 10,62^{\circ} ; 12,23^{\circ} ; 14,98^{\circ} ; 16,48^{\circ} ; 18,44^{\circ} ; 21,11^{\circ} ; 24,53^{\circ}\right.$; $25,84^{\circ} ; 26,43^{\circ}$ e $\left.31,59^{\circ}\right)$ que possuem precisão nas casas decimais e centesimais com os picos apresentados na Figura 18 do capítulo 3. No entanto, também existem outras 9 facetas cristalinas provavelmente associadas aos outros produtos na forma de coloides presentes na solução química de deposição que acabam emergindo para a superfície da lâmina de silício (PAN, 2011). Apesar de ter sido possível levantar o espectro XRD, a espessura estimada a partir da análise RBS foi de apenas algumas centenas de nanômetros, porém não foi uniforme ao longo da superfície da lâmina de silício. 
Figura 30: Espectro XRD típico para camadas depositadas por spinning $(2,5 \mathrm{ml}+2000 \mathrm{rpm})$ que passaram por secagem na temperatura ambiente por 24 horas.

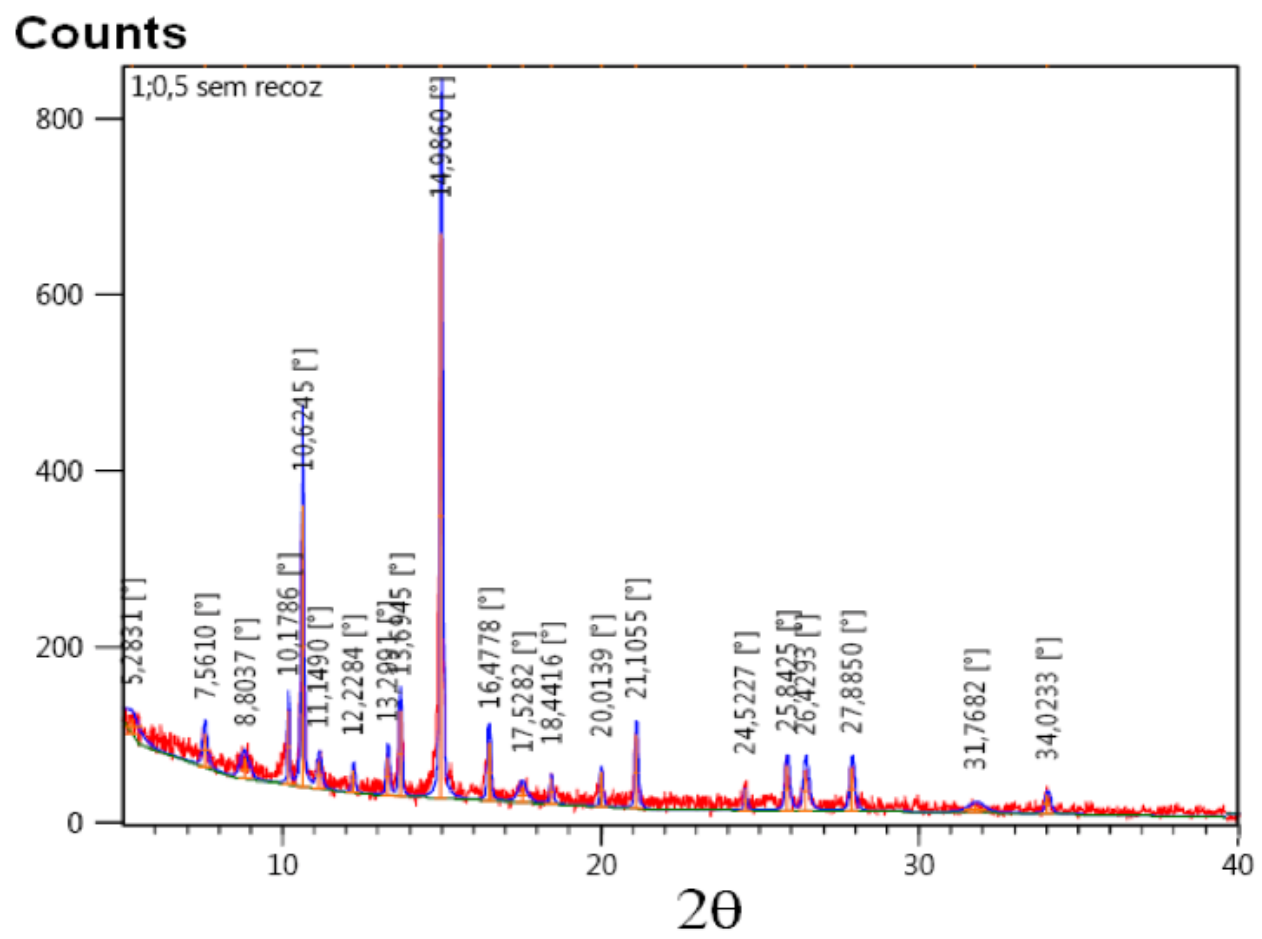

Fonte: Autor

A Figura 31 ilustra a morfologia da superfície da camada obtida de ZIF-8 contendo nanocristais com tamanhos no intervalo de 5 até $10 \mathrm{~nm}$.

Figura 31: morfologia da superfície típica da camada ZIF contendo nanocristais com tamanhos na faixa de 5 a $10 \mathrm{~nm}$.

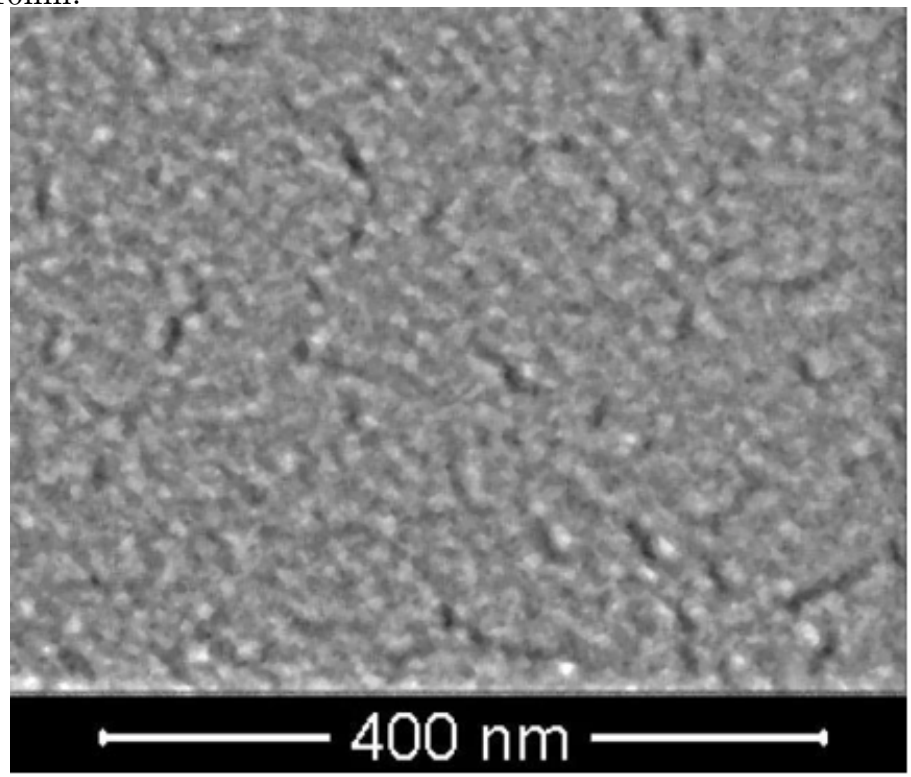

Fonte: Autor 


\subsection{Caracterização de camadas ZIF depositadas por casting}

Como mencionado no item 6.1, os melhores resultados foram os das camadas ZIF depositadas por casting, utilizando a solução química descrita no item 5.2.1 com $\mathrm{pH}$ de 7,2. A fim de otimizar a quantidade de nanocristais para espessuras das camadas de alguns micrômetros, variamos o tratamento térmico na temperatura de $150^{\circ} \mathrm{C}$ até $48 \mathrm{~h}$.

A Figura 32 ilustra a situação típica de camada depositada por casting (50ml) e recozida por $150^{\circ} \mathrm{C}$ por $48 \mathrm{~h}$ em nitrogênio ultrapuro em que se observa a formação de cristais ao longo de toda a espessura da camada.

Figura 32: Micrografia FESEM transversal típica para camadas depositadas por casting $(50 \mathrm{ml})$ que passaram por tratamento na temperatura de $150^{\circ} \mathrm{C}$ por $48 \mathrm{~h}$ em nitrogênio ultrapuro.

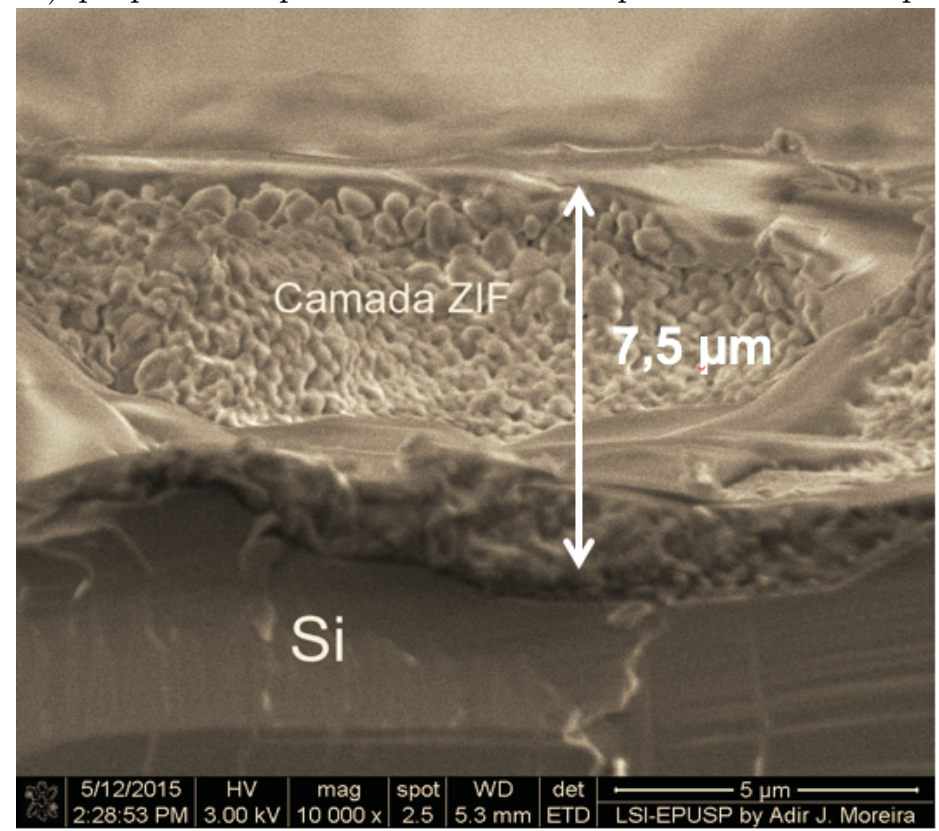

\section{$800 \mathrm{ml}(\mathrm{pH}=7,2)$}

Fonte: Autor

A Figura 33 ilustra a morfologia típica dos nanocristais ZIF obtidos para camadas depositadas por casting $(50 \mathrm{ml})$ que passaram por tratamento na temperatura de $150^{\circ} \mathrm{C}$ por $48 \mathrm{~h}$ em nitrogênio ultrapuro. É importante destacar que os nanocristais formados apresentaram tamanhos numa ampla faixa, desde cerca 
de $5 \mathrm{~nm}$ até cerca de $400 \mathrm{~nm}$. Tal fato indica que possivelmente uma outra fase diferente de ZIF-8 foi predominantemente formada dado que o tamanho característico dos nanocristais deveria estar na faixa de 5 a $10 \mathrm{~nm}$ como apresentado na Figura 31 e corroborado pela Figura 16 (VENNA; JASINSKI; CARREON, 2010). Para determinar a fase formada dos nanocristais ZIF obtidos para camadas de-

Figura 33: Micrografias FESEM típicas de superfície para camadas depositadas por casting (50ml) que passaram tratamento na temperatura de $150^{\circ} \mathrm{C}$ por $48 \mathrm{~h}$ em nitrogênio ultrapuro em diversos aumentos: (a) 50000x, (b) 100000x e 200000x.

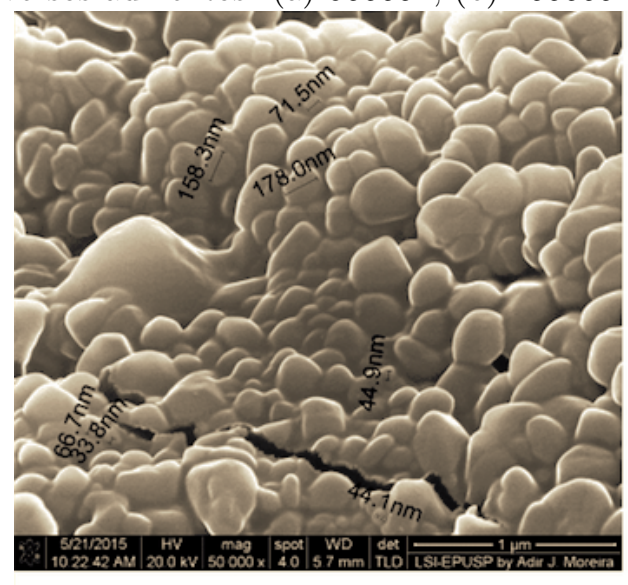

(a)

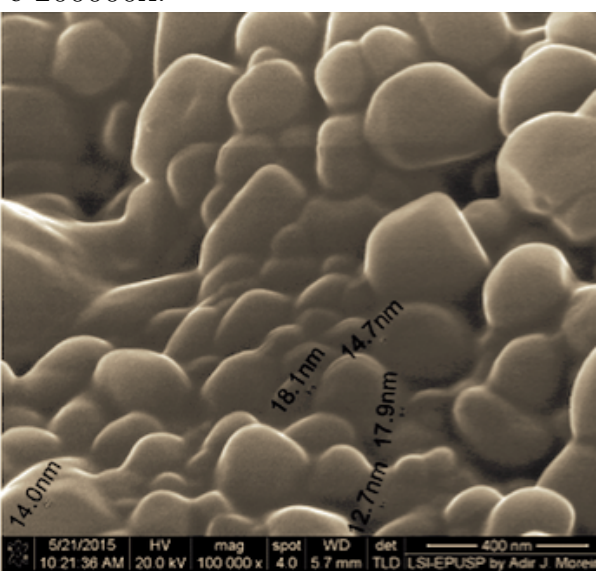

(b)

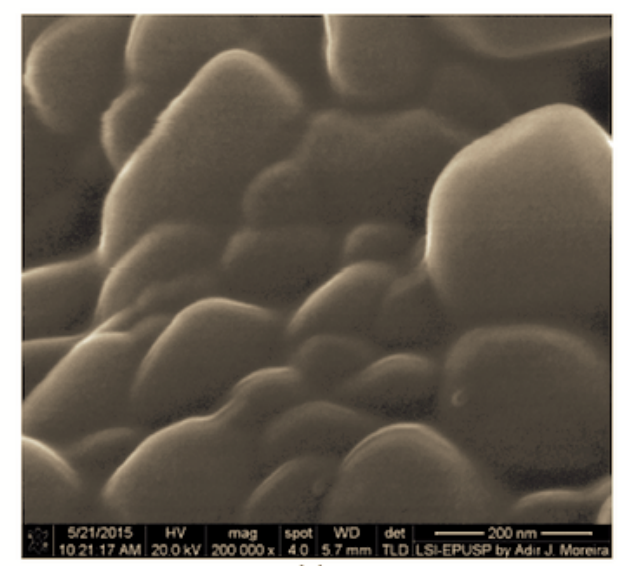

(c)

Fonte: Autor

positadas por casting $(50 \mathrm{ml})$ que passaram por tratamento na temperatura de $150^{\circ} \mathrm{C}$ por $48 \mathrm{~h}$ em nitrogênio ultrapuro, levantamos os espectros XRD. A Figura 34 mostra o espectro XRD típico para as camadas ZIF depositada com a solução química de $\mathrm{pH}=7,2$ (diluição em $800 \mathrm{ml}$ de etanol). Neste caso, como já mencionamos, o etanol foi empregado pela primeira vez, em lugar do metanol (veja 
capítulo 3) durante a preparação da solução química para deposição das camadas ZIF. É importante destacar novamente que foi observada a formação do ZIF somente quando foi empregada a diluição em $800 \mathrm{ml}$ de etanol. O pH próximo de 7,0 , como mostrado no item 6.2 , foi o principal fator a ser controlado a fim de ter uma formação com êxito de camadas ZIF. Além disso, foi também verificado a alta estabilidade do pH durante várias horas após preparação da solução química de deposição das camadas ZIF.

Na Figura 34, é importante chamar a atenção que apenas umas poucas (5) facetas cristalinas poderiam ser identificadas como sendo referentes à fase ZIF-8 $\left(7,50^{\circ} ; 10,32^{\circ} ; 16,18^{\circ} ; 24,45^{\circ} ; 25,68^{\circ}\right)$ supondo precisão dos ângulos $2 \theta$ em décimos de graus.

Figura 34: Espectro XRD típico para as camadas ZIF preparada com a solução descrita no item 5.2.1 utilizando diluição em $800 \mathrm{ml}$ de etanol

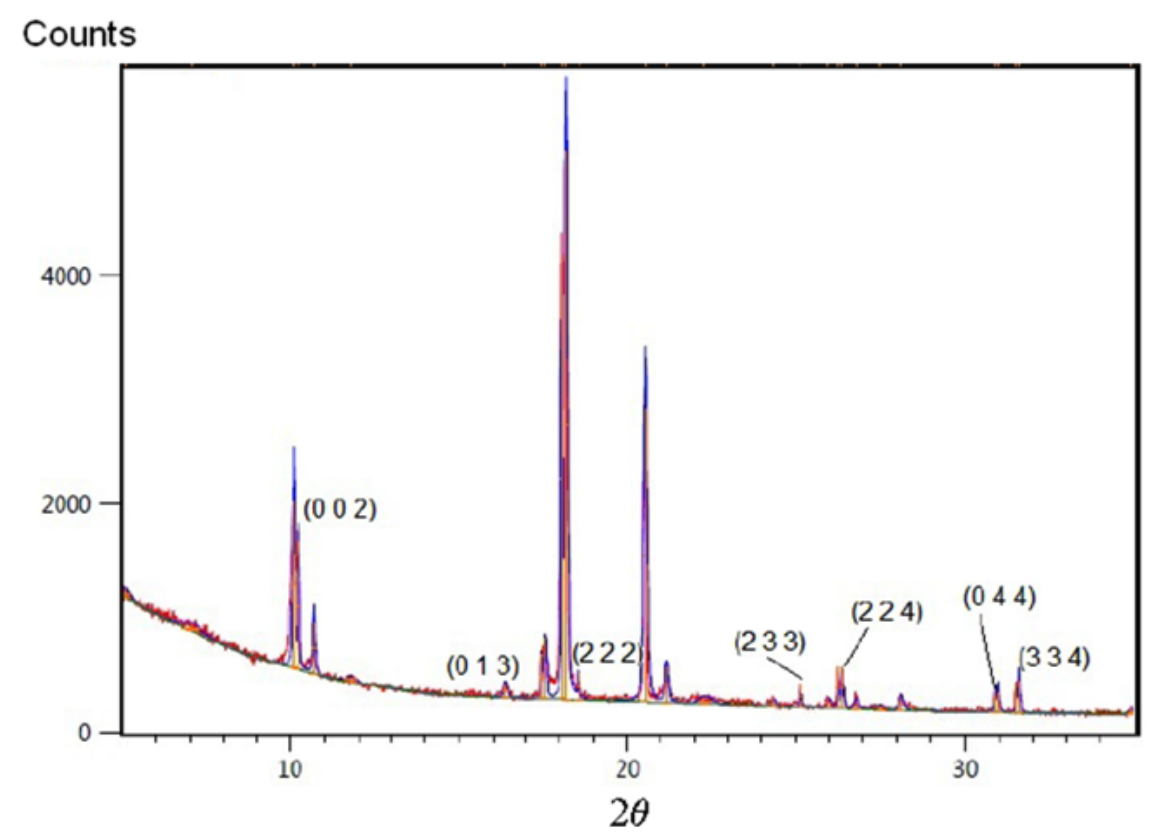

Fonte: Autor

Por outro lado, facetas cristalinas características do ZIF-8 desapareceram $\left(12,23^{\circ} ; 14,98^{\circ} ; 18,44^{\circ} ; 21,11^{\circ} ; 26,43^{\circ}\right.$ e $\left.31,59^{\circ}\right)$. Portanto, uma outra estrutura ZIF deve estar sendo predominante na camada sintetizada. Após uma procura 
exaustiva na literatura, verificou-se que todas as facetas cristalinas presentes no espectro XRD da Figura 32 casam na primeira ou segunda casa depois da vírgula com os padrões XRD da estrutura ZIF-90 (7,50 ; 10,26 $; 11,77^{\circ} ; 15,39^{\circ}$; $16,42^{\circ} ; 17,52^{\circ} ; 19,94^{\circ} ; 20,54^{\circ} ; 21,19^{\circ} ; 22,28^{\circ} ; 24,31^{\circ} ; 25,11^{\circ} ; 26,16^{\circ} ; 28,08^{\circ}$; $\left.30,34^{\circ} ; 31,53^{\circ}\right)($ BHATTARCHARJEE; LEE; AHN, 2015).

A Figura 35 mostra o espectro RBS típico obtido para as camadas ZIF-90 sobre o qual foi sobreposto o espectro simulado com a ajuda do programa SIMRA (MAYER, 1997. 62p.).

Figura 35: Espectro RBS típico para as camadas ZIF preparada com a solução descrita no item 5.2.1 utilizando diluição em $800 \mathrm{ml}$ de etanol.

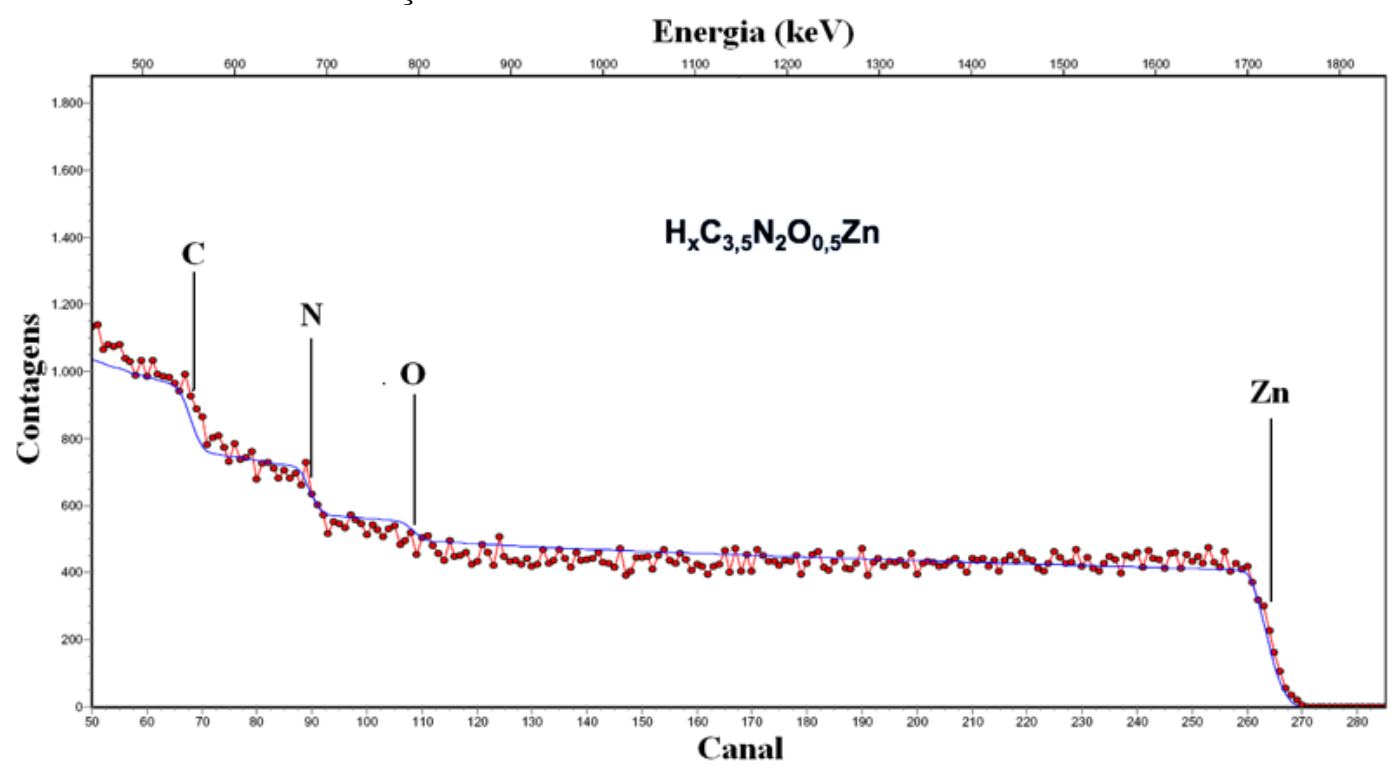

Fonte: Autor

Observa-se, respectivamente, a posição dos degraus correspondentes aos elementos C, N, O e Zn. O espectro simulado foi obtido tendo como parâmetros de entrada a energia do feixe, o ângulo de espalhamento, a curva de calibração energia/canal e a resolução do detetor conforme descrito nos procedimentos experimentais. O ajuste da simulação sobre o espectro experimental foi realizado a partir do ajuste adequado das concentrações planares totais dos elementos que resultava no menor erro entre todos os pontos experimentais e o espectro simu- 
lado. Baseado no ajuste, obtivemos fórmula estequiométrica $\mathrm{H}_{x} \mathrm{C}_{3,5} \mathrm{~N}_{2} \mathrm{O}_{0,5} \mathrm{Zn}$ que é consistente com a fórmula estequiométrica do ZIF-90 (BHATTARCHARJEE; LEE; AHN, 2015).

\subsection{Caracterização dos processos de absorção e adsorção de $\mathrm{CO}_{2}$ pelas camadas ZIF}

Como mencionado no item 6.2 , os melhores resultados foram obtidos para deposição de ZIF pelo método casting $(\mathrm{pH}=7,2)$, situação na qual foram obtidos camadas uniformes sobre silício com espessuras de alguns micrômetros. Baseado nesse melhor resultado, escolheram-se as camadas depositadas por esse método para caracterizar os processos de absorção e adsorção de $C_{2}$ pelas camadas ZIF.

A Figura 36 apresenta o espectro FTIR típico para a camada ZIF depositada pela técnica casting após diferentes condicionamentos em $\mathrm{CO}_{2}$ em diferentes pressões e para tempos diferentes.

Em primeiro lugar, o espectro infravermelho (IR) referente à camada ZIF (fig 36a) é consistente com o previamente relatado na literatura (HU et al., 2011); (HU et al., 2013);(BHATTARCHARJEE; LEE; AHN, 2015) relativos às faixas de 700 a 2300 $\mathrm{cm}^{-1}$ e acima de $2500 \mathrm{~cm}^{-1}$. Em segundo lugar, as duas bandas de absorção bem delineadas em 670 e $2350 \mathrm{~cm}^{-1}$ no espectro de referência ZIF são atribuídas, respectivamente, ao modo "encurvamento"(v2: bending) e ao modo estiramento assimétrico (v3: asymmetric stretching). É importante observar na Figura 36 que o sinal do modo 3 aumenta com o tempo durante o qual a pressão é mantida. Como será mostrado a seguir, o aumento desse sinal é devido ao armazenamento de $\mathrm{CO}_{2}$ dentro da camada ZIF.

Na Figura 37, mostramos duas componentes, uma em $2337 \mathrm{~cm}^{-1}$ e outra em 
Figura 36: Espectro FTIR típico da camada ZIF após diferentes condicionamentos em $\mathrm{CO}_{2}$. (a) referência ZIF sem condicionamento, (b) 15psi por $30 \mathrm{~min}$, (c) 32 psi por 30 min e (d) 32 psi por $150 \mathrm{~min}$.

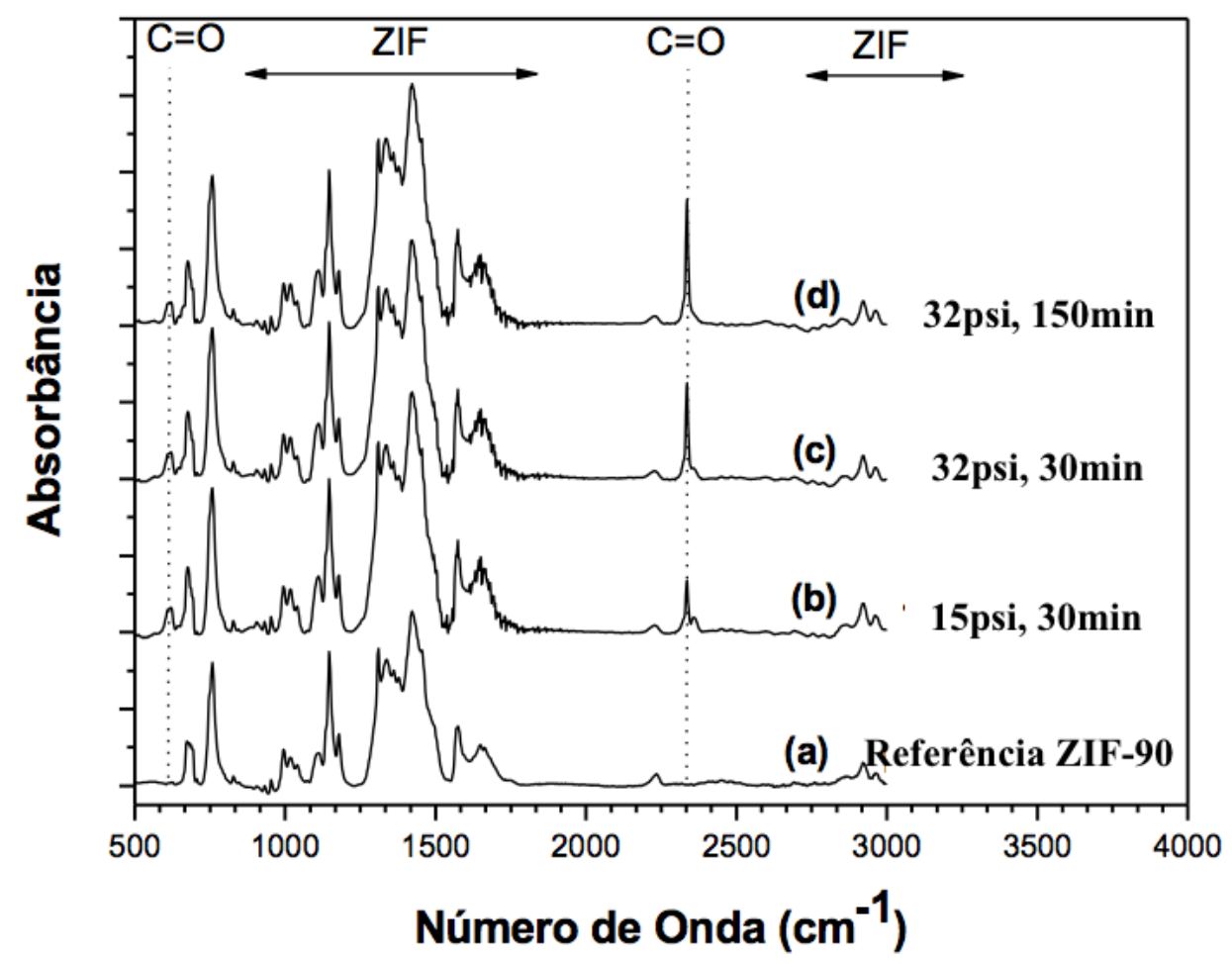

Fonte: Autor

$2360 \mathrm{~cm}^{-1}$, que indicam dois diferentes tipos de resposta das moléculas de $\mathrm{CO}_{2}$ armazenadas na camada ZIF. Comparando as alturas e a evolução temporal desses picos que tendem a desaparecer como no espectro de referência ZIF, também indicado na Figura 37, a componente em $2337 \mathrm{~cm}^{-1}$ pode ser interpretada como uma porção substancial de moléculas de $\mathrm{CO}_{2}$, inseridas dentro da camada ZIF no contorno dos monocristais ou ocupando os arcabouços dentro da estrutura cristalina, e a componente em $2360 \mathrm{~cm}^{-1}$ indica uma porção de moléculas de $\mathrm{CO}_{2}$ adsorvidas na superfície do ZIF que podem ser facilmente dessorvidas.

A Figura 37 também apresenta a evolução da altura do pico em $2337 \mathrm{~cm}^{-1}$, em função do tempo após condicionamento da camada ZIF em $\mathrm{CO}_{2}$ na pressão de 32psi durante $90 \mathrm{~min}$ seguidos por imersão de $N_{2}$ ultrapuro $(5 \mathrm{l} / \mathrm{min})$. Ao cessar a carga de $\mathrm{CO}_{2}$, a altura do pico diminui progressivamente devido ao processo de 
Figura 37: Espectro FTIR típico da camada ZIF em função do tempo, após condicionamento em $\mathrm{CO}_{2}$ em 32 psi durante 90 min.

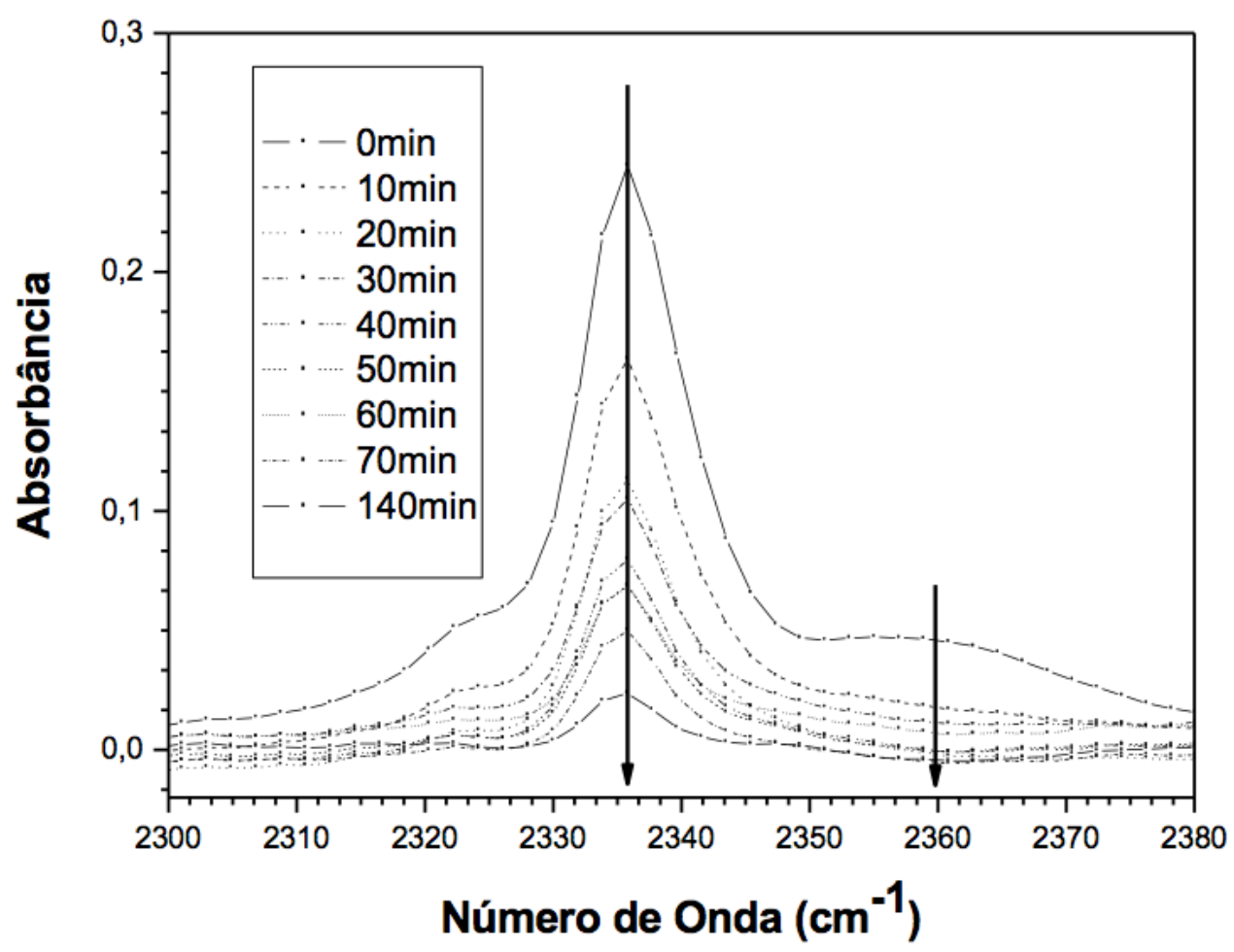

Fonte: Autor

difusão do $\mathrm{CO}_{2}$ para fora da camada ZIF.

É importante destacar que a absorbância, na Figura 37, é diretamente proporcional à concentração planar total de $\mathrm{CO}_{2}$ na camada ZIF $\left(N_{P}=N_{V} t_{Z I F}\right)$ de acordo com a equação de Beer-Lambert (SWINEHART, 1962) como a seguir:

$$
A=-\log \left(\frac{I_{1}}{I_{0}}\right)=\alpha N_{V} t_{Z I F}
$$

onde $A$ é a absorbância (ou absorvância), $I_{0}$ é a intensidade da luz incidente, $I_{1}$ é a intensidade da luz após atravessar a camada ZIF, $t_{Z I F}$ é a espessura da camada ZIF que a luz atravessa $(\mathrm{cm}), \mathrm{N}_{V}$ é a concentração volumétrica do $\mathrm{CO}_{2}$ $\left(\right.$ moles $\left./ \mathrm{cm}^{3}\right)$ e $\alpha$ é a absorbtividade molar do $\mathrm{CO}_{2}\left(\mathrm{~cm}^{2} / \mathrm{mol}\right)$. Para determinar a evolução temporal da concentração de $\mathrm{CO}_{2}$ na camada ZIF, é necessário resolver a equação de conservação de massa unidimensional para a camada ZIF com espessura $t_{Z I F}$ (KARGER; RUTHVEN; THEDOROU, 2012. 902 p.) a qual pode 
escrita como segue:

$$
\frac{d N_{P}(t)}{d t}=-\left(\frac{D_{0}}{t^{2} Z I F}\right) N_{P}(t)
$$

onde $N_{P}(t)$ é a concentração planar total de $\mathrm{CO}_{2}$ na camada ZIF que varia com o tempo, $t_{Z I F}$ é a espessura da camada ZIF e $D_{0}$ é a constante de difusão do $C O_{2}$ dentro da camada ZIF.

A solução da equação 6.2 já é bem conhecida (KARGER; RUTHVEN; THEDOROU, 2012. 902 p.). Supondo como condições de contorno $N_{P}(t=0)=N_{P 0}$ e $N_{P}(t=\infty)=N_{P M}$, a solução da equação 6.2 é dada por:

$$
N_{P}(t)=\left(N_{P 0}-N_{P M}\right) e^{-t /\left(t^{2} Z I F /\left(D_{0}\right)\right)}+N_{P M}
$$

onde $N_{P}(t)$ é a concentração planar total de $\mathrm{CO}_{2}$ na camada ZIF que varia com o tempo, $t_{Z I F}$ é a espessura da camada ZIF, $D_{0}$ é a constante de difusão do $C_{2}$ dentro da camada ZIF, $N_{P 0}$ é a concentração planar total de $\mathrm{CO}_{2}$ no instante $t=0$ e $N_{P M}$ é a concentração planar total de $C O_{2}$ para $t=\infty$ atribuída a um efeito de memória do $\mathrm{CO}_{2}$ na camada ZIF.

Por outro lado, se analisarmos a evolução temporal da altura do pico localizado em $2360 \mathrm{~cm}^{-1}$ (veja Figura 37), verifica-se facilmente que a evolução é muito rápida o que comprova uma célere dissolução da porção adsorvida das moléculas de $\mathrm{CO}_{2}$ da superfície da camada ZIF para o ambiente de $\mathrm{N}_{2}$, como mencionado anteriormente. Nesse caso, não é possível estabelecer um modelo simples de dessorção superficial devido à rápida evolução do pico de absorbância localizado em $2360 \mathrm{~cm}^{-1}$.

A Figura 38 apresenta um gráfico da evolução da altura do pico com o tempo e sobre o qual foi ajustado um decaimento do tipo exponencial consistente com a equação 6.3 onde em lugar da concentração planar $N_{P}(t)$ foi utilizada a absorbância $A(t)$. Desta forma, o processo de difusão dominante do $\mathrm{CO}_{2}$ saindo do corpo da camada ZIF para o ambiente de $N_{2}$ ultrapuro resultou em uma constante de 
Figura 38: Altura do pico em $2337 \mathrm{~cm}^{-1}$ em função do tempo após condicionamento da camada ZIF em $\mathrm{CO}_{2}$ em 32 psi durante 90 min seguido por imersão em $N_{2}$ ultrapuro (5l/min)

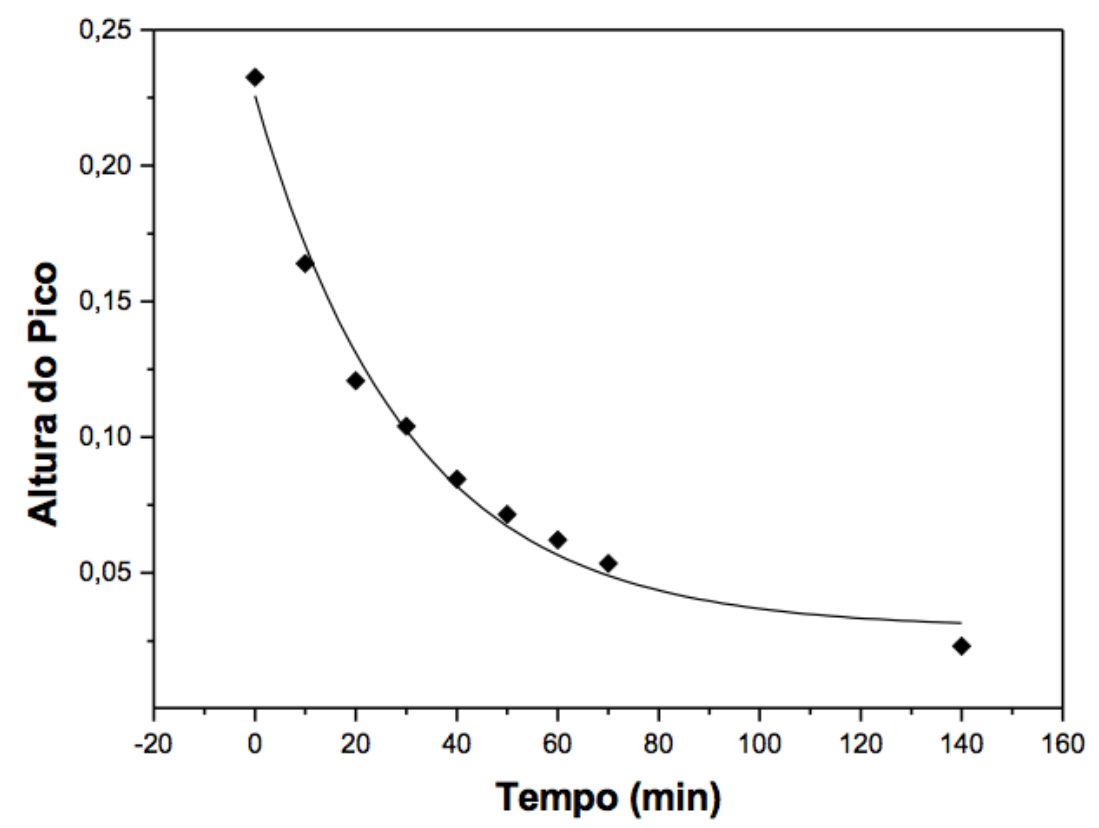

Fonte: Autor

difusão $D_{0}=0,93 \mu \mathrm{m}^{2} / \mathrm{min}$ para uma espessura média $t_{Z I F}=7,5 \mu \mathrm{m}$.

Ao variar a pressão e o tempo de carga do $\mathrm{CO}_{2}$ imediatamente antes de passar ao ambiente de $N_{2}$ ultrapuro para a medida FTIR, verificou-se que a constante de difusão aumentava com a diminuição do valor máximo do pico da absorbância qualquer que fosse a pressão ou tempo de carga empregados para atingir esse valor máximo. Para uma absorbância máxima inicial 1,8 vezes menor de 0,139 (pressão e tempo de carga, respectivamente, 32 psi e 10min) comparado ao valor de 0,245 na Figura 37, a constante de difusão resultou 2,8 vezes maior $\left(2,59 \mu \mathrm{m}^{2} / \mathrm{min}\right)$. Nesse caso, possivelmente a menor carga de $\mathrm{CO}_{2}$ dentro dos cristais ZIF acaba por facilitar a sua saída de dentro da camada.

Também, é importante destacar que a absorbância associada ao efeito de memória resultou aproximadamente igual nos dois casos descritos $(0,139$ e 0,245$)$ dentro da faixa de incerteza $\left(A_{M}=\alpha N_{P M}=0,028 \pm 0,003\right)$ o que indica que existe maior dificuldade de remover todo o $\mathrm{CO}_{2}$ de dentro da camada abaixo 
de uma concentração mínima de $\mathrm{CO}_{2}$. Por outro lado, foi observado que esta concentração incubada dentro da camada ZIF na forma de "efeito de memória"é totalmente removida quando a amostra de ZIF é mantida aproximadamente 5 horas em ambiente de $N_{2}$ ultrapuro.

Para calcular a concentração planar total de $\mathrm{CO}_{2}$ incorporada dentro do filme, é necessário conhecer a absorbtividade " $\alpha$ "da camada ZIF-90. Após uma procura exaustiva na literatura, não foi possível encontrar a absorbtividade das moléculas de $\mathrm{CO}_{2}$ em matriz de ZIF-90. No entanto, foram encontradas referências sobre a absorbtividade para o gás $\mathrm{CO}_{2}$ em função da pressão e da temperatura (KAWAHARA; TOMITA; OHTSUKI, 2010) e (KAWAHARA; TOMITA, 2011).

Assumindo que a matriz ZIF-90 não tenha influência substancial na absorbtividade pelo fato de ser um material transparente e pouco absorvente (SWINEHART, 1962), podemos estimar a absorbtividade das moléculas de $\mathrm{CO}_{2}$ dentro da camada ZIF como sendo $1,0 \times 10^{5} \mathrm{~cm}^{2} / \mathrm{mol}$ (KAWAHARA; TOMITA; OHTSUKI, 2010) e (KAWAHARA; TOMITA, 2011). Como resultado, baseado no fato dos valores dos picos de absorbância medidos terem ficado na faixa de 0,02 a 0,33 (no âmbito do presente trabalho) e aplicando a equação 6.1, a incorporação de $\mathrm{CO}_{2}$ nas camadas ZIF-90 $\left(N_{P}=A / \alpha\right)$ ficou na faixa de $2,0 \times 10^{-7}$ a $3,3 \times 10^{-6}$ moles $/ \mathrm{cm}^{2}$ ou de $1,2 \times 10^{17}$ a $2,0 \times 10^{18}$ molculas $/ \mathrm{cm}^{2}$ o que significa alta capacidade de préconcentração de $\mathrm{CO}_{2}$ das camadas ZIF testadas para a pressão de carga de $\mathrm{CO}_{2}$ variando desde a ambiente até 32psi (FENG et al., 2015).

A Figura 39 mostra a evolução da altura dos picos em $2337 \mathrm{~cm}^{-1} \mathrm{e}, 2360 \mathrm{~cm}^{-1}$, respectivamente, como função da pressão de condicionamento da camada ZIF em $\mathrm{CO}_{2}$ durante $10 \mathrm{~min}$ seguido por extração imediata do espectro IR em ambiente de $N_{2}$ ultrapuro (5l/min). É importante destacar que a altura do pico em $2337 \mathrm{~cm}^{-1}$, correspondente à absorção de $\mathrm{CO}_{2}$, diminui de 14,3\% quando a pressão cai de 32 para 10 psi e diminui mais $38,6 \%$ quando a pressão cai de 10 para 5 psi. Já o 
Figura 39: Espectros IR típicos da camada ZIF em função da pressão de condicionamento em $\mathrm{CO}_{2}$ em durante 10 min. A extração do espectro IR foi feita imediatamente após o condicionamento em ambiente de $N_{2}$ ultrapuro $(5 \mathrm{l} / \mathrm{min})$.

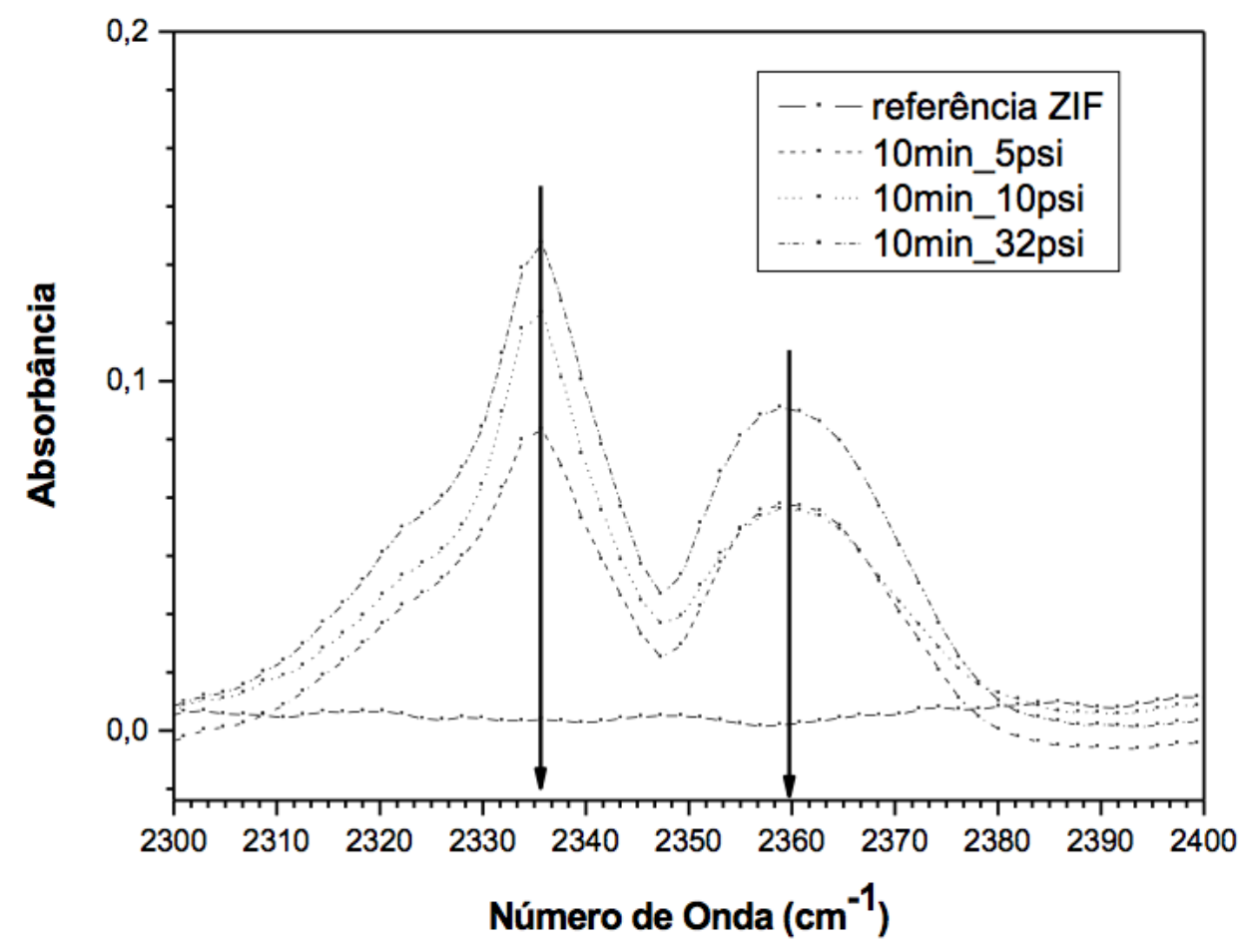

Fonte: Autor

pico em $2360 \mathrm{~cm}^{-1}$ apresenta uma variação de $32,6 \%$ ao passar de 32 para 10psi, e praticamente nenhuma variação ao passar de 10 para 5psi. Tais fatos observados para os picos em $2337 \mathrm{~cm}^{-1}$ e $2360 \mathrm{~cm}^{-1}$ permitem concluir, respectivamente, que quanto maior a pressão de carga ou de condicionamento, maior é a concentração planar de $\mathrm{CO}_{2}$ absorvido no corpo da camada ZIF e, também, maior é a concentração de $\mathrm{CO}_{2}$ adsorvido na superfície da camada ZIF.

A Figura 40 mostra a evolução da altura dos picos em $2337 \mathrm{~cm}^{-1} \mathrm{e}, 2360 \mathrm{~cm}^{-1}$, respectivamente, como função do tempo de condicionamento da camada ZIF em $\mathrm{CO}_{2}$ na pressão de 32 psi seguido por extração imediata do espectro IR em ambiente de $N_{2}$ ultrapuro $(5 \mathrm{l} / \mathrm{min})$. É importante destacar que a altura do pico em $2337 \mathrm{~cm}^{-1}$, correspondente à absorção de $\mathrm{CO}_{2}$ no corpo da camada ZIF, enriquece substancialmente quando o tempo de condicionamento vai a 150min (absorbân- 
Figura 40: Espectros IR típicos da camada ZIF em função do tempo de condicionamento em $\mathrm{CO}_{2}$ na pressão de 32 psi. A extração do espectro IR foi feita imediatamente após o condicionamento em ambiente de $N_{2}$ ultrapuro (5l/min).

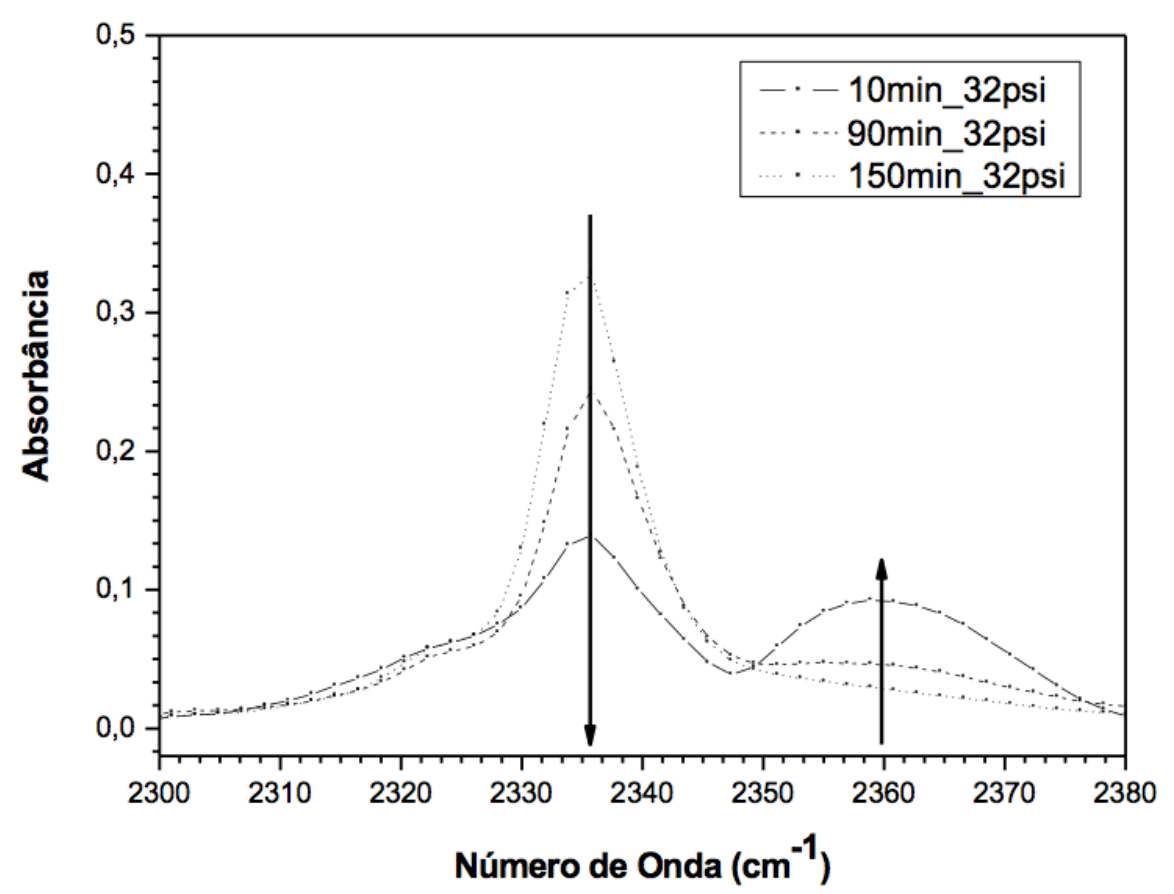

Fonte: Autor

cia de 0,328 ) e diminui $25,6 \%$ quando o tempo cai de 150 para 90min, e mais $42,6 \%$ quando o tempo cai de 90 para $10 \mathrm{~min}$. Já o pico em $2360 \mathrm{~cm}^{-1}$ apresenta uma grande variação no sentido inverso de 49,5\% ao passar de 10 para 90min e $40,3 \%$ ao passar de 90 para $150 \mathrm{~min}$. Portanto, para o pico em $2337 \mathrm{~cm}^{-1}$, quanto maior o tempo de condicionamento, maior é a concentração planar total de $\mathrm{CO}_{2}$ absorvida dentro da camada. Já para o pico em $2360 \mathrm{~cm}^{-1}$, é possível verificar que quanto maior o tempo de condicionamento, menor é a altura do pico e, portanto, menor é a concentração de moléculas de $\mathrm{CO}_{2}$ adsorvidas. Tal fato pode possivelmente estar ligado à uma maior velocidade de dessorção das moléculas de $\mathrm{CO}_{2}$ a partir da superfície da camada ZIF induzida por uma maior velocidade de difusão das moléculas de $\mathrm{CO}_{2}$ de corpo as quais podem estar se chocando com o $\mathrm{CO}_{2}$ adsorvido e promovendo a sua remoção da superfície. Neste caso, durante cerca de 1min, leva-se para transferir a amostra de dentro da câmara de condicionamento em $\mathrm{CO}_{2}$ para o equipamento de medida FTIR em ambiente de 
$N_{2}$ ultrapuro, e provavelmente a camada adsorvida já deve ter desaparecido em virtude da maior velocidade de difusão do $\mathrm{CO}_{2}$ de corpo quando as camadas ZIF apresentam inicialmente maior concentração planar de $\mathrm{CO}_{2}$.

A Figura 41 ilustra o espectro FTIR típico em função do tempo após condicionamento do $\mathrm{CO}_{2}$ com um fluxo de $0,5 \mathrm{l} / \mathrm{min}$ na superfície da camada ZIF durante 10 min na pressão atmosférica. Vale a pena ressaltar que após o desligamento

Figura 41: - Espectro FTIR típico da camada ZIF depositado por "casting" como função do tempo, após condicionamento em $\mathrm{CO}_{2}$, fluxo de $0,5 \mathrm{l} / \mathrm{min}$ na superfície do ZIF durante $10 \mathrm{~min}$.

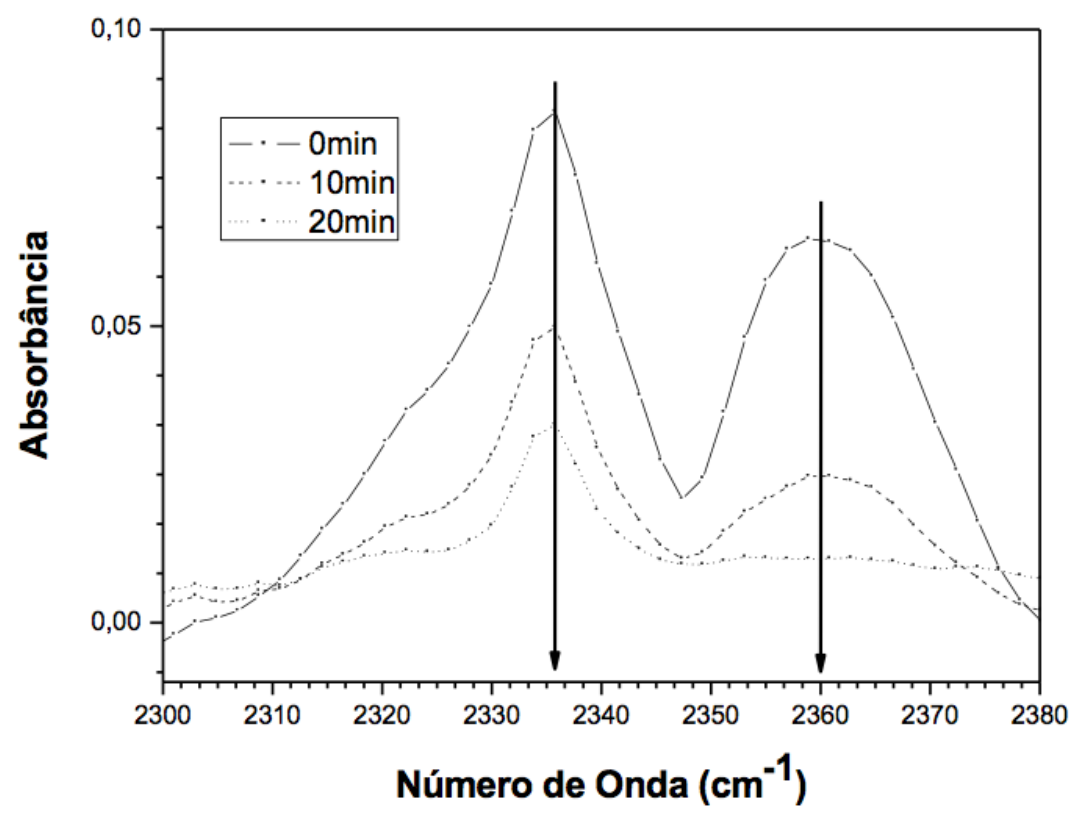

Fonte: Autor

do fluxo de $\mathrm{CO}_{2}$, a altura do pico em $2337 \mathrm{~cm}^{-1}$ diminui progressivamente e a evolução da altura do pico em $2360 \mathrm{~cm}^{-1}$ é mais rápida, embora as alturas iniciais dos dois picos localizados, respectivamente, em 2337 e $2360 \mathrm{~cm}^{-1}$ sejam aproximadamente as mesmas. Mais uma vez esse fato corrobora a hipótese de saída rápida da porção adsorvida das moléculas de $\mathrm{CO}_{2}$ a partir da superfície da camada ZIF. Além disso, baseado nos resultados apresentados até agora, a camada ZIF é uma excelente camada preconcentradora para o gás $\mathrm{CO}_{2}$ cuja carga aumenta com a pressão do gás e com o tempo de carga. Finalmente, foi observado que se o tempo de carga na pressão atmosférica é de pelo menos duas horas, a quantidade 
de partículas de $\mathrm{CO}_{2}$ é de 100ppm, atingindo uma absorbância mínima de 0,02. 


\section{CONCLUSÕES E PERSPECTIVAS FUTURAS}

Como conclusão do presente trabalho, foram depositadas, sobre lâminas de silício, camadas de zeólitos cristalinos formados por cadeias de átomos de zinco com bases conjugadas do imidazol com o objetivo de avaliar os processos de adsorção e absorção do $\mathrm{CO}_{2}$ e aplicar essas camadas como pré-concentradores para a detecção de $\mathrm{CO}_{2}$. Para a deposição das camadas ZIF através dos processos spinning ou casting, foi proposta uma solução química alternativa que emprega etanol como solvente em vez de metanol, como reportado na literatura.

As camadas ZIF foram depositadas, utilizando uma solução química obtida a partir da mistura de nitrato de zinco (4,3g) e 2-metilimidazol (9,7g) em etanol com diversas diluições (100ml, 400ml e 800ml) a fim de variar o pH na faixa de 7,2 a 8,2. Como resultado, verificou-se que as camadas apresentaram estrutura cristalina ZIF-8 ou ZIF-90 apenas na situação de pH próximo de 7. Além disso, as camadas depositadas através da técnica spinning apresentaram baixa aderência sobre lâminas de silício e não foi possível depositar camadas com espessuras na faixa de micrômetros.

Por outro lado, camadas repetitivas com aproximadamente 7, $5 \mu \mathrm{m}$ de espessura foram depositadas nas lâminas de silício através do processo casting em solução de $\mathrm{pH}=7,2(50 \mathrm{ml})$. Após o recozimento dessas camadas na temperatura de $150^{\circ} \mathrm{C}$ por $48 \mathrm{~h}$ em ambiente de nitrogênio ultrapuro, obtiveram-se distribuições repetitivas de nanocristais com tamanhos na faixa de 5 a 400nm com estrutura 
cristalina tipo ZIF-90.

Das medidas de espectroscopia IR nas camadas de ZIF-90, observou-se que a banda localizada em $2337 \mathrm{~cm}^{-1}$ aumenta com o aumento da pressão do $\mathrm{CO}_{2}$ e com o tempo em que a pressão é mantida. Além da banda em $2337 \mathrm{~cm}^{-1}$, foi observado também uma segunda banda em $2360 \mathrm{~cm}^{-1}$, indicadora de dois tipos de resposta das moléculas de $\mathrm{CO}_{2}$. Analisando a evolução temporal da altura dos picos correspondentes às duas bandas após cessar a exposição ao $\mathrm{CO}_{2}$, concluiu-se que a banda localizada em $2337 \mathrm{~cm}^{-1}$ está associada a uma porção substancial de moléculas de $\mathrm{CO}_{2}$ absorvidas dentro da camada formada por nanocristais de ZIF-90 junto aos contornos dos nanocristais ou dentro da sua estrutura cristalina. Já a banda localizada em $2360 \mathrm{~cm}^{-1}$ foi atribuída à porção de moléculas de $\mathrm{CO}_{2}$ adsorvidas na superfície das camadas ZIF depositadas.

Além disso, observou-se que se o tempo de exposição da camada de ZIF-90 ao $\mathrm{CO}_{2}$ na pressão atmosférica for de pelo menos $2 \mathrm{~h}$, atinge-se sensibilidade de 100 ppm ao $\mathrm{CO}_{2}$ considerando a leitura mínima de absorbância como sendo igual à 0,02 quando o fluxo de $C \mathrm{O}_{2}$ sobre a amostra é de $0,5 \mathrm{l} / \mathrm{min}$.

Como descrito anteriormente, podemos destacar nesse trabalho dois pontos de grande importância para os trabalhos futuros. O primeiro ponto a ser destacado foi a utilização de lâminas de silício, como substrato, viabilizando aplicações para os circuitos integrados da área de microeletrônica. Com relação ao solvente, foi utilizado pela primeira vez o etanol em vez do metanol para obtenção de materiais cristalinos tipo ZIF-8 e ZIF-90. O etanol é reconhecidamente um composto menos tóxico que não exige equipamentos de proteção individual (EPI's) para laboratórios como no caso dos experimentos que envolve o solvente metanol. Como continuação do presente trabalho, pretendemos estudar a influência de outros tipos de solventes, incluindo o isopropanol e a água deionizada, no tipo de estrutura cristalina formada pelas cadeias Zn-Im-Zn onde Im é a base conjugada 
do imidazol.

Ainda, com o propósito de melhorar a eficiência do processo de deposição das camadas ZIF sobre silício, pretende-se estudar a influência da rugosidade superficial das lâminas de silício no processo de ancoragem dos nanocristais formados e caracterizar a aderência das camadas depositadas sobre os substratos de silício. Um outro ponto que também pretendemos estudar de forma detalhada é influência dos tamanhos dos nanocristais nas características de pré-concentração, visando a aplicação como sensor de $\mathrm{CO}_{2}$. 


\section{REFERÊNCIAS}

BASU, S.; CANO-ODENA, A.; VANKELECON, I. F. J. Mof-containing mixed-matrix membranes for $\mathrm{CO}_{2} / \mathrm{CH}_{4}$ binary gas mixture separations. Separation and Purification Tecnology, New York, v. 81, n. 1, p. 31-40, 2011.

BHATTARCHARJEE, S.; LEE, Y. R.; AHN, W. S. Post-synthesis functionalization of a zeolitic imidazolate structure ZIF-90: a study on removal of $\mathrm{Hg}$ (II) from water and epoxidation of alkenes. Cryst Eng Comm, London, v. 17 , p. $2575-2582,2015$.

BRAGA, A. A. C.; MORGON, N. Descrições estruturais cristalinas de zeólitos. Quimica Nova, São Paulo, v. 30, p. 178-188, 2007.

BUCKERIDGE, M. S. O efeito estufa e a biodiversidade. 2013. São Paulo, out [2006?]. Disponível em: <http://www.felix.ib.usp.br/pessoal/marcos/ minhaweb5/schedule.htm.>. Acesso em: 13 de Set 2013.

BUX, H. et al. Zeolitic imidazolate framework membrane with molecular sieving properties by microwave-assisted solvothermal syntesis. Journal of the American Chemical Society, Washington, v. 131, p. 16000-16001, 2009.

CHU, W. K.; MAYER, J.; NICOLET, M. A. Backscattering spectrometry. New York: Academic Press, p. 45-70-116-210, 1978.

CHU, W. K. et al. Principles and applications of ion bean techniques for the analysis of solids and thin films. Thin Solid Films, [S.l.], v. 17, p. 1-47, 1973.

CRUZ, F. Emissão de gases de efeito estufa não tem redução efetiva em 2012. 2012. Agência Brasil, Brasilia, ago 2013. secção meio ambiente. Disponível em: <http://memoria.ebc.com.br/agenciabrasil/noticia/2013-08-05/ emissao-de-gases-de-efeito-estufa-nao-tem-reducao-efetiva-em-2012/ -mostra-estudo>. Acesso em: 09 Abr 2013.

EARTH, S. R. L. Global Monitoring Division. Trends in atmospheric carbon dioxide: january. 2016. United State American: Department of Commerce; National Oceanic and Atmospheric Administration, 2016. Disponível em: <http://www. esrl.noaa.gov/gmd/ccgg/trends/graph.html>. Acesso em: 21 Set 2013.

FENG, C. et al. Recent progress in zeolite/zeotype membranes. Journal of Membrane Science and Research, v. 1, p. 49-72, 2015. 
FIGUEIREDO, M. A. G.; ALVES, E. D. L.; VECCHIA, F. A. Geosciences and humanities research medium. Ituiutaba: [s.n.], 2012. 17 p.

FOURIER, J. B. Memória sobre temperatura da Terra e dos espaços planetários [S.l.]. 2001. Disponível em: <http://www.connolley.org.uk/ sci/fourier-1827/fourier-1827.html>. Acesso em: 02 Abr 2015.

GUERRERO, V. V. et al. Membranes on porous supports using secondary growth. Journal of Materials Chemistry, Cambridge, v. 20, p. 3938-3943, 2010 .

HAAG, W.; WEISZ, P. B. The active site of acidic aluminosilicate catalysts. Nature, London, v. 309, p. 589, 1984.

HABERT, A. C.; BORGES, C. P.; NOBREGA, R. Processos de separação por membranas. Rio de Janeiro. E-pappers, 2006. 180 p.

HEWITT, P. G. Fisica conceitual. Bookman, ed: 9o , p. 285-297, 2002.

HU, Y. et al. In situ high pressure study of ZIF-8 by ftir spectroscopy.

Chemical Communications, California, v. 47, p. 12694-12696, 2011.

HU, Y. et al. Evidence of pressure enhanced $\mathrm{CO}_{2}$ storage in ZIF-8 probed by FTIR spectroscopy. Journal of the American Chemical Society, Washington, v. 135, p. 9287-9290, 2013.

HUANG, A. et al. Organosilica functionalized zeolitic imidazolate framework zif-90 membrane for $\mathrm{CO}_{2} / \mathrm{CH}_{4}$ separation. Microporous and Mesoporous Materials, Switzerland, v. 192, p. 18-22, 2014.

HUNGER, K. et al. Investigation of cross-linked and additive containing polymer materials for membranes with improved performance in pervaporation and gas separation. Membranes Journal, Switzerland, v. 2, p. 727-763, 2012.

KARGER, J.; RUTHVEN, D. M.; THEDOROU, D. N. Diffusion in nanoporous materials. New Jersey: Wiley, 2012. 902 p.

KAWAHARA, N.; TOMITA, E. In situ $\mathrm{CO}_{2}$ concentration measurement inside a combustion chamber using infrared laser absorption technique. In: Proceedings of 49th AIAA Aerospace Sciences Meeting, Proceedings, Orlando, Florida, January 4-7, 2011.

KAWAHARA, N.; TOMITA, E.; OHTSUKI, A. Residual gas concentration measurement inside a spark-ignition engine using infrared laser absorption method. IProceedings of the 15th Int. Symp on Appl. Laser Techniques to Fluid Mechanics, Proceedings, Lisboa, Portugal, July 5-8, 2010.

KERN, W. The evolution of silicon wafer cleaning technology. Journal of The Electrochemistry Society, New Jersey, v. 137, n. 6, p. 1887, 1990.

KERN, W. Handbook of semiconductor wafer cleaning technology. New Jersey: Noyes Publicatins, 1993. ISBN 978-0-8155-1331-5. 
KERN, W.; PUOTINEN, D. A. Cleaning solution based on hydrogen peroxide for use in silicon semiconductor technology. $\boldsymbol{R} \boldsymbol{C A} \boldsymbol{R e v}$., Princeton, v. 31, p. 187-205, 1970.

KERN, W.; REINHARDT, K. A. Handbook wafer cleaning technology. William Andrew, 2008. ISBN 978-0-8155-1554-8.

KRENO, L. et al. Metal-organic framework materials as chemical sensors. Chemical Reviews, Washington, v. 112, p. 1105-1125, 2012.

LAVARDA, F. Efeito estufa. [São Paulo]. 2012. Disponível em: <http: //www.fc.unesp.br/lavarda/procie/dez14/luciana/index.htm>. Acesso em: 18 Abr 2015.

LERNER, B. A. Resid processing in FCCU's: concepts and catalysts.

International Journal of Hydrocarbon Engineering, Farnham, v. 3, n. 3, p. 26-28, 1998.

LI, J. et al. Design and sensing applications of metal-organic framework composites. Trends in analytical chemistry, Waterlo, v. 58, p. 71-78, 2014.

LI, J. R. et al. Carbon dioxide capture related gas adsorption and separation in metal-organic frameworks. Coordination Chemistry Reviews, Toronto, v. 255, p. 1791-1823, 2011.

MAYER, M. Simnra user's guide - report IPP 9/113. Germany: MaxPlanck-Institut für Plasmaphysik, 1997. 62p.

MCCARTHY, M. C. et al. Synthesis of zeolitic imidazolate framework films and membranes with controlled microstructures. Langmuir, Washington, v. 131, n. 18, p. 14636-14641, 2010.

NEWS, C. New materials can selectively capture $\mathrm{CO}_{2}$, scientists say. 2008. Disponível em: <http://www.ca/news/technology/ new-materials-can-selectively-capture-co2-scientists-say-1. 713473>. Acesso em: 04 Nov 2015.

PARK, K. S. et al. Exceptional chemical and thermal stability of zeolitic imidazolate frameworks. Proceedings of the National Academy of Sciences, Washington, v. 103, p. 10186-10191, 2006.

PEREZ, E. V. et al. Mixed-matrix membranes containing MOF-5 for gas separations. Journal of membrane science, San Francisco, v. 328, n. 1, p. 165-173, 2009.

RACKLEY, S. A. Carbon Capture and storage, Burlington, MA. Elsevier, 2010. 392p. ISBN 978-1-85617-636-1.

RANJAN, R.; TSAPATISS, M. Microporous metal organic framework membrane on porous support using the seeded growth method. Chemistry of Materials, Washington, v. 20, p. 4920-4924, 2009. 
RAUPP, D. T.; DEL-PINO, J. C. Estereoquímica no ensino superior: historicidade e contextualização em livros didáticos de química orgânica. Acta Scientiae, Canoas, RS, v. 17, n. 1, p. 146-168, 2015.

ROOSA, A. J.; JHAVERI, A. G. Carbon reduction: Policies, strategies and technologies. lilburn, GA: The Fairmont press, 2009. 2009, 246p. ISBN 978-1-4200-8382-8.

SANAEEPUR, H. et al. Preparation and characterization of acrylonitrilebutadiene-styrene/poly(vinil acetate) membrane for $\mathrm{CO}_{2}$ removal. Separation and Purification Technology, New York, v. 80, n. 3, p. 499-508, 2011.

SANTOS-FILHO, S. G. Oxidação térmica rápida do silício: influência dos procedimentos de limpeza e dos perfis temporais de temperatura na qualidade dos óxidos de porta MOS. Tese (doutorado) Escola Politécnica, Universidade de São Paulo, São Paulo, 1996.

SANTOS-FILHO, S. G.; HASENACK, C. M. Achievement of high quality thin gate oxides grown by rapid thermal oxidation. Journal of Solid-State Devices and Circuits, [S.1.], v. 3, n. 1, p. 1-9, 1995b.

SANTOS-FILHO, S. G. et al. Rapid thermal oxidation of silicon with different thermal annealing cycles in nitrogen: Influence on surface micro-roughness and electrical characteristics. Semiconductor Science and Technology, Bristol, v. 10, n. 5 , p. 990-6, 1995c.

SANTOS-FILHO, S. G. et al. Less critical cleaning procedure for silicon wafers using diluted HF dip and boiling in isopropyl alcohol as final steps. Journal of the Electrochemical Society, Manchester, v. 142, n. 3, p. 902-7, 1995a.

SCOTTISH, C. C.; AL et. Scottish Fourth assessment report of the intergovernamental panel on climate change. 2012. IPCC. Disponível em: <http: //www.ipcc.ch/publications_and_data/ar4/syr/en/contents.html>. Acesso em: 14 de novembro de 2016.

SHERMAN, J. D. Synthetic zeolites and other microporous oxide molecular sieves. Proccedings of the National Academy of Sciences, v. 96, n. 7, p. 3471-3478, 1999.

SHOEMAKER, D. P.; ROBSON, H. E.; BROUSSARD, L. Proceedings of the in third international conference on molecular sieves, zurich. American chemical society, Zurique, 1973.

SPOT, D. de Quimica e Ciencias Biológicas da Universidad de las A. Nuevos Materiales para la Capitura. 2008. Al-Chemicals. Disponível em: <http://www.al-quimicos.blogspot.com.br/2008/04/ nuevos-materiales-para-la-capitura.html>. Acesso em: Mai de 2010.

SUN, C. Y. et al. Zeolitic imidazolate framework-8 as efficient ph-sensitive drug delivery vehicle. Dalton Transactions, Cambridge, v. 41, p. 6906-6909, 2012. 
SURENDAR, R. V.; CARREON, M. A. Highly permeable zeolite imidazolate framework-8 membranes for $\mathrm{CO}_{2} / \mathrm{CH}_{4}$ separation. Journal of the American Chemical Society, Washington, v. 132, p. 76-78, 2009.

SWINEHART, D. F. The beer-lambert law. J. Chem. Educ.,, v. 39, n. 7, p. 333, 1962.

USP. Efeito Estufa. 2003. Educar USP São Carlos. Disponível em: <http://educar.sc.usp.br/licenciatura/2003/ee/efeito_estufa.html>. Acesso em: 05 Abr 2012.

VENNA, S.; JASINSKI, J.; CARREON, M. Structural evolution of zeolitic imidazolate framework-8. Journal of the American Chemical Society, Washington, v. 132, p. 18030-18033, 2010.

WILSON, E.; GERARD, D. Carbon capture and sequestration: integrating technology, monitoring, regulation. 2007. Ames: Wiley-Blackwell, 2007. 296p. ISBN 978-0-8138-0207-7.

YAFENG, Y. et al. Gas permeability properties of matrimid ${ }^{\circledR}$ membranes containing the metal-organic framework cu-bpy-hfs. Journal of Membrane Science, San Francisco, v. 313, p. 170-181, 2008.

YAN, M. P. Crystal growth of the metal-organic framework ZIF-8. Manchester: The University of Manchester, 2012. 260p.

YAO, J. et al. Contra-diffusion synthesis of ZIF-8 films on a polymer substrate. Chemical communications, Cambridge, v. 47, p. 2559-2561, 2011.

YOO, Y.; LAI, Z.; JEONG, H. K. Fabrication of MOF-5 membranes using microwave-induced rapid seeding and solvothermal secondary growth. Microporous and Mesoporous Materials, New York, v. 123, n. 1-3, p. 100-106, 2009. 